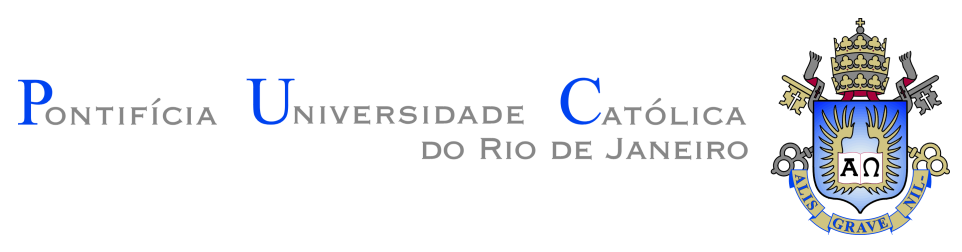

Fabricio Fernández

\title{
Modelagem Numérica de Problemas Geotécnicos de Grandes Deformações Mediante o Método do Ponto Material
}

Tese de Doutorado

Tese apresentada como requisito parcial para obtenção do grau de Doutor pelo Programa de Pós-graduação em Engenharia Civil do Departamento de Engenharia Civil e Ambiental da PUC-Rio.

Orientador : Prof. Eurípedes do Amaral Vargas Jr. Co-orientador: Dr. André Luís Müller 


\section{Modelagem Numérica de Problemas Geotécnicos de Grandes Deformações Mediante o Método do Ponto Material}

Tese apresentada como requisito parcial para obtenção do grau de Doutor pelo Programa de Pós-graduação em Engenharia Civil do Departamento de Engenharia Civil e Ambiental da PUCRio. Aprovada pela Comissão Examinadora abaixo.

Prof. Eurípedes do Amaral Vargas Jr. Orientador Departamento de Engenharia Civil e Ambiental - PUC-Rio $\begin{array}{r}\text { Dr. André Luís Müller } \\ \text { Co-orientador }\end{array}$
Instituto de Desenvolvimento de Software Técnico-Científico -
TECGRAF/PUC-Rio
Universidade Grenoble Alpes - Laboratório $\begin{array}{r}\text { Prof. Daniel Dias } \\ \text { PSolitécnico de } \\ \text { Grenoble }\end{array}$

Prof. Ivan Fábio Mota de Menezes Departamento de Engenharia Mecânica - PUC-Rio

Prof. Luiz Fernando Martha Departamento de Engenharia Civil e Ambiental - PUC-Rio

Dr. Marcio Arab Murad

Departamento de Mecânica Computacional - Laboratório Nacional de Computação Científica 
Todos os direitos reservados. É proibida a reprodução total ou parcial do trabalho sem autorização da universidade, do autor e do orientador.

\section{Fabricio Fernández}

Graduou-se em Engenharia Civil na Universidad Nacional de Cuyo - UNCuyo, em Mendoza, Argentina, em 2012. Onde participou de projetos de pesquisa nas áreas de simulação numérica, dinâmica de estruturas e fluxos em meios porosos durante o período 2009-2012. Em 2015 obteve o título de Mestre em Engenharia Civil na área de Geotécnica na Universidade Católica do Rio de Janeiro - PUC-Rio. Atualmente forma parte do grupo de pesquisa Geoanálise da PUC-Rio, atuando principalmente na área de geomecânica computacional.

Ficha Catalográfica

Fernández, Fabricio

Modelagem numérica de problemas geotécnicos de grandes deformações mediante o método do ponto material / Fabricio Fernández; orientador: Eurípedes do Amaral Vargas Jr.; co-orientador: André Luís Müller - 2020.

168 f. : il. color. ; $30 \mathrm{~cm}$

Tese (doutorado) - Pontifícia Universidade Católica do Rio de Janeiro, Departamento de Engenharia Civil e Ambiental, 2020.

Inclui bibliografia

1. Engenharia Civil e Ambiental - Teses. 2. Fluxo de detritos. 3. Deslizamentos de solo em taludes. 4. Método do Ponto Material (MPM). 5. Grandes deformações. 6. Acoplamento fluido mecânico. I. Vargas, Eurípedes do Amaral. II. Müller, André Luís. III. Pontifícia Universidade Católica do Rio de Janeiro. Departamento de Engenharia Civil e Ambiental. IV. Título. 


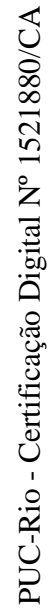

A Irene e Jacinto. 


\section{Agradecimentos}

Ao Professor Vargas, pelas enriquecedoras discussões que contribuíram na orientação deste trabalho e na minha formação.

À Professora Raquel Velloso, pelas oportunidades e pela confiança.

Ao Dr. André Müller pela disponibilidade do código MVGimp.

A todas as pessoas que conformam o Departamento de Engenharia Civil e Ambiental.

Aos membros participantes da Comissão examinadora.

O presente trabalho foi realizado com apoio do Conselho Nacional de Desenvolvimento Científico e Tecnológico (CNPq).

O presente trabalho foi realizado com apoio da Coordenação de Aperfeiçoamento de Pessoal de Nível Superior - Brasil (CAPES) - Código de Financiamento 001. 


\section{Resumo}

Fernández, Fabricio; Vargas, Eurípedes do Amaral; Müller, André Luís. Modelagem Numérica de Problemas Geotécnicos de Grandes Deformações Mediante o Método do Ponto Material. Rio de Janeiro, 2020. 168p. Tese de Doutorado - Departamento de Engenharia Civil e Ambiental, Pontifícia Universidade Católica do Rio de Janeiro.

Os problemas geotécnicos e geológicos envolvem a descrição do comportamento de materiais tais como solo e rocha e sua eventual interação com fluidos e estruturas. Em geral, a evolução desses problemas é caracterizada por grandes deformações e deslocamentos, descontinuidades, heterogeneidades e um comportamento constitutivo complexo. A abordagem deste tipo de problemas requer técnicas numéricas que levem em conta essas características, sem apresentar inconvenientes numéricos associados à distorção dos elementos como acontece no método dos elementos finitos (FEM). A presente tese desenvolve um algoritmo computacional baseado no método do ponto material (MPM) para aproximar a solução das equações governantes dos fenômenos mencionados. O algoritmo é baseado numa formulação dinâmica tridimensional do contínuo, considerando grandes deformações. Os amortecimentos de Rayleigh e o local não viscoso são incorporados para modelar problemas dinâmicos e quase-estáticos. A geração dinâmica das poro-pressões é formulada assumindo o meio poroso saturado e um ponto material para discretizar a mistura. Diversas técnicas de suavização das pressões são avaliadas em problemas de impacto sobre meios saturados. Diferentes modelos constitutivos são implementados para modelar tanto a formação da superfície de ruptura e o processo de escoamento da massa de solo durante as instabilidades, quanto a gênese, evolução e quantificação de zona de falhas nos processos geológicos. Para a abordagem da discretização de problemas de escala geológica de grande número de partículas usando o MPM, uma metodologia é proposta e verificada com a discretização do deslizamento do Daguangbao, na China. Visando à diminuição do tempo computacional, o algoritmo é implementado segundo o paradigma de programação paralela.

\section{Palavras-chave}

Fluxo de Detritos; Deslizamentos de Solo em Taludes; Método do Ponto Material (MPM); Grandes Deformações; Acoplamento Fluido Mecânico; Processos Geológicos; 


\section{Abstract}

Fernández, Fabricio; Vargas, Eurípedes do Amaral (Advisor); Müller, André Luís (Co-Advisor). Numerical Modeling of Geotechnical Problems of Large Deformations Using the Material Point Method. Rio de Janeiro, 2020. 168p. Tese de Doutorado - Departamento de Engenharia Civil e Ambiental, Pontifícia Universidade Católica do Rio de Janeiro.

Geotechnical and geological problems involve the description of the behavior of materials such as soil and rock, and their eventual interaction with fluids and structures. In general, the evolution of these problems is characterized by large deformations and displacements, discontinuities, heterogeneities and complex constitutive behavior. Addressing these problems requires numerical techniques that take these characteristics into account, without numerical drawbacks associated with element distortion as occurs in the finite element method (FEM). In this thesis is developed a computational algorithm based on the material point method (MPM) to approximate the solution of the governing equations to the mentioned phenomena. The algorithm is based on a three-dimensional dynamic formulation of the continuum considering large deformations. Rayleigh damping and non-viscous local damping are incorporated to model dynamic and quasi-static problems. The dynamic generation of pore pressures is formulated assuming the saturated porous medium and a single material point to discretize the mixture. Different techniques are evaluated to mitigate spurious pressure in impact problems on saturated media. Different constitutive models are implemented to model the failure surface and the soil mass flow process during slope instabilities, as well as the genesis, evolution and failure zone quantification in geological processes. To address the discretization of large-scale geological problems using MPM, a methodology is proposed and validated with the discretization of the Daguangbao landslide, in China. In order to decrease the computational time, the algorithm is implemented according to the parallel programming paradigm.

\section{Keywords}

Debris Flow; Soil Displacements on Slopes; Material Point Method (MPM); Large Strains; Hydromechanical Coupled Analysis; Geological Processes; 


\section{Sumário}

1 Introdução $\quad 22$

1.1 Revisão bibliográfica 25

1.1.1 Introdução à modelagem do sólido geomecânico 25

1.1.2 Revisão dos principais métodos numéricos disponíveis baseados no enfoque contínuo $\quad 25$

1.1.3 Uso do MPM na modelagem de processos de grandes deformações 29

$\begin{array}{lll}1.2 & \text { Escopo e objetivos } & 29\end{array}$

$\begin{array}{ll}1.3 \text { Contribuição da tese } & 30\end{array}$

$\begin{array}{lll}1.4 & \text { Estrutura do trabalho } & 32\end{array}$

2 Método do Ponto Material - MPM 34

2.1 Introdução ao Método do Ponto Material 34

2.2 Formulação matemática 35

2.2.1 Discretização das equações de movimento 35

2.2.2 Integração no tempo 39

2.2.2.1 Integração explícita 39

2.2.2.2 Estabilidade do algoritmo explícito 41

2.2.3 Amortecimento $\quad 41$

2.2.3.1 Amortecimento de Rayleigh $\quad 42$

2.2.3.2 Amortecimento local 42

2.2.4 Condições de contorno não refletoras 43

2.2.5 Algoritmo explícito no MPM 44

2.3 Implementação computacional do MPM 46

2.3.1 Exemplo de arquivo de entrada de dados do programa MPM-PUCRio 47

3 Modelagem constitutiva $\quad 49$

3.1 Definições e convenções 49

3.2 Taxas de tensões objetivas 50

3.3 Formulação incremental $\quad 51$

3.4 Modelo elástico linear $\quad 52$

3.4.1 Implementação numérica do modelo elástico linear 54

3.5 Modelos elasto-plásticos $\quad 55$

3.5.1 Algoritmo de retorno $\quad 57$

3.5.2 Modelo Drucker-Prager $\quad 58$

3.5.2.1 Corretor plástico do modelo Drucker-Prager 60

3.5.2.2 Corretor plástico de cisalhamento do modelo Drucker-Prager 61

3.5.2.3 Corretor plástico de tração do modelo Drucker-Prager 63

3.5.2.4 Implementação numérica do modelo Drucker-Prager 64

3.5.3 Modelo Mohr-Coulomb 65

3.5.3.1 Corretor plástico do modelo Mohr-Coulomb 67

3.5.3.2 Corretor plástico de cisalhamento do Modelo Mohr-Coulomb 67

3.5.3.3 Corretor plástico de tração do modelo Mohr-Coulomb 69

3.5.3.4 Implementação numérica do Modelo Mohr-Coulomb 70

3.5.4 Modelo de transição sólido - fluido viscoso 71 
3.5.4.1 Implementação numérica do modelo de transição

4 Acoplamento fluido mecânico $\quad 75$

4.1 Revisão do acoplamento fluido mecânico no MPM 75

$\begin{array}{lll}4.2 & \text { Fases do meio poroso } & 77\end{array}$

4.3 Princípio das tensões efetivas 78

$\begin{array}{lll}4.4 & \text { Conservação de massa } & 78\end{array}$

4.5 Equações de movimento $\quad 80$

4.6 Discretização das equações governantes $\quad 80$

4.7 Implementação numérica do acoplamento fluido mecânico 83

4.8 Procedimento de suavização das pressões espúrias 85

5 Discretização de modelos MPM de escala geológica $\quad 87$

5.1 Introdução à discretização de modelos de escala geológica 87

5.2 Revisão dos procedimentos de discretização usados no MPM 87

5.3 Procedimento para criação de modelos MPM de escala geológica $\quad 89$

5.4 Exemplo de aplicação 90

5.5 Gerador de partículas $\quad 92$

6 Resultados $\quad 95$

6.1 Verificações das implementações computacionais 95

6.1.1 Condição de contorno não refletora 95

6.1.2 Talude elástico amortecido 96

$\begin{array}{lll}6.1 .3 & \text { Talude elasto-plástico } & 99\end{array}$

6.1.4 Talude elasto-plástico heterogêneo 101

6.1.5 Acoplamento fluido mecânico 105

6.1.5.1 Coluna poro-elástica: problema de Terzaghi 106

$\begin{array}{ll}\text { 6.1.5.2 Esfera poro-elástica: problema de Cryer } & 108\end{array}$

6.1.5.3 Propagação de ondas não drenadas 110

6.1.5.4 Verificação do procedimento de suavização de pressões espúrias 112

6.2 Ruptura de túnel 3D 115

6.2.1 Estudo paramétrico e análise do escorregamento da massa do túnel 122

$\begin{array}{lll}6.3 & \text { Simulação de processos geológicos } & 123\end{array}$

6.4 Talude natural em Oregon, Estados Unidos 128

6.5 Impacto de bloco de rocha sobre meio saturado 132

6.6 Deslizamento de Daguangbao, China 137

6.6.1 Características do deslizamento de Daguangbao 137

6.6.2 Discretização do domínio em modelo MPM 139

6.6.3 Características do terremoto de Wenchuan, China 142

6.6.4 Resultados das análises do deslizamento de Daguangbao 143

6.6.4.1 Resultados da análise em 2D 144

$\begin{array}{lll}\text { 6.6.4.2 Resultados da análise em 3D } & 147\end{array}$

6.6.4.3 Comentários finais e discussão dos resultados 152

7 Considerações finais $\quad 153$

7.1 Conclusões 153

$\begin{array}{lll}\text { 7.2 Sugestões para futuros trabalhos } & 155\end{array}$

$\begin{array}{lr}\text { Referências bibliográficas } & 157\end{array}$ 
A Publicações produzidas durante o presente trabalho

B Exemplo de Arquivo de Entrada de Dados

166

B.1 Convenção da numeração dos nós do elementos do 8 nós 


\section{Lista de figuras}

Figura 1.1 Fluxo de detrito na vila La Conchita, California, após chuva intensa onde 10 pessoas resultaram mortas [13].

Figura 1.2 Deslizamentos de terra em Rio de Janeiro, 2011, deixam 916 pessoas mortas. a) Imagem aérea da devastação em área de Nova Friburgo. b) Deslizamento de terra em Nova Friburgo [14].

Figura 1.3 Enfoque discreto e contínuo do sólido geomecânico.

Figura 1.4 Deformação de elemento finito de 4 nós. Variação do Jacobiano dentro do elemento.

Figura 1.5 Revisão de 40 publicações sobre o MPM entre os anos 1994 e 2018.

Figura 2.1 Esquema de discretização do domínio contínuo em pontos materiais. Configuração geral do modelo numérico MPM.

Figura 2.2 Ciclo computacional no método do ponto material.

Figura 2.3 Esquema de diferenças finitas centrais usado na integração explícita no tempo.

Figura 2.4 Condições de contorno não refletoras em meios semiinfinitos. a) Pulso num meio contínuo semi-infinito. b) Reflexão de pulso devido às condições de contorno do modelo numérico.

Figura 2.5 Esquema de funcionamento e características do programa MPM-PUCRio.

Figura 3.1 Vetores normais aos planos positivos em torno ao ponto A.

Figura 3.2 Tensor de tensões de Cauchy num ponto A. a) Tensor de tensões para o estado inicial $\phi=0$. b) Tensor de tensões sobre rotação do corpo rígido de $\phi=\pi / 2$.

Figura 3.3 Curva de resposta tensão - deformação de material elasto-plástico.

Figura 3.4 Passo preditor elástico e corretor plástico do algoritmo de retorno.

Figura 3.5 Modelo Drucker-Prager ajustado em diferentes pontos do modelo Mohr-Coulomb.

Figura 3.6 Modelo Drucker-Prager composto com limitação à resistência máxima de tração.

Figura 3.7 Modelo Drucker-Prager dividido em zonas para determinar a regra do fluxo plástico na interseção entre $f^{t}$ e $f^{s}$.

Figura 3.8 Modelo de Mohr-Coulomb com limitação à resistência máxima de tração.

Figura 3.9 Modelo Mohr-Coulomb dividido em zonas para determinar a regra do fluxo plástico no ponto de interseção entre $f^{t} \mathrm{e}$ $f^{s}$.

Figura 3.10 Modelo numérico para solos de comportamento elastoplástico-viscoso com transição. 
Figura 4.1 Fases do meio poroso. a) Meio poroso real. b) Representação numérica do meio poroso de diferentes fases.

Figura 4.2 Procedimento de suavização das pressões espúrias.

Figura 5.1 Procedimentos de discretização normalmente usados no MPM. a) Pontos materiais definidos por célula. b) Pontos materiais em malha de elementos finitos de suporte. c) Pontos materiais definidos de maneira individual.

Figura 5.2 Sequência para criação de modelos MPM heterogêneos em 3D de escala geológica.

Figura 5.3 Sequência para criação de modelos MPM heterogêneos em 3D de escala geológica. a) Dados digitais de elevação do terreno e de cada material. b) Mapeamento de cada ponto DEM do terreno $P$ com cada ponto DEM de cada material $M_{i}$.

Figura 5.4 Cubo heterogêneo com onda plana de interface entre os materiais.

Figura 5.5 Discretização de cubo heterogêneo com nível de refinamento de $0.1 \mathrm{~m}$. a) 5270 partículas distribuídas usando o centroide de cada elemento finito da malha de suporte. b) 8.0e+3 partículas distribuídas uniformemente em cada célula de $\Delta x=\Delta y=\Delta z=0.1 \mathrm{~m}$ usando uma malha de elementos finitos para identificar os materiais. c) $8.0 \mathrm{e}+3$ partículas distribuídas usando uma onda plana como dado de elevação do material 2.

Figura 5.6 Discretização de cubo heterogêneo com nível de refinamento de $0.05 \mathrm{~m}$. a) 36253 partículas distribuídas usando o centroide de cada elemento finito da malha de suporte. b) 64.0e+3 partículas distribuídas uniformemente em cada célula de $\Delta x=\Delta y=\Delta z=0.05 \mathrm{~m}$ usando uma malha de elementos finitos para identificar os materiais. c) $64.0 \mathrm{e}+3$ partículas distribuídas usando uma onda plana como dado de elevação do material 2.

Figura 6.1 Verificação das condições de contorno não refletoras. a) Modelo de coluna vertical com pulso externo e diferentes condições de contorno. b) Variação das ondas longitudinais no tempo.

Figura 6.2 Geometria e condições de contorno de talude elástico.

Figura 6.3 Deslocamentos horizontais $u_{x}$ do ponto de controle $A$ do talude elástico. Modelo MPM e FEM com amortecimento de Rayleigh $\alpha^{R}=\beta^{R}=0.05$.

Figura 6.4 Deslocamentos horizontais $u_{x}$ do ponto de controle $A$ do talude elástico. Modelo MPM com amortecimento local não viscoso $\alpha^{\mathrm{nv}}=0.075$. Modelo FEM com amortecimento de Rayleigh $\alpha^{R}=\beta^{R}=0.05$.

Figura 6.5 Geometria do talude elasto-plástico.

Figura 6.6 Comparativa dos resultados com o código MPM3D-F90 [38].

Figura 6.7 Evolução da ruptura do talude elasto-plástico. 
Figura 6.8 Talude heterogêneo. Definição de geometria, distribuição de materiais e condições de contorno.

Figura 6.9 a) Malha de elementos finitos usada no método NLA. b) Distribuição de pontos materiais usada no MPM.

Figura 6.10 Fator de segurança obtido por diferentes métodos. a) SRF obtido com NLA [102]. b) Deslocamentos adimensionais obtidos com FEM (Abaqus) [102]. c) Deslocamentos máximos para cada SRF obtido com MPM. d) Taxa de deslocamentos máximos obtida com MPM.

Figura 6.11 Mecanismo de ruptura do talude heterogêneo. a) Distribuição de velocidades obtidas com NLA para $\mathrm{SF}=1.11$ [102]. b) Distribuição de deslocamentos obtidos com FEM (Abaqus) para $\mathrm{SRF}=0.98$ [102]. c) Campo de deslocamentos obtidos com MPM para $\mathrm{SF}=1.19$.

Figura 6.12 Verificação da implementação do acoplamento fluido mecânico com a coluna poro-elástica. a) Modelo da coluna poroelástica com pressão aplicada no extremo permeável, condições iniciais e de contorno. b) Comparação de resultados numérico e analítico em termos de pressão no tempo.

Figura 6.13 Verificação da implementação do acoplamento fluido mecânico com a esfera poro-elástica. a) Modelo da esfera poroelástica com carregamento radial aplicado no contorno permeável. b) Comparação de resultados numérico e analítico em termos de pressão normalizada no centro da esfera.

Figura 6.14 Variação do acréscimo de poro-pressão relativo à tensão total no contorno, num ponto de controle na posição $z=0.58 \mathrm{~m} .111$

Figura 6.15 Geometria e condições de contorno do modelo de verificação do algoritmo de suavização das pressões.

Figura 6.18 Evolução das pressões do fluido no ponto de controle na posição $z=7.0 \mathrm{~m}$ (ver Figura 6.16).

Figura 6.16 Evolução do campo de pressões durante o impacto do bloco sobre o meio saturado. a) Caso 1: sem suavização, $t=0.152 \mathrm{~s}$. b) Caso 2: suavização simplificada, $t=0.152 \mathrm{s.} \mathrm{c}$ ) Caso 3: com suavização, $t=0.152$ s. d) Caso 1: sem suavização, $t=0.153 \mathrm{~s}$. e) Caso 2: suavização simplificada, $t=0.153 \mathrm{s.f}$ ) Caso 3: com suavização, $t=0.153 \mathrm{~s}$. $\bigcirc$ ponto de controle em $z=7.0 \mathrm{~m}$.

Figura 6.17 Evolução do campo de pressões durante o impacto do bloco sobre o meio saturado. a) Caso 1: sem suavização, $t=0.157 \mathrm{~s}$. b) Caso 2: suavização simplificada, $t=0.157 \mathrm{s.} \mathrm{c})$ Caso 3: com suavização, $t=0.157$. d) Caso 1: sem suavização, $t=0.165 \mathrm{~s}$. e) Caso 2: suavização simplificada, $t=0.165 \mathrm{s.f}$ ) Caso 3: com suavização, $t=0.165 \mathrm{~s}$. $\equiv$ ponto de controle em $z=7.0 \mathrm{~m}$.

Figura 6.19 Geometria do modelo do túnel, condições de contorno, e posição dos transdutores no topo do modelo.

Figura 6.20 Registro dos deslocamentos superficiais nos transdutores h1-h6 durante a redução da pressão na face do túnel. 
Figura 6.21 Modelo MPM do túnel. Diferentes pontos materiais usados no modelo para representar as partículas de areia, a lâmina de plástico onde é aplicada a pressão e as partículas das paredes do túnel.

Figura 6.22 Configuração final de colapso. Formação de cratera em superfície como consequência das altas deformações pós-ruptura. 119

Figura 6.23 Evolução dos deslocamentos pós-ruptura do modelo do túnel 3D. A linha amarela representa a parede do túnel durante a ruptura.

Figura 6.24 Magnitude dos deslocamentos totais no colapso $|\boldsymbol{u}|$. a) Resultados obtidos com MPM. b) Resultados obtidos com FEM por Sterpi et al. (2004) [106].

Figura 6.25 Deslocamentos superficiais numéricos e experimentais. a) Valores registrados nos transdutores $h 1, h 2$ e $h 3$. b) Valores registrados nos transdutores $h 4, h 5$ e $h 6$ (ver Figura 6.19).

Figura 6.26 Energia cinética do modelo MPM durante a evolução do processo de ruptura.

Figura 6.27 Comparação da configuração deformada da massa de solo na ruptura para diferentes ângulos de atrito residual.

Figura 6.28 Comparação da configuração deformada da massa de solo na ruptura para diferentes ângulos de atrito residual.

Figura 6.29 Geometria do modelo de caixa de areia usado para simulação de formação de falhas induzidas por deformação de compressão de velocidade constante.

Figura 6.30 Evolução da formação de falhas e da deformação plástica acumulada $\epsilon_{p}$.

Figura 6.31 Comparação do ângulo da superfície do modelo para diferentes deslocamentos compressionais. Resultados obtidos por diferentes modelos numéricos e análogos [108].

Figura 6.32 Comparação do número de falhas formadas nos modelos para diferentes deslocamentos compressionais. Resultados obtidos por diferentes modelos numéricos e análogos (Modificado de S.Buiter et al.(2006) [108]).

Figura 6.33 Estado de deformação para $14 \mathrm{~cm}$ de deslocamento compressional. a) Modelos numéricos I2ELVIS, LAPEX-2D, Microfem, PFC2D e Sopale [108]. b) Modelos análogos Univ. Bern, Univ. Parma, Univ. Pavia, IFP Rueil-Malmaison e Univ. Toronto [108]. c) Modelo MPM mostrando, à esquerda, o estado de deformação e, à direita, as deformações plásticas acumuladas $\epsilon_{p}$.

Figura 6.34 a) Curvas de nível do terreno e do nível de água. b) Altura da camada de solo sobre a rocha (Adaptado de Camargo et al.(2016) [112]).

Figura 6.35 a) Geometria inicial e definição de materiais. b) Modelo MPM formado por $1130304 \approx 1.1 \mathrm{e}+6$ partículas.

Figura 6.36 Comparação da zona de ruptura calculada com NLA [112] e MPM, com a zona de ruptura observada. Evolução da zona de ruptura para 3, 6 e 9 segundos obtida com MPM. 
Figura 6.37 Evolução da zona de ruptura em termos da magnitude dos deslocamentos $|u|(m)$, para 3, 6 e 9 segundos.

Figura 6.38 Geometria do problema do bloco de rocha impactando sobre meio poroso saturado. a) Plano X-Y, $b_{y}=b_{x}=5 \mathrm{~m}$; b) Plano Z-Y, $b_{z}=2 \mathrm{~m}, h_{r}=2 \mathrm{~m}, h_{s}=1 \mathrm{~m}, H_{r}=1.7 \mathrm{~m}, H_{s}=2.5$ $\mathrm{m}$; c) Perspectiva tridimensional.

Figura 6.39 Evolução da energia cinética do sistema.

Figura 6.40 Evolução da pressão do fluido nos pontos de controle $p_{1}$ e $p_{2}$.

Figura 6.41 Processo de falha durante o impacto do bloco de rocha sobre o solo saturado. Evolução das zonas de falhas em termos da deformação efetiva plástica $\left.\epsilon^{p}=\sqrt{\left(2 / 3 \epsilon_{i j}^{p}\right.} \epsilon_{i j}^{p}\right)$.

Figura 6.42 Processo de falha durante o impacto do bloco de rocha sobre o solo saturado. Evolução das zonas de falhas em termos da deformação efetiva plástica $\left.\epsilon^{p}=\sqrt{(} 2 / 3 \epsilon_{i j}^{p} \epsilon_{i j}^{p}\right)$.

Figura 6.43 Mapa geológico do deslizamento de Daguangbao [120].

Figura 6.44 Seção geológica pós-terremoto [122] definida como $\overline{A B}$ na Figura 6.43.

Figura 6.45 Topografia da região do deslizamento de Daguangbao antes do terremoto. a) Curvas de níveis e dimensões do domínio. b) Perspectiva tridimensional da topografia.

Figura 6.46 Posições das seções utilizadas para definir heterogeneidades.

Figura 6.47 Dados digitais de elevação de cada material. a) Material $1=$ grupo $Z$. b) Material $2=$ grupo $D$. c) Material $3=$ grupo $P .140$

Figura 6.48 Modelo discreto MPM formado por $1.8 \mathrm{e}+6$ partículas.

a) Elevação $x_{z}^{0}(\mathrm{~m})$. b) Distribuição espacial de materiais.

Figura 6.49 Seção característica do deslizamento de Daguangbao. Seção $\overline{A^{\prime} B^{\prime}}$ definida na Figura 6.47. a) Elevação $x_{z}^{0}(\mathrm{~m})$. b) Distribuição espacial dos materiais e posição dos pontos de controle $p_{1}, p_{2}$ e $p_{3}$.

Figura 6.50 Identificação de zona de ruptura. a) Zona de ruptura observada. b) Zona de ruptura no modelo MPM.

Figura 6.51 Terremoto considerado na análise. Deslocamentos $u$, velocidades $\dot{u}$ e acelerações $\ddot{u}$ no tempo, nas direções $x, y$ e $z$.

Figura 6.52 Comparação da superfície de falha e da configuração da topografia pós-terremoto. Resultados obtidos com MPM e valores reportados [122]. Modelo 2D.

Figura 6.53 Evolução da superfície de falha em termos de deformação efetiva plástica $\left.\epsilon^{p}=\sqrt{(} 2 / 3 \epsilon_{i j}^{p} \epsilon_{i j}^{p}\right)$. Modelo 2D.

Figura 6.54 Evolução dos deslocamentos nos pontos de controle $p_{1}$, $p_{2}$ e $p_{3}$. a) Deslocamentos verticais $u_{z}(\mathrm{~m})$. b) Deslocamentos horizontais $u_{x}(\mathrm{~m})$. Modelo 2D.

Figura 6.55 Comparação da superfície de falha e da configuração final da topografia pós-terremoto. Resultados numéricos obtidos com MPM em 3D e valores reportados [122]. 
Figura 6.56 Evolução da superfície de falha em termos da deformação efetiva plástica $\left.\epsilon^{p}=\sqrt{(} 2 / 3 \epsilon_{i j}^{p} \epsilon_{i j}^{p}\right)$. Modelo 3D.

Figura 6.57 Comparação da superfície de falha e da configuração final da topografia pós-terremoto. Resultados numéricos obtidos com MPM e valores reportados [122].

Figura 6.58 Área afetada pelo deslizamento de Daguangbao. a) Magnitude dos deslocamentos na condição de equilíbrio pósterremoto. b) Comparação da área afetada obtida numericamente com a reportada.

Figura 6.59 Comparação da topografia na configuração final pósruptura. a) Modelo numérico MPM em 3D. b) Parede vertical [120]. c) Zona de acumulação [120].

Figura B.1 Exemplo de arquivo de entrada de dados do programa MPM-PUCRio. a) Malha de cubo de $1 \mathrm{mx} 1 \mathrm{mx} 1 \mathrm{~m}$ formada por 8 elementos de 8 nós. b) Modelo MPM com 8 partículas por elemento.

Figura B.2 Convenção de numeração do elemento de 8 nós. 


\section{Lista de tabelas}

Tabela 1.1 Instabilidades e movimentos de grandes massas de terra com um grande número de vítimas fatais (Modificado de De Blasio et al.[1]).

Tabela 1.2 Principais programas computacionais do MPM.

Tabela 5.1 Comparação do número de pontos materiais incorretamente colocados usando a malha de suporte e a metodologia proposta.

Tabela 6.1 Parâmetros da coluna elástica com condição de contorno não refletora.

Tabela 6.2 Parâmetros do talude elástico amortecido. $\quad 98$

Tabela 6.3 Parâmetros do talude elasto-plástico. $\quad 99$

Tabela 6.4 Propriedades dos materiais do talude heterogêneo. 102

Tabela 6.5 Fator de segurança e tempo computacional do talude heterogêneo.

$\begin{array}{lll}\text { Tabela 6.6 } & \text { Parâmetros da coluna poro-elástica. } & 107\end{array}$

Tabela 6.7 Parâmetros da esfera poro-elástica. $\quad 109$

Tabela 6.8 Parâmetros da propagação de ondas no meio saturado. 111

Tabela 6.9 Parâmetros da verificação do algoritmo de suavização de pressões espúrias. 113

Tabela 6.10 Parâmetros do modelo do túnel 3D. 116

Tabela 6.11 Parâmetros do modelo geológico compressional. $\quad 125$

Tabela 6.12 Parâmetros do talude natural em Oregon. 128

Tabela 6.13 Comparação dos fatores de segurança do talude natural em Oregon. $\quad 130$

Tabela 6.14 Parâmetros do impacto de bloco sobre meio saturado. 133

Tabela 6.15 Características do terremoto de Wenchuan. 143

Tabela 6.16 Parâmetros de correção do terremoto. 143

Tabela 6.17 Parâmetros da análise 2D do deslizamento de Daguangbao.145

Tabela 6.18 Parâmetros da análise 3D do deslizamento de Daguangbao. 148

Tabela 6.19 Área afetada pelo evento. Estado de equilíbrio pósterremoto.

Tabela 6.20 Altura da parede vertical e altura do material depositado sobre o vale Huangdongzi. Configuração pós-terremoto. Comparação de resultados numéricos com valores reportados. 


\section{Lista de símbolos}

$\Omega$ - Domínio material

$M^{\Omega}$ - Massa total do domínio material

$\Omega_{i j}-$ Tensor de rotação

$\Gamma$ - Contorno do domínio

$p$ - Partícula ou ponto material, Pressão do fluido

$n_{p}$ - Número de partículas

$\Omega_{p}$ - Domínio da partícula

$m_{p}$ - Massa da partícula

$\nabla$ - Operador Nabla

$\Delta$ - Incremento finito

$\delta_{i j}-$ Delta de Kronecker

$m_{I J}$ - Matriz de massa

$\boldsymbol{b}, b_{i}$ - Vetor de forças de corpo por unidade de massa

$u_{i}$ - Vetor de deslocamentos

$\dot{u}_{i}-$ Vetor de velocidades

$\dot{\boldsymbol{v}}, \dot{v}_{i}, \ddot{u}_{i}-$ Vetor de acelerações

$\delta u_{i}$ - Deslocamentos arbitrários

$\delta u_{i, j}$ - Derivadas $j$ dos deslocamentos arbitrários

$\boldsymbol{x}_{p}$ - Vetor de posição da partícula

$v_{i I}$ - Vetor de velocidades nodais

$d_{c}$ - Dimensão de uma célula da malha Euleriana

$I$ - Nó da malha Euleriana

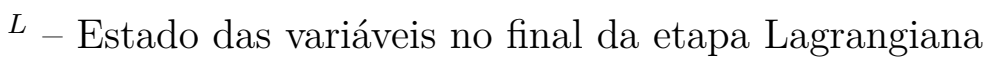

$l_{e}$ - Comprimento característico de elemento

$\hat{\mathbf{n}}$ - Vetor normal ao plano positivo em torno de um ponto

$N_{I p}$ - Função de interpolação do nó $I$ avaliada na posição $\boldsymbol{x}_{p}$ da partícula

$N_{I p, j}$ - Gradiente da função de interpolação do nó $I$

$\hat{w}_{i}-$ Funções de ponderação

$\boldsymbol{\sigma}, \sigma_{i j}-$ Tensor de tensões de Cauchy

$\sigma_{i j}^{*}$ - Tensão específica

$\sigma_{i j}^{\prime}$ - Tensão efetiva no esqueleto sólido

$\sigma_{m}-$ Tensão média

$\dot{\sigma}_{i j}^{\mathrm{J}}$ - Taxa de tensões de Jaumann 
$\sigma_{\text {ext }}-$ Pulso externo

$\sigma^{t}-$ Resistência a tração

$S_{y}^{B}$ - Tensão de escorregamento de Bingham

$S_{y}^{M C}$ - Tensão desviadora de ruptura do modelo de Mohr-coulomb

$\boldsymbol{\epsilon}, \epsilon_{i j}-$ Tensor de deformação

$\dot{\boldsymbol{\epsilon}}_{\mathrm{vol}}$ - Taxa da deformação volumétrica

$\boldsymbol{\epsilon}_{e}-$ Tensor de deformações elásticas

$\boldsymbol{\epsilon}_{p}-$ Tensor de deformações plásticas

$\bar{\epsilon}_{v o l}$ - Deformação volumétrica média na partícula

$\varepsilon-$ Deformação volumétrica

$J$ - Determinante do gradiente de deformação

$E$ - Módulo de Young

$E^{\text {edo }}$ - Módulo de compressão confinada

$E_{\text {kin }}$ Energia cinética

$K$ - Módulo volumétrico

$K_{m}$ - Módulo volumétrico do meio poroso

$K_{f}$ - Módulo volumétrico do fluido no meio poroso

$K_{s}$ - Módulo volumétrico do sólido no meio poroso

$G$ - Módulo cisalhante

$\nu$ - Coeficiente de Poisson

$\lambda, \mu$ - Constantes de Lamé

$g$ - Gravidade

$\rho$ - Densidade de massa

$C_{i j k l}$ - Tensor elástico de quarto ordem

$c_{v}$ - Coeficiente de adensamento

$c_{w}$ - Velocidade da onda de compressão da água

$c_{p}-$ Velocidade do som na partícula

$c_{e}$ - Velocidade do som no elemento

$c_{d}, c_{s}$ - Velocidades de ondas compressionais e cisalhantes

$t$ - Tempo

$T_{v}-$ Fator de tempo

$f^{\text {dmp }}$ - Força de amortecimento

$f_{I}$ - Força não balanceada no nó $I$

$f_{i I}^{\text {sb }}$ - Força viscosa não refletiva no nó $I$

$\hat{\sigma}_{i}, \hat{\tau}_{i}-$ Força normal e tangencial do contorno não refletivo

$t_{i}$ - Força de tração no contorno

$\alpha, \beta$ - Coeficientes de amortecimento de Rayleigh

$\alpha^{\mathrm{nv}}-$ Coeficiente de amortecimento local não viscoso

$\boldsymbol{v}_{\boldsymbol{n}}, \boldsymbol{v}_{\boldsymbol{t}}$ - Velocidades normais e tangenciais ao contorno 
$\psi$ - Função de potencial plástico

$\lambda$ - Parâmetro de carga

$f$ - Função de fluência

$f^{t}, f^{s}$ - Funções de fluência de tração e de cisalhamento

$J_{2}$ - Segundo invariante do tensor desviador

$\phi$ - Ângulo de atrito

$c$ - Coesão do material

$q_{\phi}, k_{\phi}$ - Constantes do critério de ruptura Drucker-Prager

$S_{i}$ - Operadores lineares de integração

$\eta$ - Viscosidade

$d^{2} W$ - Critério do trabalho de segunda ordem

$n$ - Porosidade

$e-$ Relação de vazios

$V_{v}$ - Volume de vazios

$V_{s}$ - Volume de sólidos

$v^{s}$ - Velocidade do sólido

$v^{w}$ - Velocidade do fluido

$S_{f}-$ Grau de saturação

$k_{i j}$ - Tensor de condutividade hidráulica

$S_{p}$ - Coeficiente de armazenamento

$\alpha_{B}$ - Coeficiente de Biot

$\square_{I}-$ Relativo ao nó da malha Euleriana

$\square^{p}-$ Parâmetro de pico

$\square^{r}$ - Parâmetro residual

$\square^{s}, \square_{s}-$ Relativo ao sólido

$\square^{w}, \square_{w}$ - Relativo ao fluido

$\square_{\mathrm{dev}}-$ Tensor desviador

$\square_{m}$ - Valor médio ou hidrostático

$\square$ vol - Relativo a volumétrico

$\square^{E}, \square^{P} \square^{V}-$ Componentes elásticas, plásticas e viscosas

$\square^{k}$ - Relativo ao passo de tempo computacional

2D - Duas dimensões

3D - Três dimensões

UE - União Europeia

PB - Países Baixos

ILC - Interface de linha de comandos

MPM - Material Point Method

FEM - Finite Element Method

FDM - Finite-Difference Method 
ALE - Arbitrary Lagrangian Eulerian

CEL - Coupled Eulerian - Lagrangian

SPH - Smooth Particle Hydrodynamics

PFEM -Particle Finite-Element Method

FEMLIP - FEM with Lagrangian Integration Points

EFG - Element-Free Galerkin

USF - Update Stress First

USL - Update Stress Last

NLA - Numerical Limit Analysis

PFC - Particle Flow Code

ASC - Advanced Simulation and Computing

$\mathrm{SRF}$ - Strength Reduction Factor

$\mathrm{RC}$ - Research Community 


\section{Introdução}

As instabilidades de taludes, em particular os movimentos que envolvem grandes massas de material geológico, constituem uma ação geomorfológica constante sobre o ambiente natural [1] e um risco de desastre natural para os centros urbanos, tanto para as pessoas (ver Tabela 1.1) quanto para as infraestruturas (ver Figuras 1.1 e 1.2). O desafio que se apresenta para a comunidade está relacionado com a redução deste risco mediante a previsão do fenômeno, e principalmente mediante o entendimento dos mecanismos envolvidos [2].

Dentro dos diferentes tipos de eventos de instabilidade de material geológico, os movimentos classificados como tipo fluxo $[3,4,5,6]$ apresentam algumas das seguintes características:

- Elevada quantidade de movimento devido às altas velocidades durante o processo de escorregamento;

- Grandes distâncias de escorregamento em comparação com a escala da massa envolvida;

- Elevada periculosidade e risco de catástrofe natural;

Do ponto de vista geotécnico, o fenômeno da ruptura da massa de solo pode ser dividido em duas etapas: a) Etapa inicial de ruptura, onde a capacidade de suporte é crítica e consequentemente as condições de estabilidade da massa são comprometidas; b) Etapa pós-ruptura, onde grandes deformações e deslocamentos são acompanhados de uma considerável liberação de energia. Em relação às etapas mencionadas, se evidencia que a modelagem constitutiva deste tipo de evento requerer modelos com mudanças de reologia, onde se leve em conta um comportamento constitutivo diferencial para a massa em função do nível de deformação. Neste sentido, uma primeira aproximação pode ser assumir um material do tipo sólido na etapa anterior à ruptura e um material do tipo fluido na etapa posterior à ruptura [7].

O entendimento dos mecanismos envolvidos durante a ruptura e no escorregamento pós-ruptura requerem a identificação das principais variáveis envolvidas, tais como: efeito da saturação em massas de solos não saturados [8]; efeito da vegetação nas camadas superiores e sua influência na sucção [8]; 
variação cíclica da pressão de poros nas características de cimentação [9]; ação dinâmica de terremotos [10]; efeito do intemperismo sobre a poro pressão [11]; efeitos de mudanças climáticas [12]; entre outras.

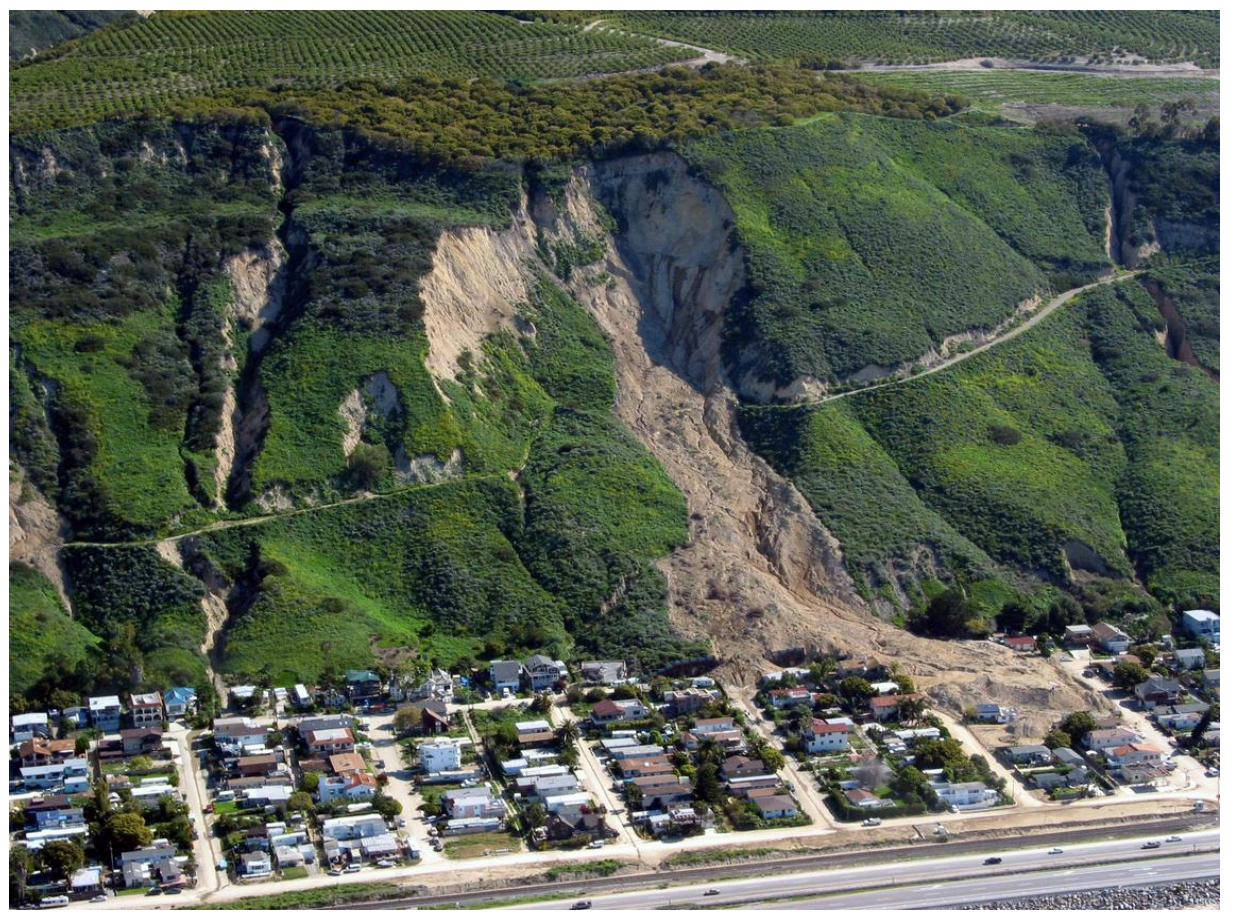

Figura 1.1: Fluxo de detrito na vila La Conchita, California, após chuva intensa onde 10 pessoas resultaram mortas [13].

a)

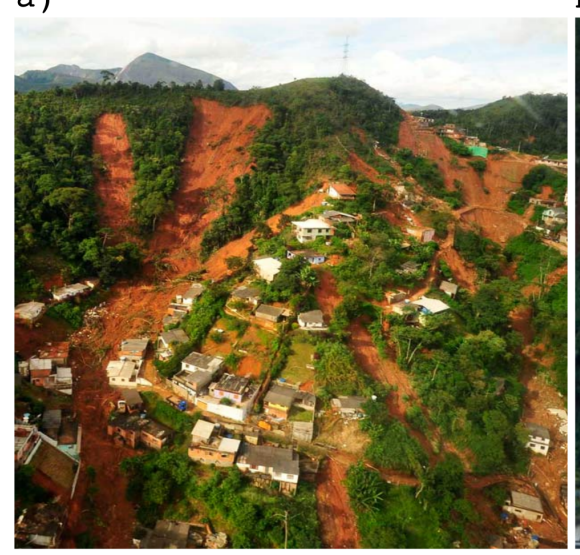

b)

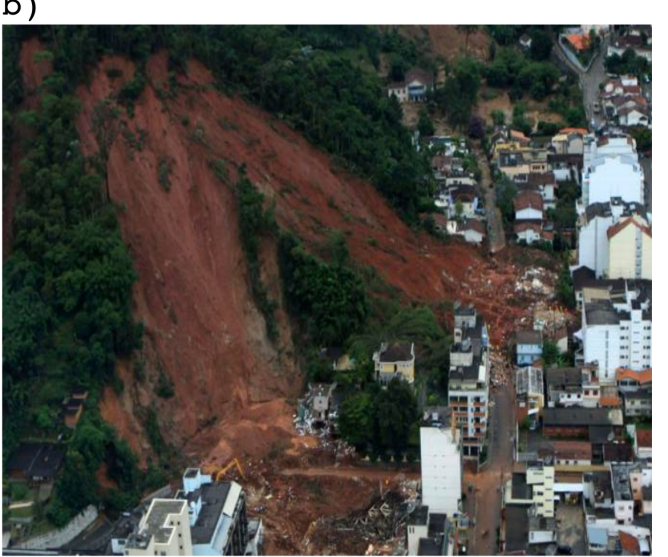

Figura 1.2: Deslizamentos de terra em Rio de Janeiro, 2011, deixam 916 pessoas mortas. a) Imagem aérea da devastação em área de Nova Friburgo. b) Deslizamento de terra em Nova Friburgo [14].

Com estas características, a ocorrência de movimentos de grandes massas constitui um fenômeno que apresenta um desafio ao tentar antecipá-lo com exatidão. Em geral, os dados estão disponíveis depois da ocorrência do 
escoamento; os materiais envolvidos resultam anisotrópicos, não lineares, não homogêneos, com propriedades variáveis no tempo; os ensaios de laboratório não representam os níveis de deformações envolvidas; ou se dispõe de pouca ou nula informação antes da ocorrência do escoamento.

Tabela 1.1: Instabilidades e movimentos de grandes massas de terra com um grande número de vítimas fatais (Modificado de De Blasio et al.[1]).

\begin{tabular}{lllll} 
Lugar & País & Data & Mortes & Características \\
\hline Gansu & China & $16 / 12 / 1920$ & 180000 & Fluxo de lama \\
Armero & Colômbia & $13 / 11 / 1985$ & 25000 & Fluxo de lama \\
Yungay & Peru & $31 / 05 / 1970$ & 18000 & Avalanche de rochas \\
Khait & Tajikistan & 1949 & 12000 & Avalanche de rochas \\
Huaraz & Peru & $12 / 1941$ & 5000 & Fluxo de detritos \\
Kelud & Indonésia & 1919 & 5160 & Drenagem cratera \\
Yungay & Peru & $10 / 01 / 1962$ & 4500 & Avalanche de rochas \\
Colima & Honduras & $20 / 09 / 1973$ & 2800 & - \\
Ranrahirca & Peru & $10 / 01 / 1962$ & 4000 & Avalanche/Fluxo detritos \\
Longarone & Itália & $09 / 10 / 1963$ & 2000 & Avalanche de rochas \\
Bihar, Bengal & India & $01 / 10 / 1968$ & 1000 & Terremoto \\
Villa Tina & Colômbia & $27 / 9 / 217$ & 2000 & Solos residuais \\
La Conchita & USA & $10 / 01 / 2005$ & 2000 & Fluxo de detritos \\
\hline
\end{tabular}

Os métodos clássicos de análises geotécnicos estão focados principalmente na previsão da ruptura no início do escorregamento e na estimativa de um fator de segurança para o projeto de estruturas de suporte [7]. Algumas das principais características dos métodos clássicos de análise geotécnica são:

- Previsão de ruptura no início do escorregamento;

- Projeto de estruturas para suportar cargas em função de um fator de segurança;

- Pouca ou nenhuma informação do comportamento pós-ruptura;

- Em geral, envolvem análise mecânica do solo submetido a forças extremas;

- Em geral, são análises estáticas;

- Uso do conceito de equilíbrio limite;

- Uso de modelos rígidos perfeitamente plásticos;

- Uso de métodos clássicos:

$\diamond$ Método de gráficos de estabilidade mediante o número de estabilidade $[15,16]$;

$\diamond$ Método ordinário das fatias de Fellenius a partir do conceito de trabalho virtual [17]; 
$\diamond$ outros métodos clássicos [18];

Com estas características, os métodos tradicionais de análise geotécnicos não permitem descrever adequadamente o comportamento pós-falha das massas de solo com grandes deformações e deslocamentos. Surge consequentemente a necessidade de desenvolver novas metodologias para simular não somente o início da ruptura, mas também o comportamento dinâmico pós-ruptura.

\section{1}

\section{Revisão bibliográfica}

Na sequência apresenta-se uma revisão bibliográfica dos métodos numéricos atuais utilizados para modelagem de movimentos de grandes massas de terra e problemas de estabilidade de taludes de grandes deformações. Os objetivos particulares da presente revisão bibliográfica são: 1) Identificar as vantagens e desvantagens de cada metodologia numérica; 2) Identificar a relevância do Método do Ponto Material (MPM) na simulação de problemas de grandes deformações; 3) Avaliar a necessidade de pesquisa no MPM.

\subsection{1}

\section{Introdução à modelagem do sólido geomecânico}

A modelagem dos materiais geomecânicos é o processo de idealização do material limitando o número de variáveis envolvidas para seu uso em relações constitutivas e equações governantes. Este processo de modelagem implica o conhecimento prévio do material com o objetivo de estabelecer diferentes hipóteses de comportamento. Em função da escala e do tipo de fenômeno envolvido, os materiais geomecânicos podem ser modelados segundo uma abordagem discreta ou contínua (ver Figura 1.3). No enfoque discreto a modelagem é em nível do grão de solo, ou de grupos de elementos individuais, a partir das interações ou contatos entre eles [19]. O enfoque discreto apresenta uma limitação computacional relacionada à quantidade de partículas individuais que podem ser simuladas para representar o comportamento macroscópico dos fenômenos de deslocamentos de grandes massas de solo. O enfoque contínuo considera o comportamento do solo mediante equações governantes e relações constitutivas macroscópicas.

\subsection{2}

\section{Revisão dos principais métodos numéricos disponíveis baseados no enfo- que contínuo}

A seguir apresenta-se uma revisão dos principais métodos numéricos baseados no enfoque contínuo, em particular aqueles utilizados na modelagem 


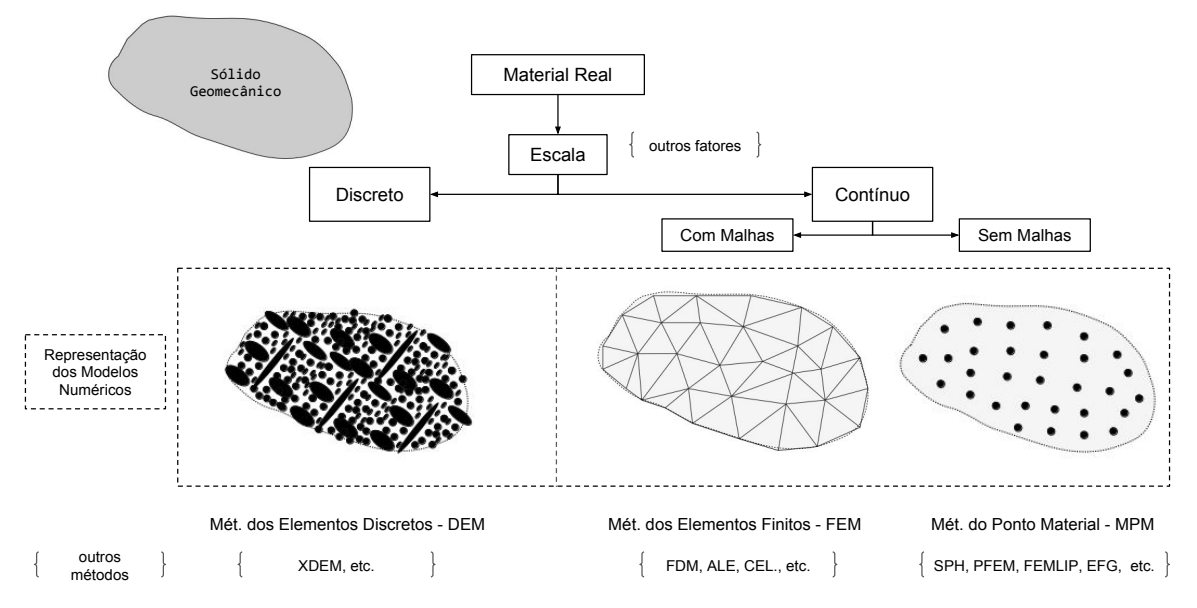

Figura 1.3: Enfoque discreto e contínuo do sólido geomecânico.

de movimentos de grandes massas de solo. A revisão dos métodos contínuos baseia-se no trabalho de Soga et al. (2015) [2]. Para cada método é feita uma breve descrição e são comentadas as vantagens e desvantagens no contexto de problemas de grandes deformações.

Em geral os métodos numéricos para problemas de grandes deformações podem ser classificados conforme são baseados em malhas ou não.

- Métodos baseados em malhas

$\diamond$ Finite-Element Method - FEM

$\diamond$ Finite-Difference Method - FDM

$\diamond$ Arbitrary Lagrangian Eulerian - ALE

$\diamond$ Coupled Eulerian - Lagrangian - CEL

- Métodos sem malhas

$\diamond$ Material Point Method - MPM

$\diamond$ Smooth Particle Hydrodynamics - SPH

$\diamond$ Particle Finite-Element Method - PFEM

$\diamond$ FEM with Lagrangian Integration Points - FEMLIP

$\diamond$ Element-Free Galerkin - EFG

O método dos elementos finitos (FEM) [20] utiliza uma malha para a discretização do modelo matemático em componentes de geometria simples chamados de elementos finitos. A resposta de cada elemento é expressa em termos de um número finito de graus de liberdade, caracterizada pelo valor de funções nos pontos nodais. Em relação às análises de movimentos de massas de solo, o FEM foi utilizado na modelagem hidromecânica de diferentes cenários de falha de encosta de solo solto, submetido a infiltração vertical de água 
[21]; para a modelagem do início da ruptura de um talude induzida por chuvas em encosta íngreme usando análise de acoplamento fluido mecânico [22]; entre outros. As principais desvantagens que o FEM apresenta neste tipo de problemas estão relacionadas à distorção da malha em problemas de grandes deformações, aos custos computacionais associados ao processo de refazer a malha, e aos erros adicionais no remapeamento de variáveis.

No método das diferenças finitas (FDM), as derivadas da equação diferencial parcial são aproximadas por combinações lineares dos valores da função nos pontos de uma grade. O domínio é particionado no espaço e no tempo. Estudos relevantes que usaram esta técnica na simulação de movimentos gravitacionais de rocha superficial ao longo do tempo [23] e na modelagem de grandes deformações em taludes pelo rebaixamento do nível de água [24], mostram a aplicabilidade do método para simular problemas de grandes deformações. Durante as grandes deformações, as coordenadas da grade são atualizadas. As desvantagens deste método estão relacionadas ao seu uso para domínios de geometrias simples, ao fato da distorção da malha causar inconvenientes em problemas de grande deformação e ao alto custo computacional [2].

No método Euleriano Lagrangeano Arbitrário (ALE) os nós da malha computacional podem se movimentar com o contínuo conforme uma abordagem Lagrangiana, ou serem mantidos fixos de forma Euleriana, ou ser movimentados de alguma forma arbitrária [25]. Este método dá liberdade de movimento à malha computacional, o que permite simular maiores distorções com melhor resolução do que o oferecido por uma abordagem puramente Euleriana. As desvantagens do método estão relacionadas à limitação da liberdade de movimento da malha, à necessidade de um passo convectivo para deslocar nós, e ao efeito convectivo sobre as variáveis dependentes do histórico de deformação $[2]$.

No método Euleriano-Lagrangeano Acoplado (CEL), o enfoque Lagrangeano é usado para modelar a estrutura em movimento, enquanto o enfoque Euleriano é usado para o solo. O limite do domínio Lagrangiano é modelado mediante uma interface entre os domínios. Diferentes modelos de interface usam a velocidade do contorno do domínio Lagrangiano como uma condição de contorno na malha Euleriana [26]. O método resulta efetivo para modelar interações sólido-fluido [27]. Ele requer termos advectivos adicionais para as variáveis que se movimentam com a malha e maior tempo computacional que o ALE. A solução numérica depende da malha Euleriana [2].

O Método do Ponto Material (MPM) é um método híbrido EulerianoLagrangiano que utiliza pontos materiais que se movimentam sobre uma malha computacional de fundo [28]. O contínuo é representado por um conjunto de 
pontos materiais e as leis do movimento de Newton determinam os deslocamentos. O MPM tem a capacidade de simular problemas de grandes deformações sem os inconvenientes associados à distorção da malha [29], como também permite a simulação da interação sólido-fluido [30]. O uso de funções de forma lineares para problemas de grandes deformações provoca erros numéricos devido aos pontos materiais que atravessam a grade, num fenômeno numérico chamado de cell crossing noise. O uso de funções de forma de alta ordem requer maior tempo computacional. O custo computacional é superior ao FEM [2] em problemas de pequenas deformações.

No método SPH, o domínio é discretizado em partículas que têm uma distância espacial chamada de comprimento de suavização (smoothing length), sobre a qual as propriedades do material são aproximadas por uma função chamada de kernel function $[2,31]$. O SPH foi utilizado para simular problemas de grandes deformações [32]. O método requer um tratamento especial no contorno, tal como o uso de nós fantasmas, e apresenta instabilidades numéricas devido à integração pontual. Um número insuficiente de partículas vizinhas causam inconsistências nos resultados. O SPH é computacionalmente custoso como resultado da busca das partículas vizinhas. O método sofre de instabilidade de tração o que pode provocar fratura numérica [2].

O PFEM usa uma malha de elementos finitos para discretizar o sólido e para integrar as equações diferenciais. Os nós da malha se movimentam de acordo com as equações de movimento num enfoque Lagrangiano. Os nós transportam todas as suas propriedades físicas, comportando-se como partículas. No final de cada intervalo de tempo a malha é reconstruída mediante triangulação para conectar as partículas na nova posição. A malha também é usada para identificar contatos e superfícies livres [33, 2]. O contato entre os nós sólido-sólido e fluido-sólido necessitam de tratamento especial. As grandes deformações exigem refazer a malha [2].

O FEMLIP é derivado da formulação rápida implícita do MPM [34]. Os pontos materiais são utilizados como pontos de integração em cada elemento. Todas as propriedades do material são armazenadas nos pontos materiais. O método tem a capacidade de simular grandes deformações [35], porém, para deformações extremas se requer de tratamento especial sobre os volumes nas partículas. Para manter o volume representativo de cada partícula, novas partículas são criadas. O FEMLIP demanda alto custo de armazenamento e computacional. A solução depende do espaçamento da malha computacional $[2]$.

No método EFG as funções de interpolação são obtidas mediante um enfoque de mínimos quadrados em movimento, onde cada nó tem uma área de 
influência [36]. As funções de ponderação são frequentemente splines e funções exponenciais contínuas. Desde que os subdomínios sejam superpostos cobrindo o domínio total, se garante o equilíbrio global e as condições de contorno. O método apresenta um custo computacional muito alto [2].

\subsection{3}

\section{Uso do MPM na modelagem de processos de grandes deformações}

Dos métodos numéricos utilizados para a modelagem de processos de grandes deformações, se evidencia que aqueles que são baseados em malhas, em geral, apresentam inconvenientes a ela associados. Em particular, inconvenientes relacionados com a sua distorção (FEM, FDM e ALE), ou com a sua dependência na solução (CEL). No entanto, os métodos sem malhas apresentam um custo computacional mais elevado (MPM, SPH, PFEM, FEMLIP e EFG). Alguns deles também apresentam inconvenientes de triangulação em processos de deformação extrema (PFEM), problemas de fratura numérica em sólidos (SPH), e problemas de interpolação ao utilizar funções lineares (MPM).

Em particular, o MPM apresenta-se como um método de grande interesse na simulação de processos de grandes deformações, com um custo computacional maior que o FEM em pequenas deformações, porém menor que outros métodos sem malhas que precisam de busca de vizinhos (SPH) e de retriangulação (PFEM). Os inconvenientes associados ao uso de funções lineares de interpolação no MPM podem ser contornados utilizando funções de ordem superior [37]. Pelos motivos acima mencionados, o MPM é o método utilizado e desenvolvido no presente trabalho para estudar o comportamento de massas de solo que apresentam grandes deslocamentos e deformações.

\section{2}

\section{Escopo e objetivos}

O presente trabalho foca-se no estudo e no desenvolvimento de implementações computacionais para contribuir na resolução e no entendimento de problemas geotécnicos, onde os métodos mais frequentemente utilizados para sua abordagem, como o método dos elementos finitos (FEM), apresentam deficiências ou limitações na sua aplicação. Exemplos desse tipo de problemas são os que apresentam grandes deformações, onde a excessiva distorção dos elementos da malha que se deforma com o sólido leva a imprecisões na solução numérica, ou até à falha do processo de cálculo devido a valores negativos do Jacobiano nos pontos de integração (Equação 4-35). Considere-se como exemplo um elemento bilinear isoparamétrico de quatro nós em coordenadas globais, no qual a variação do determinante da matriz jacobiana da transformação de 
coordenadas $|\mathbf{J}|=|\partial \mathbf{x} / \partial \xi|$ é calculada a medida que um dos nós é deslocado simulando a distorção do elemento (ver Figura 1.4).

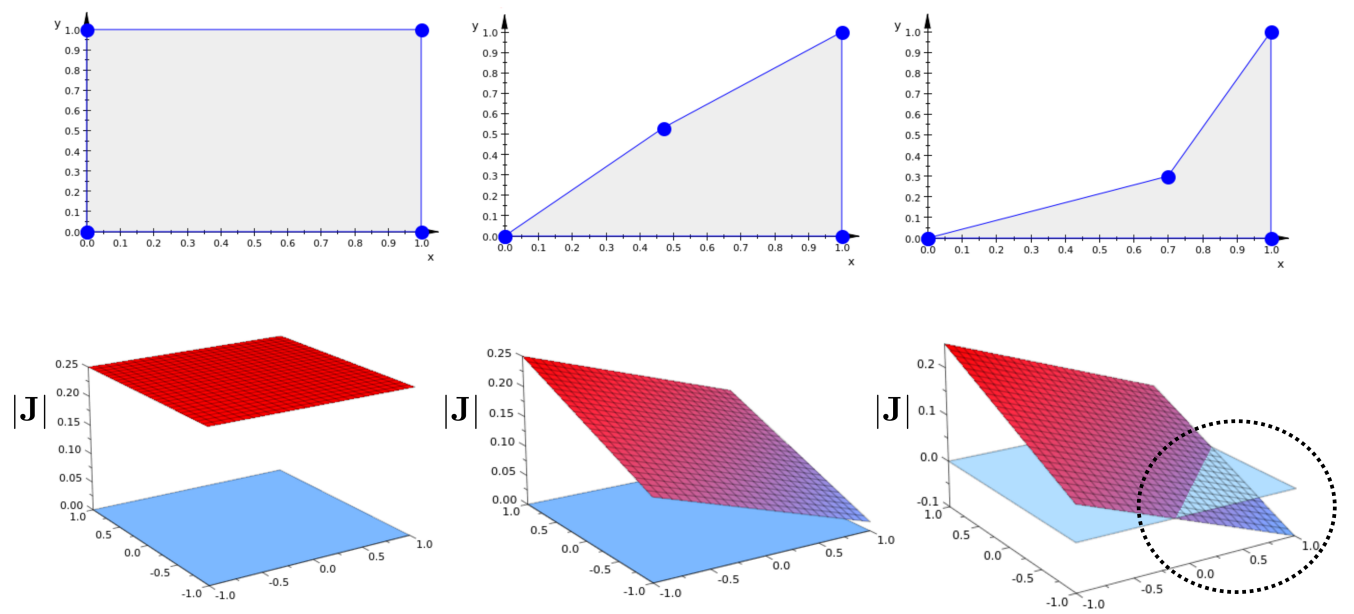

Figura 1.4: Deformação de elemento finito de 4 nós. Variação do Jacobiano dentro do elemento.

Os objetivos da presente tese de doutorado são:

- Desenvolver um algoritmo computacional para aproximar a solução das equações governantes do fenômeno de escoamento de massas de solo de grandes deformações mediante o método do ponto material;

- Implementar diferentes modelos constitutivos para modelar de forma adequada tanto a formação da superfície de ruptura, como o escoamento da massa de solo;

- Incluir o efeito da presença da água nos poros do material mediante o conceito de mistura;

- Otimizar o tempo computacional para modelos de grande número de partículas segundo o paradigma de programação paralela.

\section{3}

\section{Contribuição da tese}

Uma revisão das 40 publicações mais relevantes do MPM, entre os anos 1994 e 2018, releva uma tendência ao desenvolvimento do método para problemas em duas dimensões e sem a consideração do acoplamento fluido mecânico na sua formulação (ver Figura 1.5).

A Tabela 1.2 mostra os principais códigos MPM disponíveis e que são usados para contextualizar a contribuição da presente tese, que se resume a seguir: 

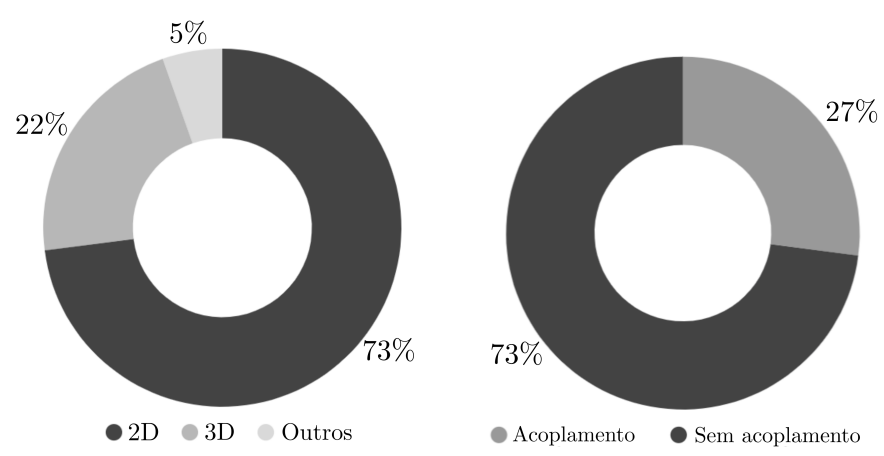

Figura 1.5: Revisão de 40 publicações sobre o MPM entre os anos 1994 e 2018.

Tabela 1.2: Principais programas computacionais do MPM.

\begin{tabular}{llll} 
Programa & Autor & País & Universidade \\
\hline MPM3D-F90[38] & Zhang, X. & China & Tsinghua \\
Anura3D[39] & Anura3D-RC & UE(PB) & UE \\
NairnMPM[40] & Nairn, J. & USA & U.Utah \\
CB-Geo[41] & Kumar, K & USA & U.Texas \\
C-SAFE[42] & ASC Center & USA & U.Utah \\
MPMsim[43] & MPMsim Ltd. & ENG & - \\
\hline
\end{tabular}

- Desenvolvimento de um simulador MPM em 3D com acoplamento fluido mecânico, cujas principais características em relação aos códigos atuais são as seguintes:

$\diamond$ Dos códigos mencionados, somente o Nairn-MPM tem implementada a transição sólido-fluido na modelagem constitutiva, porém, esta implementação tem um enfoque puramente térmico. No programa desenvolvido, a transição sólido-fluido é considerada segundo o critério do trabalho de segunda ordem, adequado para modelagem de materiais do tipo solo conforme evidencias experimentais. No modelo implementado, o sólido é caracterizado pelo modelo de Mohr-Coulomb com amolecimento e o fluido é considerado viscoso. $\diamond$ As condições de contorno não refletivas para análises dinâmicas não foram implementadas de forma específica nos códigos mencionados. No programa desenvolvido, as condições de contorno não refletivas são incorporadas mediante partículas especiais. Estas partículas podem ter qualquer orientação em relação ao contorno do domínio computacional e podem ser aplicadas a diferentes corpos simultaneamente.

$\diamond$ Dos programas mostrados na Tabela 1.2, CB-Geo e Anura3D estão orientados às análises geotécnicas. Dos quais, apenas o último in- 
corpora o acoplamento fluido mecânico usando um ponto material para representar a mistura e sem aplicar nenhuma técnica de suavização das pressões espúrias. Na presente tese o acoplamento fluido mecânico é implementado usando uma partícula para discretizar a mistura e são incorporadas duas técnicas de suavização das pressões espúrias.

$\diamond$ Dos códigos mencionados, somente Nairn-MPM e CB-Geo reportam no seus manuais a implementação da paralelização computacional das análises e permitem o seu controle explicitante. No programa desenvolvido, as principais operações estão paralelizadas mediante o paradigma de memoria compartilhada usando OpenMP e o número de processadores é controlado explicitamente no arquivo de entrada de dados.

- Desenvolvimento de um gerador de partículas adequado para geração de modelos MPM de escala geológica de grande números de partículas e com variabilidade espacial das heterogeneidades. Os programas mencionados não possuem ferramentas específicas para este tipo de problemas (Ver revisão no Capítulo 5).

- Estudo de casos que não foram analisados previamente em 3D, incorporando grandes deformações, com modelos de transição sólido-fluido e com acoplamento fluido mecânico.

\section{4}

\section{Estrutura do trabalho}

A presente tese se organiza em sete capítulos, cujos conteúdos estão descritos na sequência:

No Capítulo 1, introduz-se o tema da presente tese em conjunto a uma revisão bibliográfica do MPM e dos diferentes métodos numéricos relevantes no contexto da modelagem geomecânica de grandes deformações. Apresentase o escopo e os objetivos do presente trabalho, em particular se detalha a contribuição da tese.

O Capítulo 2 é dedicado ao método do ponto material. Apresentase uma introdução ao método, junto com os conceitos e as características fundamentais. Descreve-se em detalhe a formulação matemática e a obtenção das equações de movimento em forma discreta. Apresentam-se os algoritmos de integração explícita no tempo, os tipos de amortecimentos e as condições de contorno não refletivas para análises dinâmicas.

No Capítulo 3 descrevem-se os modelos constitutivos implementados. Define-se a convenção adotada, as taxas objetivas e a formulação incremental 
usada na integração das tensões. Para cada modelo constitutivo, apresenta-se a formulação matemática e seu algoritmo de integração.

O Capítulo 4 é dedicado ao acoplamento fluido mecânico. É feita uma revisão bibliográfica do acoplamento no contexto do MPM. Definem-se elementos conceituais como fases do meio poroso, princípio das tensões efetivas e conservação de massa. São apresentadas em detalhe as equações governantes, junto com sua discretização e o algoritmo computacional. Finalmente, o método de suavização das pressões é apresentado junto com seu algoritmo de implementação.

No Capítulo 5 apresenta-se uma metodologia para discretização de modelos MPM de escala geológica. É introduzido ao tema da discretização de modelos MPM de geometrias complexas e heterogeneidades espaciais. Apresenta-se uma metodologia para a abordagem deste tipo de problemas, junto com um exemplo de verificação e o algoritmo computacional correspondente.

O Capítulo 6 é dedicado à verificação dos algoritmos e aos resultados dos problemas analisados. A primeira parte é dedicada à verificação dos algoritmos mediante uma serie de exemplos. Alguns deles com solução teórica, e outros verificados pela comparação com outros programas computacionais. A segunda parte é dedicada ao estudo de cinco casos de interesse: a ruptura de um túnel em 3D; a simulação de processos geológicos de grandes deformações; o estudo da estabilidade do talude natural em Oregon (Estados Unidos); o impacto de bloco de rocha sobre meio saturado e o deslizamento de Daguangbao (China).

O Capitulo 7 apresenta as conclusões da tese juntamente com as sugestões para futuros trabalhos. 


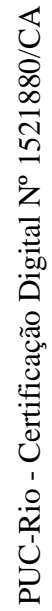




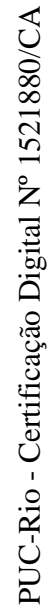




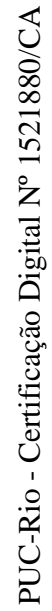




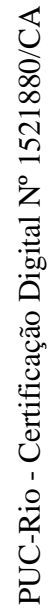




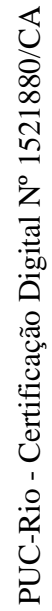




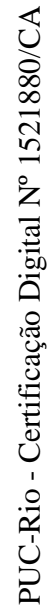




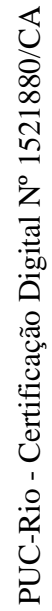




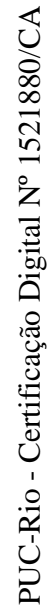




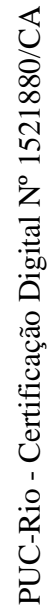




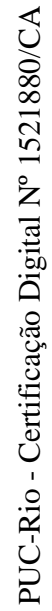




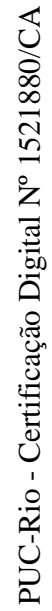




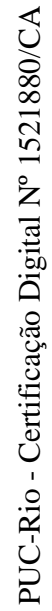




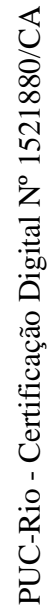




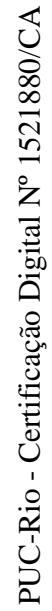




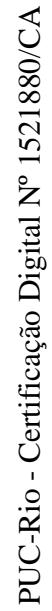




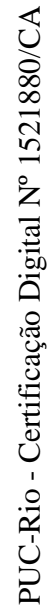




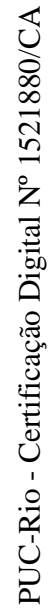




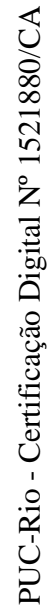




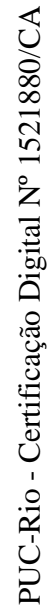




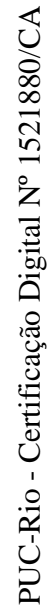




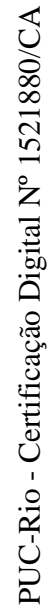




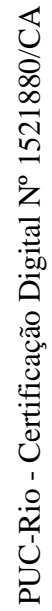




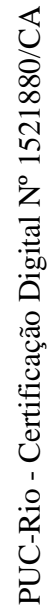




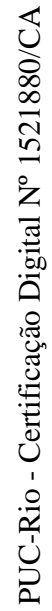




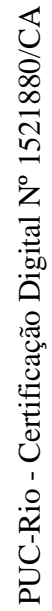




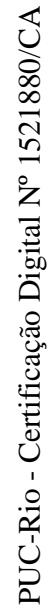




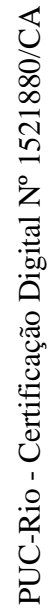




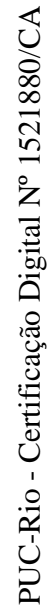




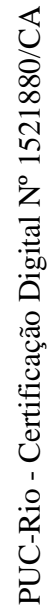




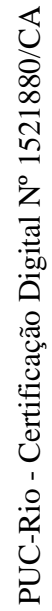




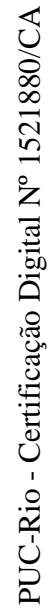




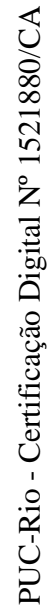




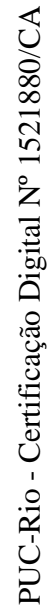




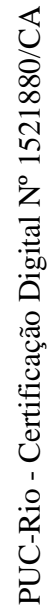




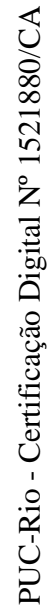




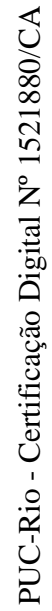




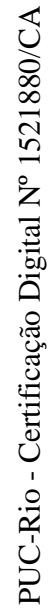




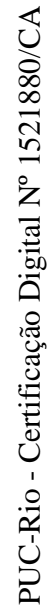




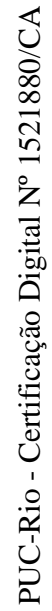




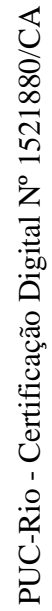




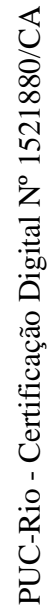




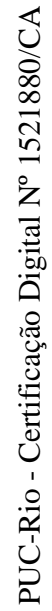




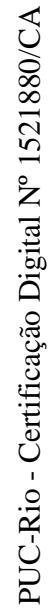




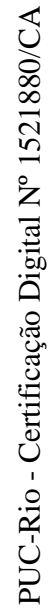




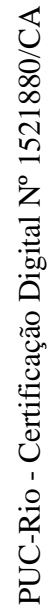




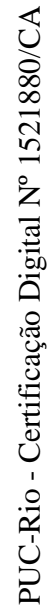




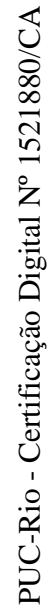




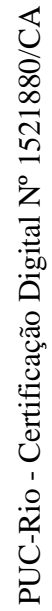




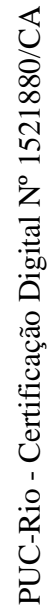




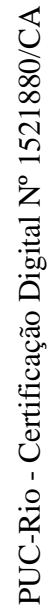




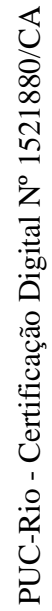




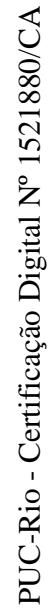




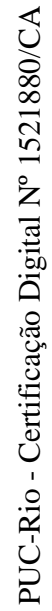




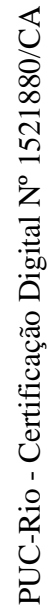




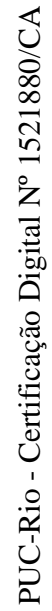




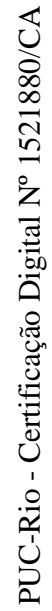




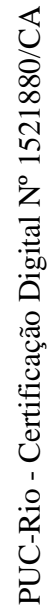




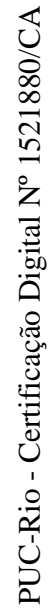




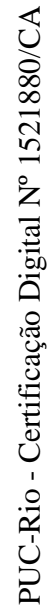




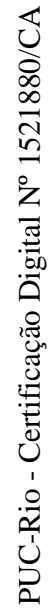




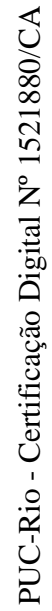




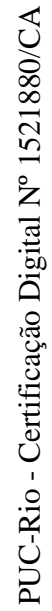




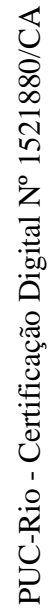




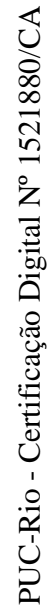




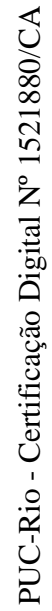




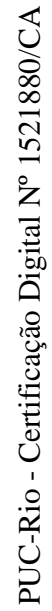




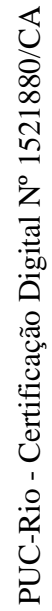




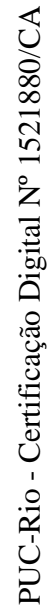




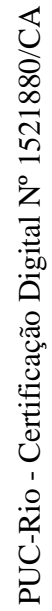




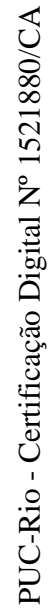




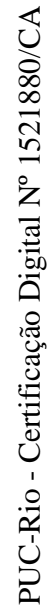




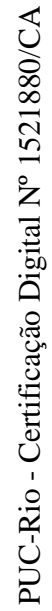




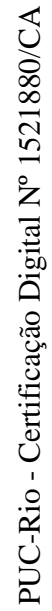




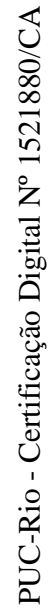




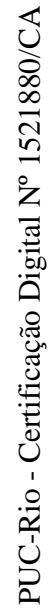




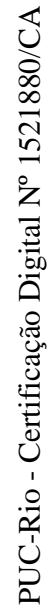




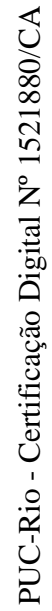




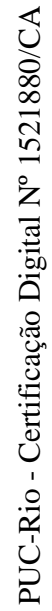




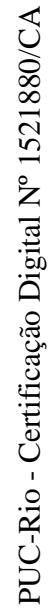


Tabela 6.9: Parâmetros da verificação do algoritmo de suavização de pressões espúrias.

\begin{tabular}{llll}
\hline Malha Euleriana & $\Delta x, \Delta y, \Delta z$ & 0.25 & $\mathrm{~m}$ \\
Partículas & $n_{p}$ & 51712 & - \\
Passo de tempo & $\Delta t$ & $1.0 \mathrm{e}-5$ & $\mathrm{~s}$ \\
Dimensão da base & $L$ & 10.0 & $\mathrm{~m}$ \\
Altura & $l$ & 10.0 & $\mathrm{~m}$ \\
Distância de queda & $h$ & 1.0 & $\mathrm{~m}$ \\
Dimensão do bloco & $l_{x}, l_{y}, l_{z}$ & 1.0 & $\mathrm{~m}$ \\
Material do bloco sólido & & & \\
$\quad$ Módulo de Young & $E_{b}$ & $200.0 \mathrm{e}+3$ & $\mathrm{MPa}$ \\
$\quad$ Coeficiente de Poisson & $\nu_{b}$ & 0.2 & - \\
$\quad \rho_{b}$ & 2200.0 & $\mathrm{~kg} / \mathrm{m}^{3}$ \\
$\quad$ Massa específica & $v_{z}^{0}$ & -5.0 & $\mathrm{~m} / \mathrm{s}$ \\
Material poroso saturado & & & \\
$\quad$ Módulo de Young & $E_{s}$ & 50.0 & $\mathrm{MPa}$ \\
$\quad$ Coeficiente de Poisson & $\nu_{s}$ & 0.3 & - \\
$\quad$ Massa específica & $\rho_{s}$ & 2647.0 & $\mathrm{~kg} / \mathrm{m}^{3}$ \\
$\quad$ Permeabilidade & $k$ & $1.0 \mathrm{e}-3$ & $\mathrm{~m} / \mathrm{s}$ \\
$\quad$ Módulo volumétrico da água & $K_{w}$ & 505.5 & $\mathrm{MPa}$ \\
$\quad$ Porosidade inicial & $n^{0}$ & 0.322 & - \\
$\quad$ Pressão inicial & $p_{w}^{0}$ & 0.0 & $\mathrm{MPa}$ \\
\hline
\end{tabular}

No Caso 1, em que não é usado o procedimento de suavização, observamse valores de pressões não físicas durante o avanço da onda de pressão. Os dois procedimentos de suavização produzem um campo de pressões com valores espúrios menores e uma frente de onda adiantada no tempo (ver Figura 6.18).

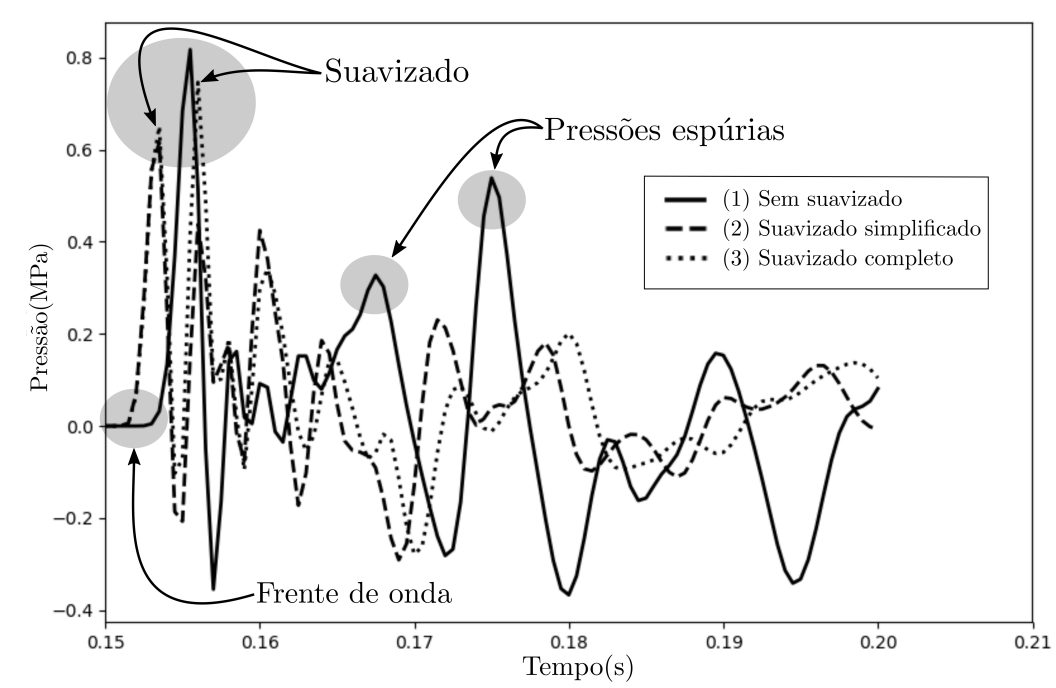

Figura 6.18: Evolução das pressões do fluido no ponto de controle na posição $z=7.0 \mathrm{~m}$ (ver Figura 6.16). 
Figura 6.16: Evolução do campo de pressões durante o impacto do bloco sobre o meio saturado. a) Caso 1: sem suavização, $t=0.152 \mathrm{~s}$. b) Caso 2: suavização simplificada, $t=0.152 \mathrm{~s}$. c) Caso 3 : com suavização, $t=0.152 \mathrm{~s}$. d) Caso 1 : sem suavização, $t=0.153 \mathrm{~s}$. e) Caso 2 : suavização simplificada, $t=0.153 \mathrm{s.f}$ ) Caso 3: com suavização, $t=0.153 \mathrm{~s} . \bigcirc$ ponto de controle em $z=7.0 \mathrm{~m}$.

Figura 6.17: Evolução do campo de pressões durante o impacto do bloco sobre o meio saturado. a) Caso 1: sem suavização, $t=0.157 \mathrm{s.}$ b) Caso 2: suavização simplificada, $t=0.157 \mathrm{~s}$. c) Caso 3: com suavização, $t=0.157$. d) Caso 1 : sem suavização, $t=0.165 \mathrm{~s}$. e) Caso 2 : suavização simplificada, $t=0.165 \mathrm{~s} . \mathrm{f}$ ) Caso 3: com suavização, $t=0.165 \mathrm{~s} . \bigcirc$ ponto de controle em $z=7.0 \mathrm{~m}$. 
Os procedimentos de suavização mostram ser adequados na redução dos valores espúrios da pressão. O procedimento simplificado, onde são usados somente os passos 1 e 4 do Algoritmo 8, resulta computacionalmente mais eficiente quando comparado com o algoritmo completo. Observe-se que o procedimento simplificado integra os incrementos de deformação volumétrica nos nós, para interpolar novamente os valores nos pontos materiais.

\section{2}

\section{Ruptura de túnel 3D}

No exemplo seguinte, o MPM é usado para estudar a estabilidade da parede e a previsão de deslocamentos que tem lugar durante a ruptura do modelo físico de um túnel 3D. O experimento da ruptura do modelo físico do túnel foi documentado e analisado numericamente usando o FEM nos trabalhos de Sterpi et al. $(1996,2004)$ [105, 106]. Os principais objetivos do presente exemplo são:

- Verificar os deslocamentos na parede do túnel mediante a comparação dos valores numéricos do MPM com os valores do experimento.

- Avaliar a capacidade do MPM de simular processos de deformação pósruptura, incluindo a eventual formação da cratera em superfície.

- Avaliar a capacidade do MPM para estimar a força mínima de ruptura na face do túnel.

O modelo físico do experimento consiste numa areia depositada por gravidade no interior de um container de aço de $3.85 \mathrm{~m} \times 3.0 \mathrm{~m} \times 3.5 \mathrm{~m}$. Dentro do container, uma tubulação de aço de $1.35 \mathrm{~m}$ de altura permite modelar as paredes laterais do túnel e uma lâmina de plástico no interior da tubulação permite aplicar uma pressão de suporte na face to túnel.

Depois de colocada a areia por gravidade no container, o experimento consiste em reduzir a pressão da face do túnel até que a ruptura aconteça. Os deslocamentos são registrados nos transdutores $h 1-h 6$ posicionados na superfície do modelo (ver Figura 6.19). A Figura 6.20 mostra os deslocamentos superficiais conforme a pressão na face do túnel é reduzida.

O modelo MPM do experimento consiste em 139680 partículas distribuídas de forma uniforme numa malha Euleriana de $\Delta x=\Delta y=\Delta z=0.1 \mathrm{~m}$. Partículas com diferentes comportamentos foram usadas para modelar o experimento. As partículas que representam a areia possuem um comportamento elasto-plástico com amolecimento por deformação. As partículas que representam a lâmina de plástico usada para aplicar a pressão na face do túnel, podem se deslocar livremente e são sujeitas a uma pressão externa. As partículas que 
representam a parede lateral do túnel são restritas aos deslocamentos, permanecendo fixas durante a simulação. Na Figura 6.21 observa-se o modelo MPM com as diferentes partículas do modelo. Os parâmetros do modelo numérico são apresentados na Tabela 6.10 .

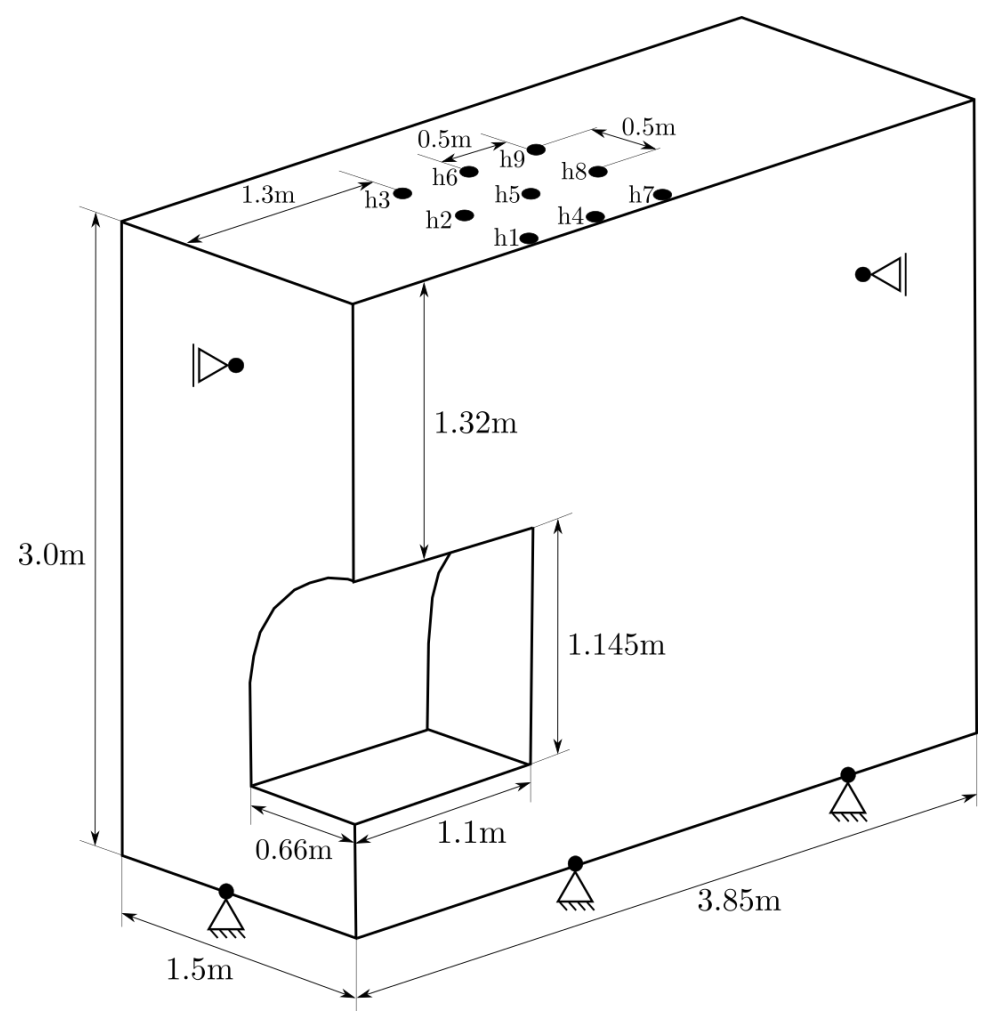

Figura 6.19: Geometria do modelo do túnel, condições de contorno, e posição dos transdutores no topo do modelo.

Tabela 6.10: Parâmetros do modelo do túnel 3D.

\begin{tabular}{llll}
\hline Malha Euleriana & $\Delta x, \Delta y, \Delta z$ & 0.1 & $\mathrm{~m}$ \\
Partículas & $n_{p}$ & 139680 & - \\
Passo de tempo & $\Delta t$ & $2.5 \mathrm{e}-4$ & $\mathrm{~s}$ \\
Módulo de Young & $E$ & 8.2 & $\mathrm{MPa}$ \\
Coeficiente de Poisson & $\nu$ & 0.35 & - \\
Massa específica da areia & $\rho$ & 1440 & $\mathrm{~kg} / \mathrm{m}^{3}$ \\
Ângulo de atrito interno de pico & $\phi^{p}$ & 32 & $\circ$ \\
Ângulo de atrito interno residual & $\phi^{r}$ & 24 & $\circ$ \\
Coesão & $c$ & 0.0 & $\mathrm{kPa}$ \\
Ângulo de dilatância de pico & $\psi^{p}$ & 6.5 & $\circ$ \\
Ângulo de dilatância residual & $\psi^{r}$ & 0 & $\circ$ \\
Deformação plástica de pico & $\epsilon_{p}^{p}$ & 0.05 & - \\
Deformação plástica residual & $\epsilon_{p}^{r}$ & 0.2 & - \\
Parâmetro do modelo Drucker-Prager & $q_{\phi}$ & 0.52 & - \\
Parâmetro do modelo Drucker-Prager & $k_{\phi}$ & 0.00 & $\mathrm{kPa}$ \\
\hline
\end{tabular}




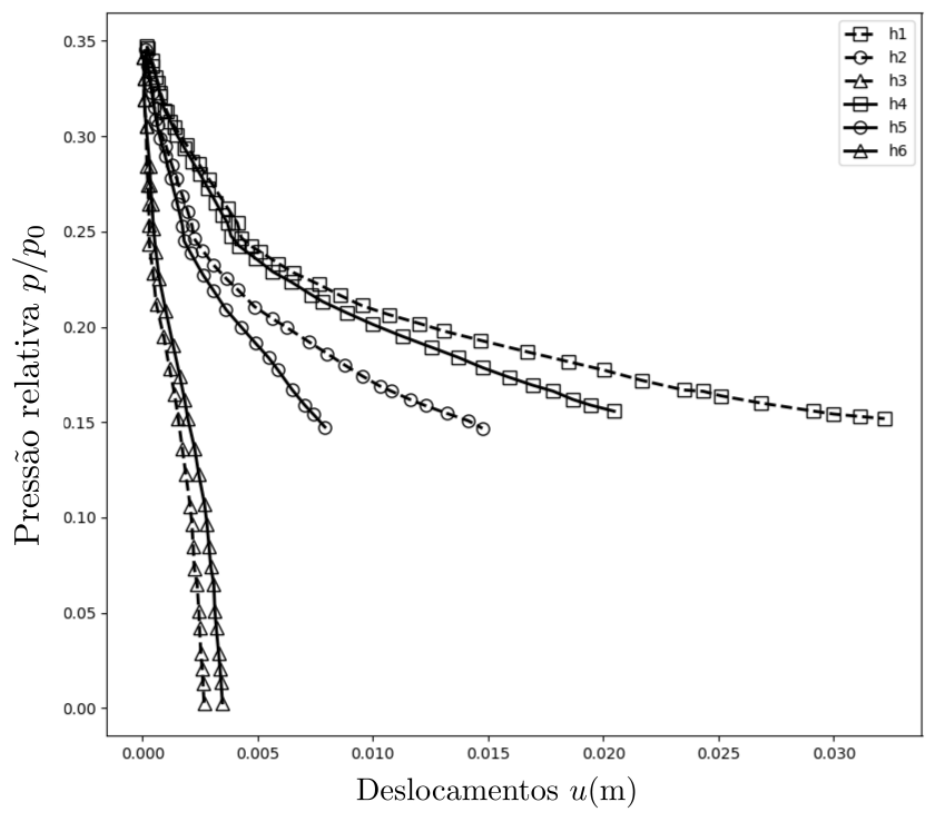

Figura 6.20: Registro dos deslocamentos superficiais nos transdutores $h 1-h 6$ durante a redução da pressão na face do túnel.

Os resultados experimentais [106] estão expressados em termos relativos à pressão aplicada na face do túnel $p$ e a pressão geostática $p_{0}$. Para permitir a comparação, duas pressões são consideradas: uma pressão geostática, calculada a partir do coeficiente de empuxo lateral de terras $K_{0}=0.5$, e uma pressão geostática calculada com o MPM.

A pressão geostática pode ser obtida com o MPM fixando as partículas da face do túnel (partículas de lâmina na Figura 6.21) e efetuando a integração do campo de tensões na direção normal à face. Usando este enfoque, a pressão média resulta em $\sigma_{\text {geo }}^{\mathrm{MPM}}=13.72 \mathrm{kPa}$. A pressão obtida com $K_{0}=0.5$ resulta em $\sigma_{\text {geo }}^{K_{0}}=13.63 \mathrm{kPa}$. A pressão geostática é a mínima pressão na face do túnel requerida para o equilíbrio. O estado de equilíbrio é determinado mediante a energia cinética do modelo, dada por

$$
E_{\mathrm{kin}}=\sum_{p} \frac{1}{2} m_{p}\left|\boldsymbol{v}_{p}\right|^{2}
$$

A pressão mínima de equilíbrio não produz liberação de energia cinética no tempo. A pressão mínima de equilíbrio obtida com o MPM resulta em $p=2.34$ $\mathrm{kPa}$. A pressão relativa mínima de equilíbrio obtida com MPM resulta entre $17.1 \%$ e $17.2 \%$. O valor experimental da pressão relativa foi reportado entre $15 \%$ e $20 \%$ [106]. Isto demostra a potencialidade do MPM para aproximar a pressão mínima de equilíbrio na face do túnel 3D. 
a)

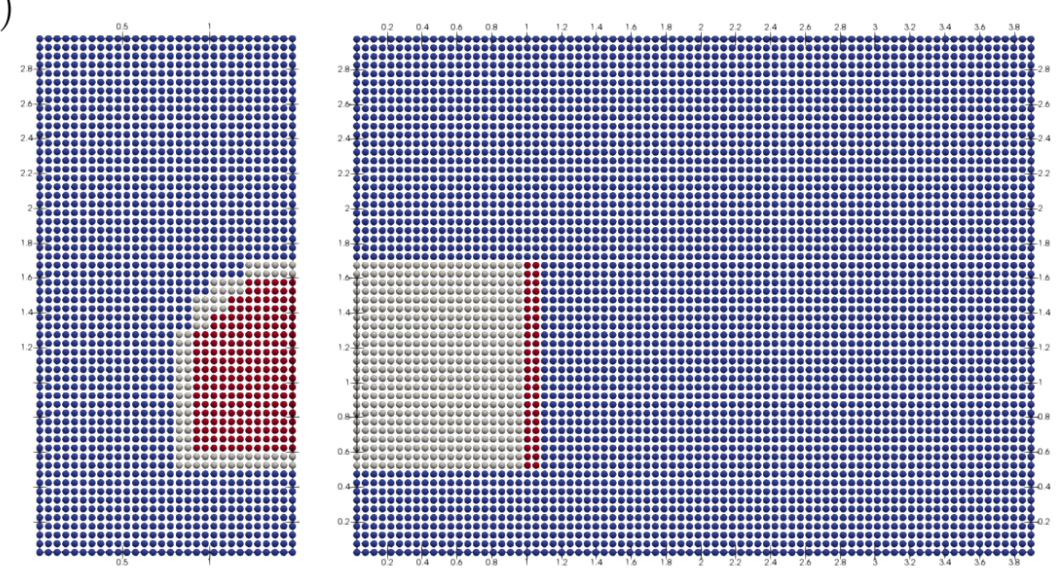

b)

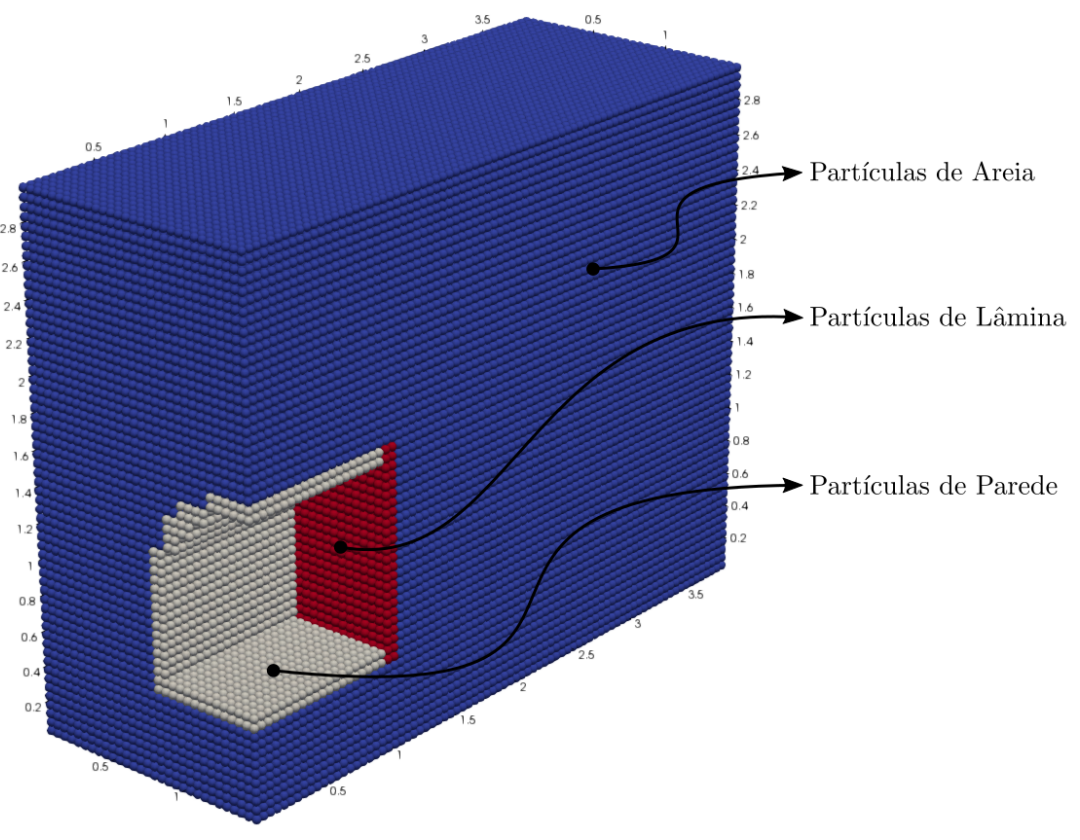

Figura 6.21: Modelo MPM do túnel. Diferentes pontos materiais usados no modelo para representar as partículas de areia, a lâmina de plástico onde é aplicada a pressão e as partículas das paredes do túnel. 


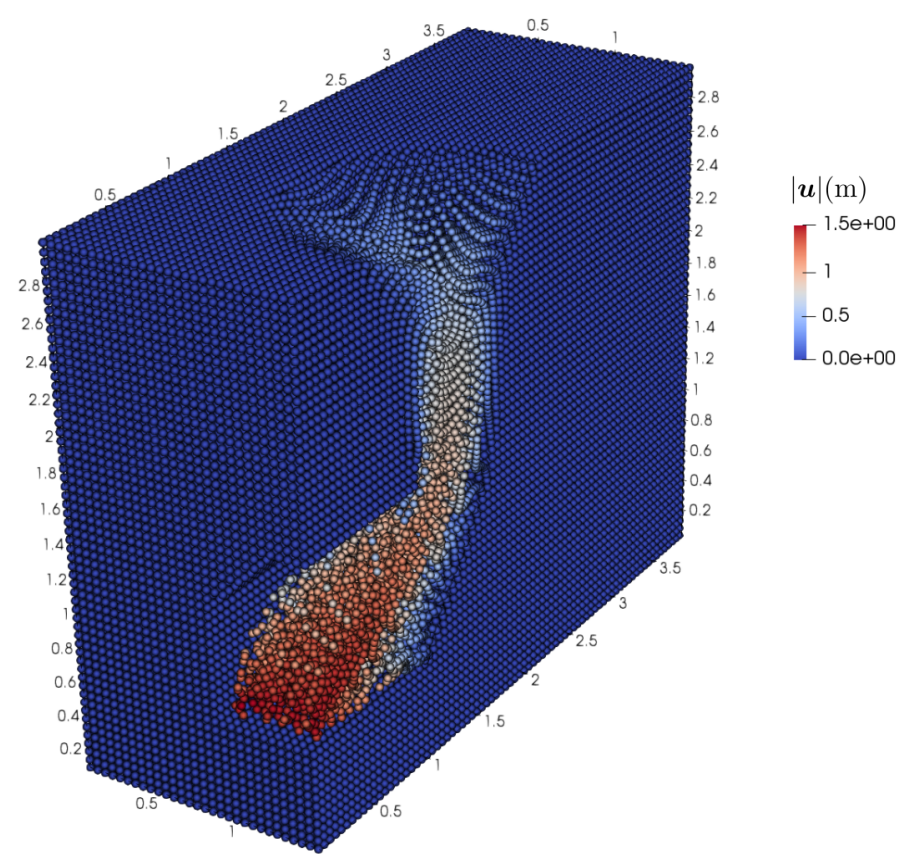

Figura 6.22: Configuração final de colapso. Formação de cratera em superfície como consequência das altas deformações pós-ruptura.

A Figura 6.24 mostra os deslocamentos no colapso, obtidos numericamente com MPM e com FEM [106]. Os resultados numéricos são muito próximos entre eles. Em ambos os casos, os deslocamentos máximos estão concentrados na face do túnel (frente de escavação) e sua distribuição se estende verticalmente sobre ela.

Os transdutores posicionados na superfície do modelo permitem a comparação entre os resultados experimentais e numéricos. A Figura 6.25 mostra a similaridade na forma da zona de ruptura para cada método numérico e para os resultados experimentais. Os resultados do modelo MPM correspondem ao estado de colapso para $t=2.5 \mathrm{~s}$ e para uma pressão constante na face do túnel de $p=2.34 \mathrm{kPa}$.

Os resultados obtidos com MPM apresentam uma boa coincidência com os valores experimentais. Os valores registrados nos transdutores $h 1, h 2$ e $h 3$ são muito próximos aos valores numéricos. Não obstante, uma leve diferença observa-se nos transdutores $h 4, h 5$ e $h 6$. Os resultados numéricos mostram uma tendência semelhante na forma de ruptura quando comparados com os resultados experimentais. 

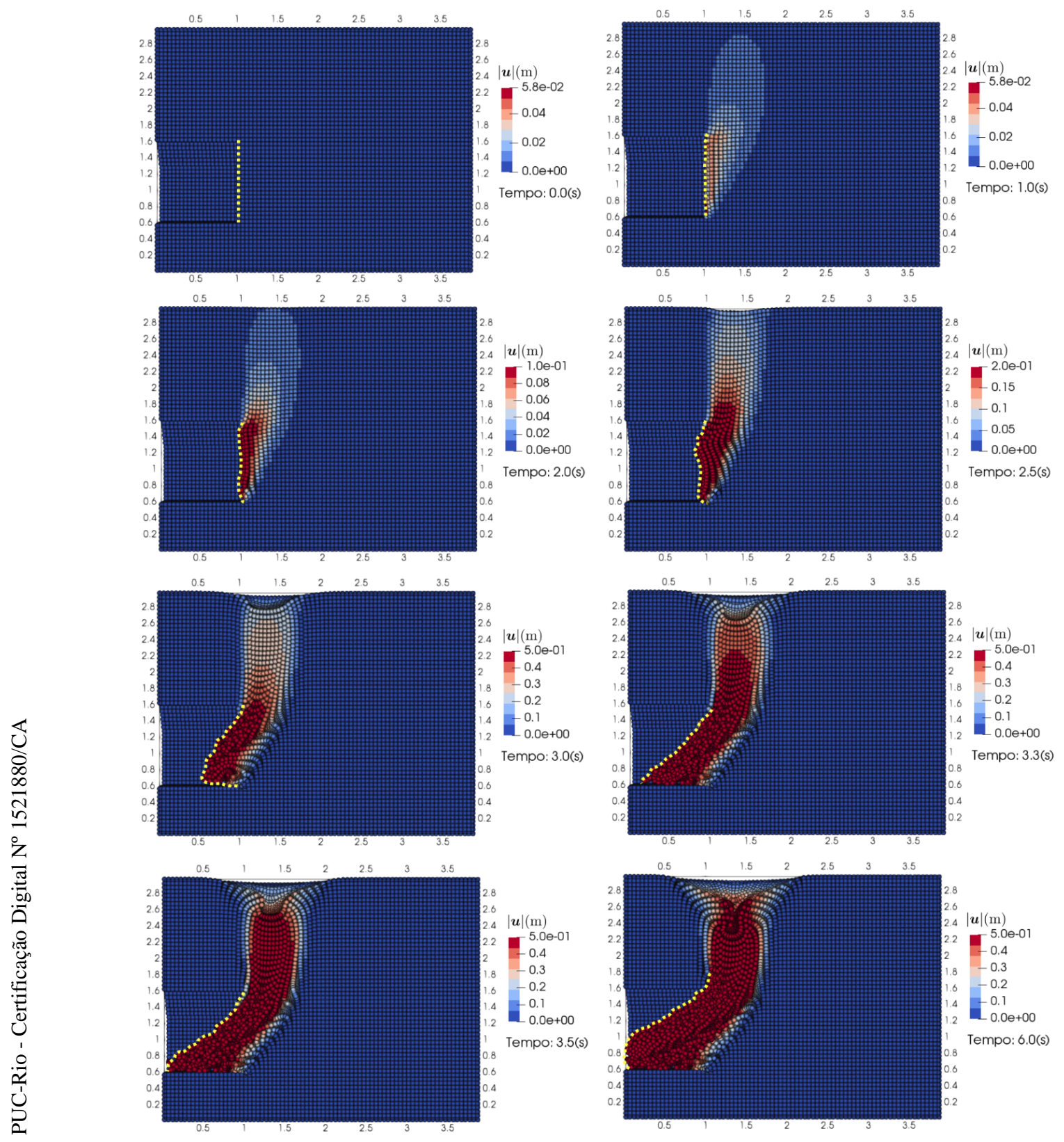

Figura 6.23: Evolução dos deslocamentos pós-ruptura do modelo do túnel 3D. A linha amarela representa a parede do túnel durante a ruptura.

A energia cinética do modelo MPM é mostrada na Figura 6.26. Durante a evolução do processo de ruptura três estados característicos podem ser identificados:

(a) Estado geostático inicial: caracterizado por um incremento linear da energia cinética e uma posterior diminuição, com tendência para o estado estático.

(b) Estado de colapso: caracterizado por uma grande liberação da energia. 
a)

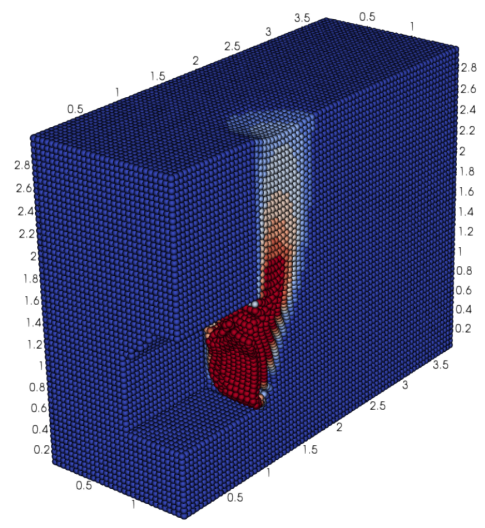

b)

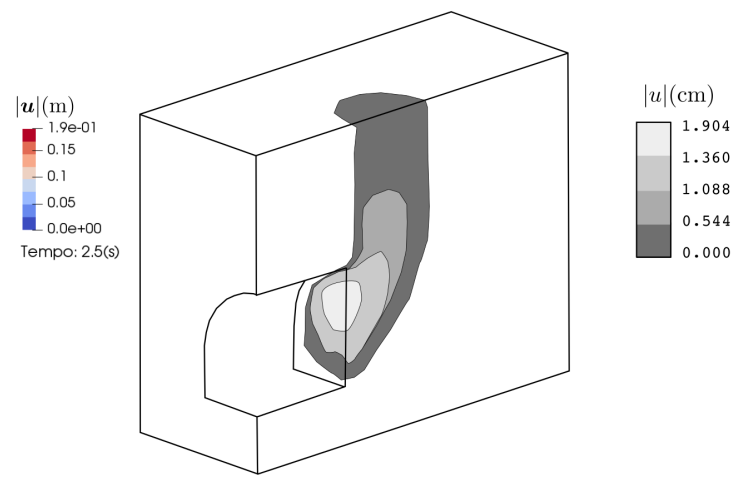

Figura 6.24: Magnitude dos deslocamentos totais no colapso $|\boldsymbol{u}|$. a) Resultados obtidos com MPM. b) Resultados obtidos com FEM por Sterpi et al. (2004) [106].

a)

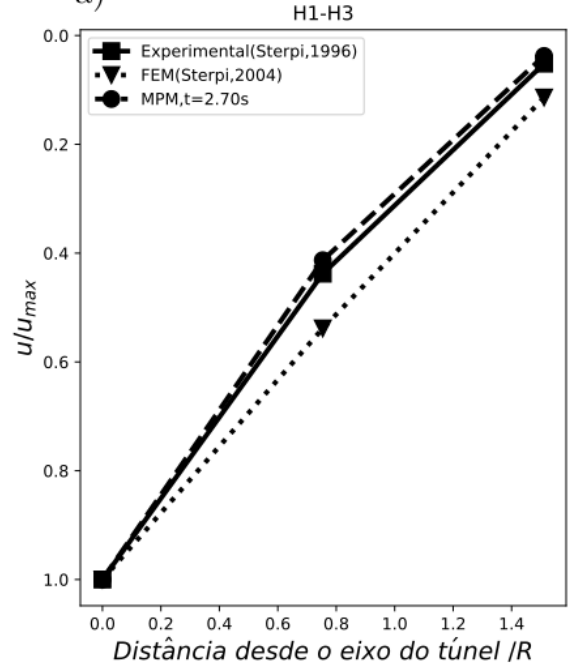

b)

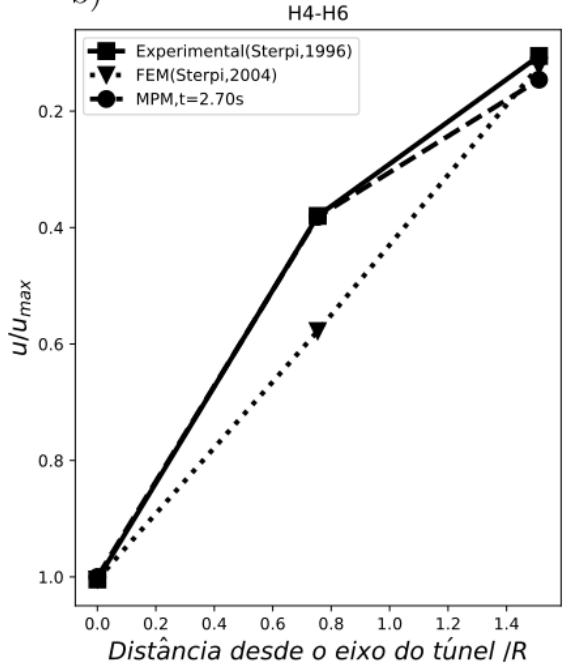

Figura 6.25: Deslocamentos superficiais numéricos e experimentais. a) Valores registrados nos transdutores $h 1, h 2$ e $h 3$. b) Valores registrados nos transdutores $h 4, h 5$ e $h 6$ (ver Figura 6.19).

(c) Estado pós-ruptura: caracterizado por uma diminuição da energia e uma redistribuição das tensões para os valores residuais de resistência (ver Figuras 6.22 e 6.23).

A predição do mecanismo de ruptura obtido com MPM mostra boa coincidência com o observado experimentalmente e com o obtido por FEM. A predição da forma da ruptura no topo do modelo, segue a tendência 


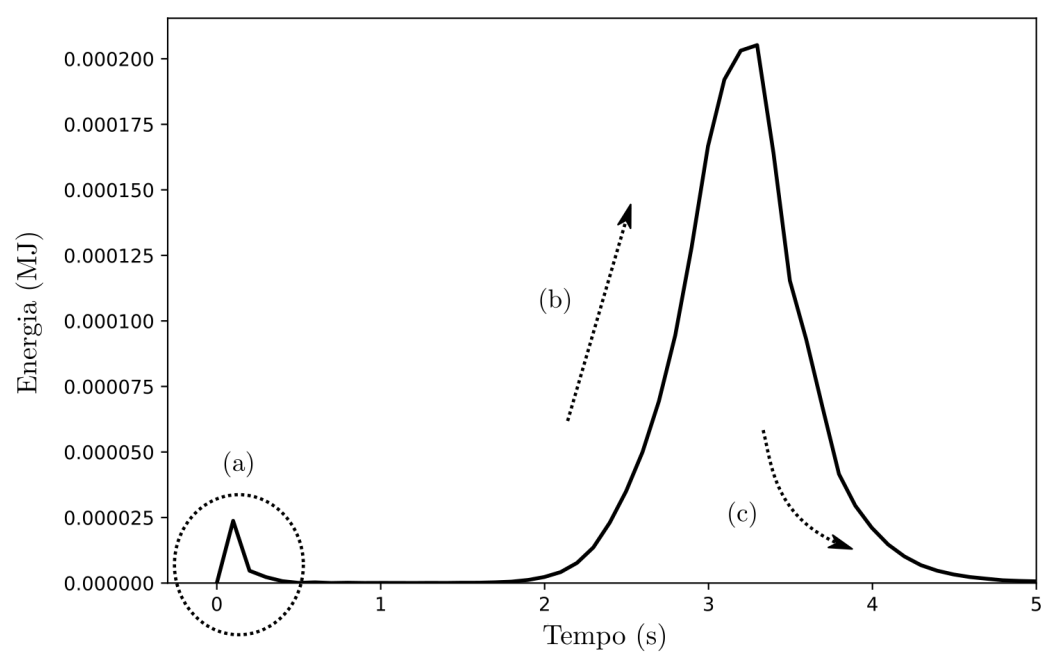

Figura 6.26: Energia cinética do modelo MPM durante a evolução do processo de ruptura.

dos resultados experimentais. Em particular, uma boa concordância com os resultados experimentais foi obtida para o valor da pressão mínima de equilíbrio.

Os resultados obtidos neste exemplo verificaram a potencialidade do MPM para estimar a forma e o mecanismo de ruptura do túnel, a obtenção da pressão mínima de equilíbrio na face do túnel e a evolução dos deslocamentos de grandes deformações no tempo.

\subsection{1}

\section{Estudo paramétrico e análise do escorregamento da massa do túnel}

$\mathrm{Na}$ seção seguinte estuda-se a influência do ângulo de atrito residual no escorregamento da massa na ruptura. A geometria original do túnel é estendida na direção do escorregamento, e quatro ângulos de atrito residual são considerados: $\phi_{r}=24^{\circ}, 21.6^{\circ}, 20.4^{\circ}, 19.2^{\circ}$. A força na parede do túnel é mantida constante no valor da condição de ruptura.

A Figura 6.27 mostra as configurações finais da massa na ruptura para os diferentes ângulos de atrito considerados, e a Figura 6.28, a comparação entre todos os estados.

Observa-se que o ângulo de atrito residual afeta diretamente a configuração final da massa na ruptura, com uma taxa de variação aproximada de deslocamento máximo de $\approx-0.08 \mathrm{~m} /$ o. Para os ângulos de atrito residual usados, não observa-se influência significativa na deformação superficial na cratera no topo do modelo. 

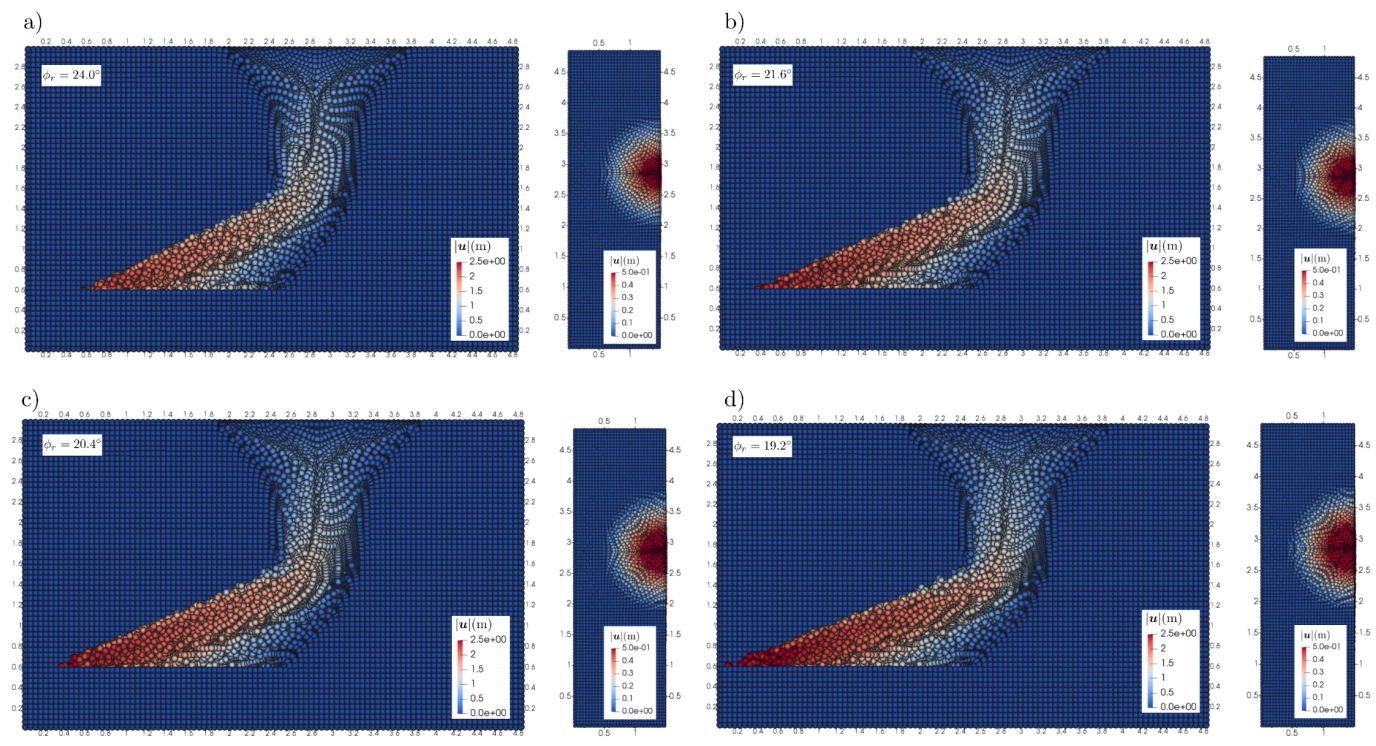

Figura 6.27: Comparação da configuração deformada da massa de solo na ruptura para diferentes ângulos de atrito residual.
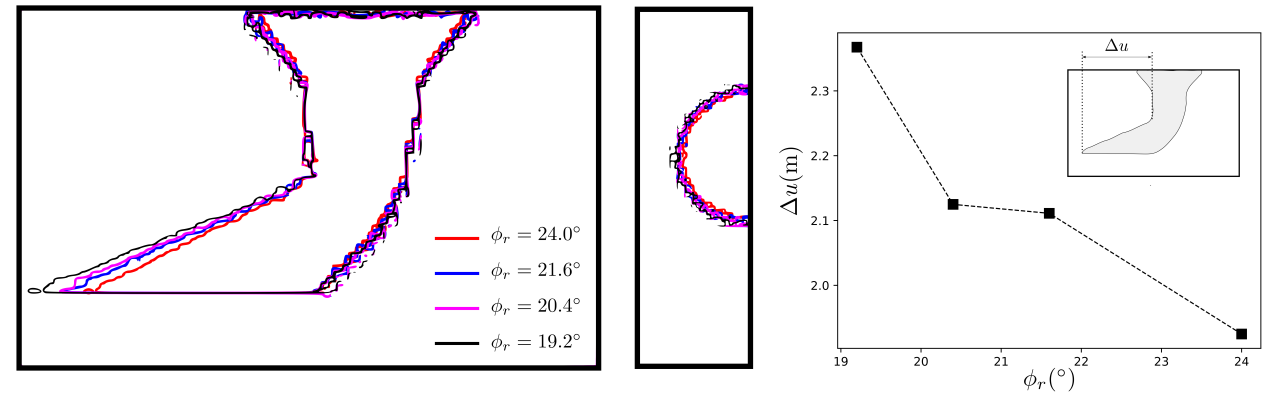

Figura 6.28: Comparação da configuração deformada da massa de solo na ruptura para diferentes ângulos de atrito residual.

\section{3}

\section{Simulação de processos geológicos}

O comportamento constitutivo complexo, as grandes deformações e as descontinuidades nos sistemas geológicos representam um desafio na sua modelagem numérica [107].

Na seção seguinte é apresentada uma aplicação do MPM num problema de interesse em Geologia Estrutural, procurando avaliar e enfatizar o uso do MPM para simular diversos processos envolvendo grandes deformações, ruptura, e em particular, as possibilidades de representação da localização de deformações e formação de falhas.

Para isto, é simulado numericamente o experimento de compressão por 
deformação de velocidade constante da caixa de areia, descrito no trabalho de S. Buiter et al. (2006) [108]. Os resultados obtidos com o MPM são comparados com diferentes modelos numéricos e com modelos físicos, ou análogos.

A Figura 6.29 mostra a configuração geral do modelo, a distribuição dos materiais e as condições de contorno. Os parâmetros específicos do modelo numérico são definidos na tabela 6.11 .

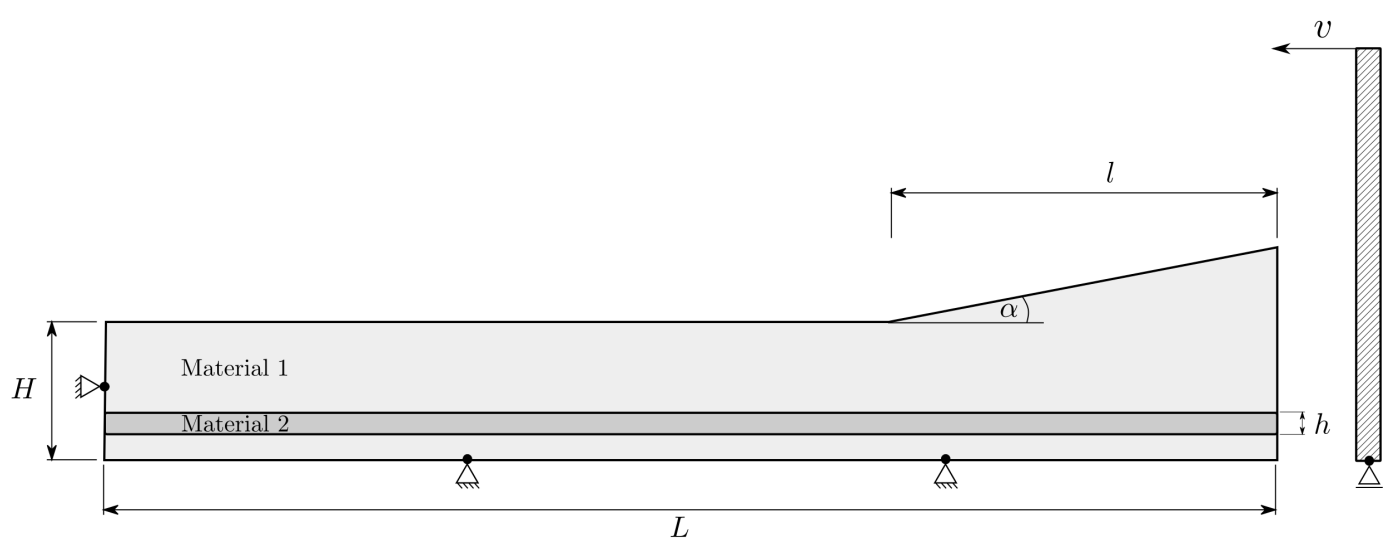

Figura 6.29: Geometria do modelo de caixa de areia usado para simulação de formação de falhas induzidas por deformação de compressão de velocidade constante.
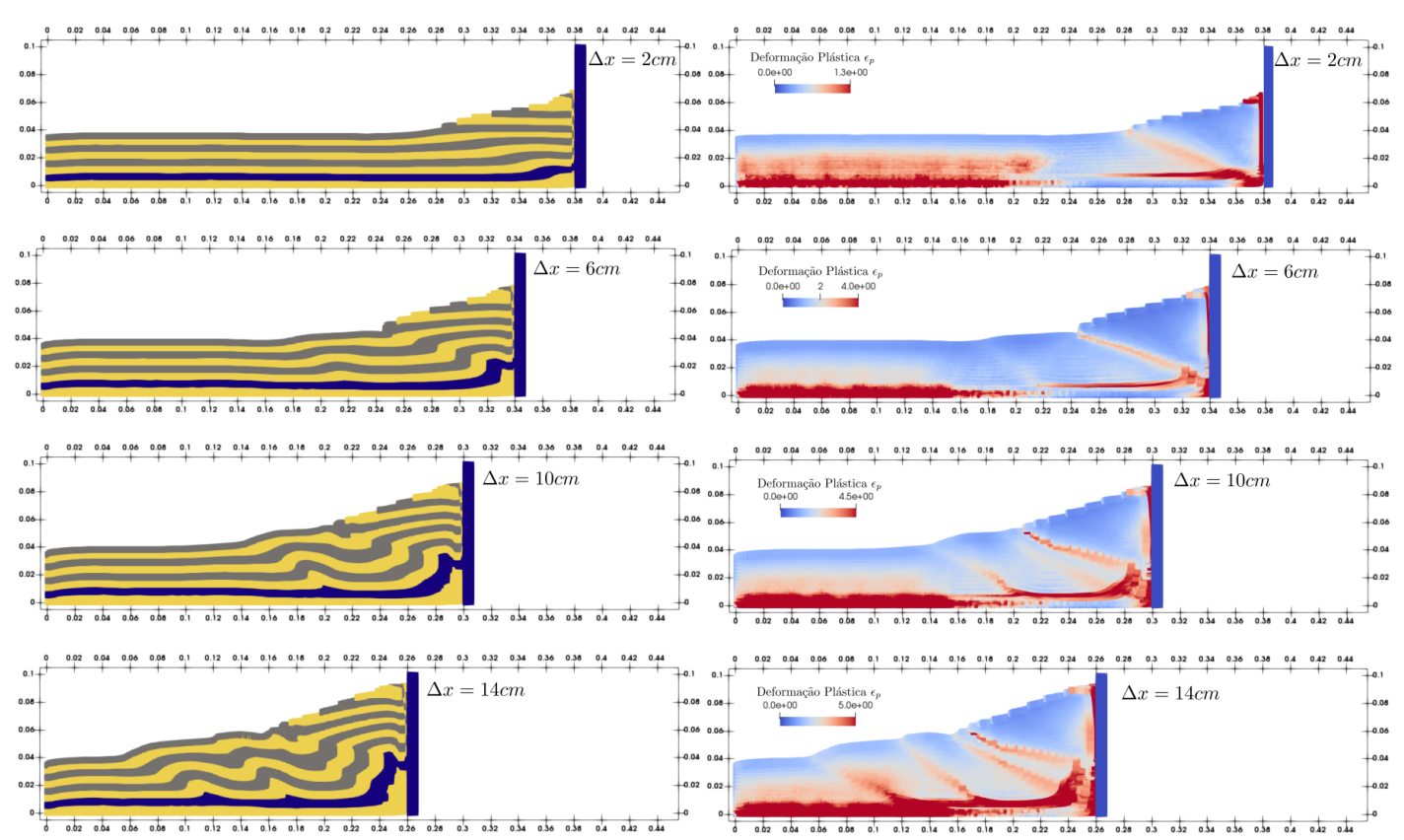

Figura 6.30: Evolução da formação de falhas e da deformação plástica acumulada $\epsilon_{p}$. 
Tabela 6.11: Parâmetros do modelo geológico compressional.

\begin{tabular}{llll}
\hline Malha Euleriana & $\Delta x, \Delta y$ & $2.5 \mathrm{e}-2$ & $\mathrm{~m}$ \\
Dimensão da base & $L$ & $40.0 \mathrm{e}-2$ & $\mathrm{~m}$ \\
Dimensão segmento inclinado & $l$ & $10.0 \mathrm{e}-2$ & $\mathrm{~m}$ \\
Inclinação & $\alpha$ & 10.0 & $\circ$ \\
Altura maior & $H$ & $3.5 \mathrm{e}-2$ & $\mathrm{~m}$ \\
Altura menor & $h$ & $0.5 \mathrm{e}-2$ & $\mathrm{~m}$ \\
Velocidade & $v$ & 0.01 & $\mathrm{~m} / \mathrm{s}$ \\
Partículas & $n_{p}$ & 9924 & - \\
Passo de tempo & $\Delta t$ & $7.0 \mathrm{e}-6$ & $\mathrm{~s}$ \\
Coeficiente de Poisson & $\nu_{1}, \nu_{2}$ & 0.25 & - \\
Coesão & $c_{1}, c_{2}$ & 0.0 & $\mathrm{MPa}$ \\
Deformação plástica de pico & $\epsilon_{p 1}^{p}, \epsilon_{p 2}^{p}$ & 0.5 & - \\
Deformação plástica residual & $\epsilon_{p 1}^{r}, \epsilon_{p 2}^{r}$ & 1.0 & - \\
Material 1 & & & \\
$\quad$ Módulo de Young & $E_{1}$ & 1.0 & $\mathrm{MPa}$ \\
$\quad$ Massa específica & $\rho_{1}$ & 1560 & $\mathrm{~kg} / \mathrm{m}^{3}$ \\
$\quad$ Ângulo de atrito de pico & $\phi_{1}^{p}$ & 36.0 & $\circ$ \\
$\quad$ Angulo de atrito residual & $\phi_{1}^{r}$ & 31.0 & $\circ$ \\
Material 2 & & & \\
$\quad$ Módulo de Young & $E_{2}$ & 0.5 & $\mathrm{MPa}$ \\
Massa específica & $\rho_{2}$ & 1480 & $\mathrm{~kg} / \mathrm{m}^{3}$ \\
Ângulo de atrito de pico & $\phi_{2}^{p}$ & 22.0 & $\circ$ \\
Ângulo de atrito residual & $\phi_{2}^{r}$ & 20.0 & $\circ$ \\
\hline
\end{tabular}

Conforme a parede rígida de velocidade constante deforma os materiais 1 e 2, as deformações no modelo são desenvolvidas por zonas. A Figura 6.30 mostra a evolução da formação de falhas e da deformação plástica acumulada $\epsilon_{p}$, durante o processo de deformação. Observa-se que a formação das falhas são coincidentes com zonas de elevada concentração de deformação plástica.

Conforme o modelo se deforma, o ângulo médio da superfície do modelo varia. A Figura 6.31 mostra a comparação do ângulo da superfície do modelo para diferentes deslocamentos compressionais.

A comparação qualitativa dos resultados revela semelhanças entre os resultados numéricos apresentados (ver Figura 6.33). A comparação quantitativa dos resultados numéricos indica uma grande variabilidade no número de falhas e na inclinação da superfície do modelo. Os modelos análogos evidenciam uma tendência geral em relação à evolução do sistema e à localização de zonas de concentração de deformações cisalhantes. 


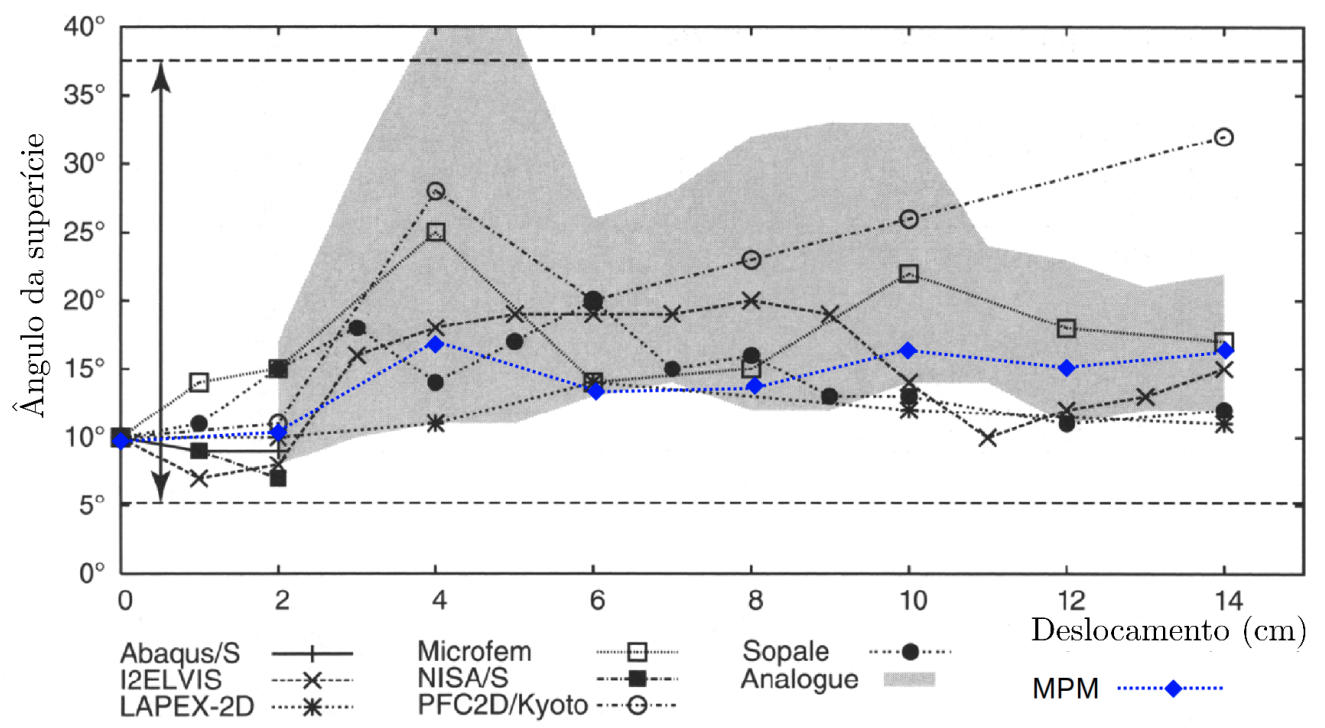

Figura 6.31: Comparação do ângulo da superfície do modelo para diferentes deslocamentos compressionais. Resultados obtidos por diferentes modelos numéricos e análogos [108].

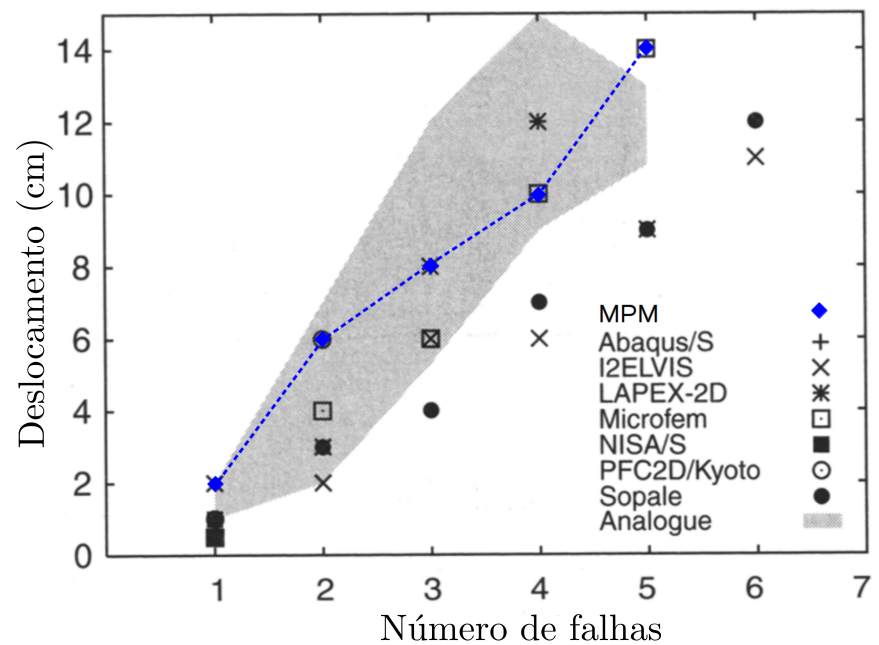

Figura 6.32: Comparação do número de falhas formadas nos modelos para diferentes deslocamentos compressionais. Resultados obtidos por diferentes modelos numéricos e análogos (Modificado de S.Buiter et al.(2006) [108]). 
a) Modelos Numéricos

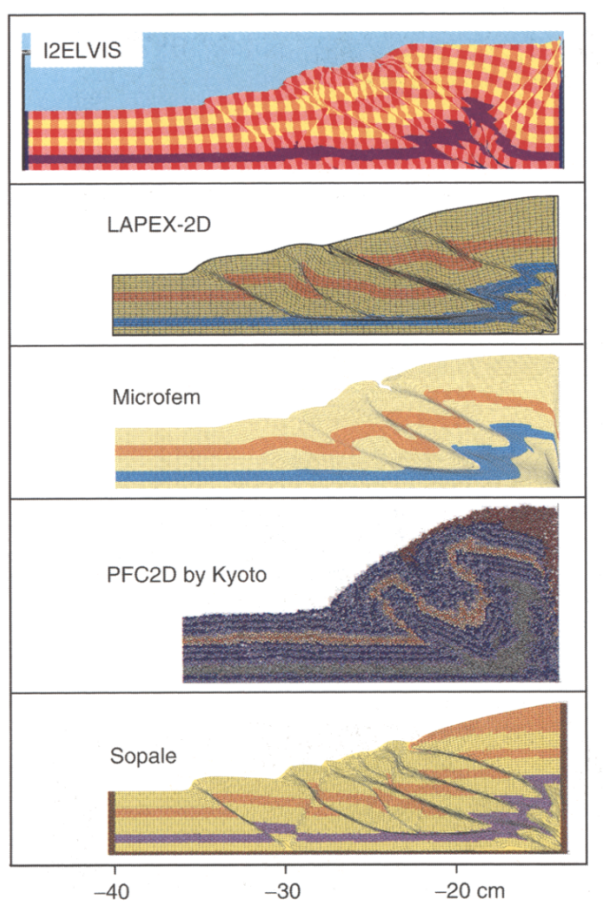

b) Modelos Análogos

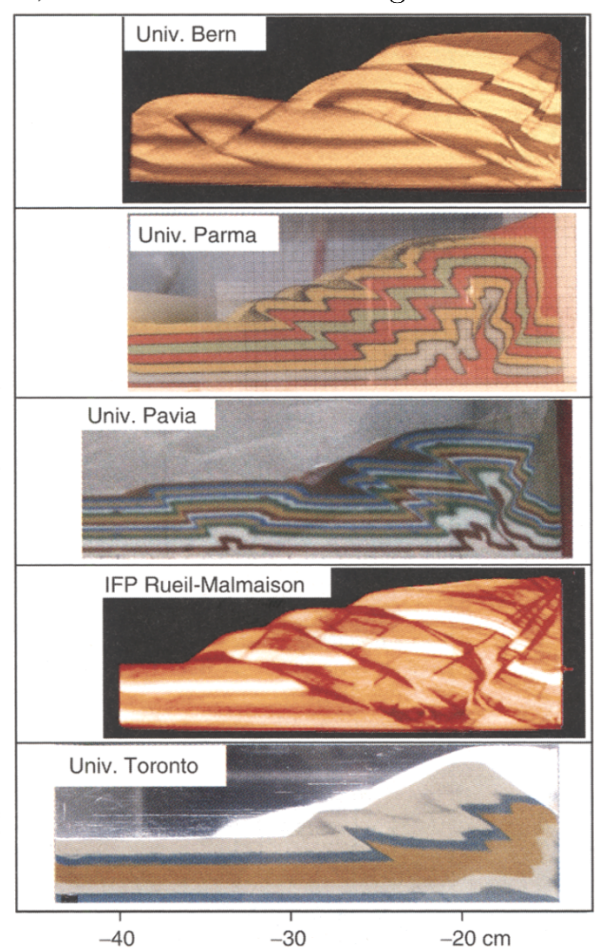

c) Modelo MPM

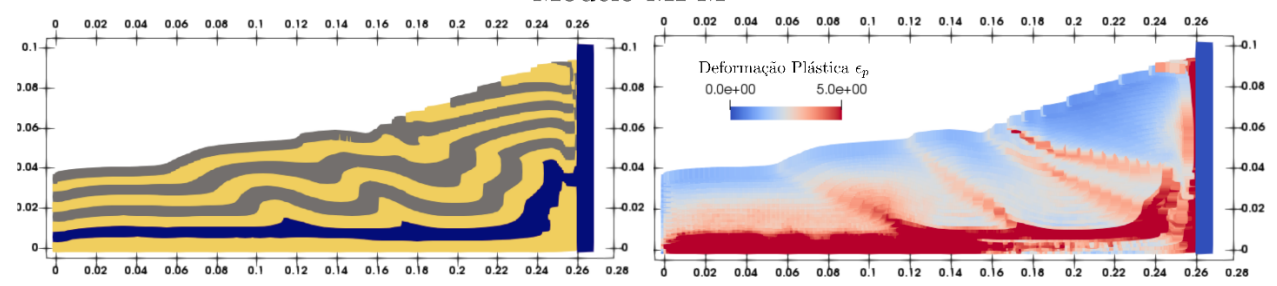

Figura 6.33: Estado de deformação para $14 \mathrm{~cm}$ de deslocamento compressional. a) Modelos numéricos I2ELVIS, LAPEX-2D, Microfem, PFC2D e Sopale [108]. b) Modelos análogos Univ. Bern, Univ. Parma, Univ. Pavia, IFP RueilMalmaison e Univ. Toronto [108]. c) Modelo MPM mostrando, à esquerda, o estado de deformação e, à direita, as deformações plásticas acumuladas $\epsilon_{p}$.

Este exemplo revela que a evolução estrutural e as principais características do processo compressional foram capturados pelo MPM. Em particular, a geração e propagação de zonas de concentração de deformações cisalhantes e a influência da camada fraca na região inferior do modelo foram adequadamente capturadas pelo MPM. 


\section{4}

\section{Talude natural em Oregon, Estados Unidos}

O caso seguinte em estudo é o talude natural em Oregon, Estados Unidos. Esta área rompeu e colapsou como fluxo de detritos após um período de intensas chuvas [118]. Os detalhes hidrogeológicos da área em questão estão documentados nos trabalhos de Anderson (1997) [109], Ebel (2007) [110] e Montgomery (2009) [111].

Nesta seção apresentam-se os resultados da análise do talude natural de Oregon com o MPM. Primeiramente, o cálculo do fator de segurança obtido com o MPM é comparado com o valor obtido com NLA e com os valores publicados na literatura. Em segundo lugar, o mecanismo de colapso obtido com MPM é comparado com o mecanismo sugerido por NLA e com a zona de ruptura observada. Por fim, apresenta-se a evolução pós-ruptura da massa que rompe, obtida com MPM, para 3, 6 e 9 segundos.

A Figura 6.34.a mostra as curvas de nível do terreno e a distribuição da altura de água no talude. A distribuição da altura da camada de solo sobre a rocha está definida na Figura 6.34.b. Com a elevação da superfície do terreno e com a altura do solo é criada uma malha de elementos finitos da massa de solo envolvida na ruptura, onde as partículas são distribuídas nos centroides dos elementos ${ }^{1}$. O modelo numérico MPM é formado por $1130304 \approx 1.1 \mathrm{e}+6$ partículas dispostas numa malha Euleriana de $\Delta x=\Delta y=\Delta z=3.0 \mathrm{e}-1 \mathrm{~m}$.

Na Figura 6.35 detalha-se a geometria inicial e a definição dos materiais. Os parâmetros do solo estão detalhados na Tabela 6.12. O material rochoso é fixado durante a simulação, isto é $\dot{u}_{i}(t)=0$ e $\ddot{u}_{i}(t)=0 \forall t$. A pressão de água nos poros é considerada não acoplada do comportamento mecânico, introduzindo seu efeito mediante as relações constitutivas.

Tabela 6.12: Parâmetros do talude natural em Oregon.

\begin{tabular}{llll}
\hline Malha Euleriana & $\Delta x, \Delta y, \Delta z$ & $3.0 \mathrm{e}-1$ & $\mathrm{~m}$ \\
Partículas & $n_{p}$ & 1130304 & - \\
Passo de tempo & $\Delta t$ & $4.66 \mathrm{e}-4$ & $\mathrm{~s}$ \\
Módulo de Young do solo & $E$ & 70.0 & $\mathrm{MPa}$ \\
Densidade do solo & $\rho$ & 1373 & $\mathrm{~kg} / \mathrm{m}^{3}$ \\
Coeficiente de Poisson do solo & $\nu$ & 0.3 & - \\
Ângulo de atrito do solo & $\phi$ & 40.0 & $\circ$ \\
Coesão do solo & $c$ & 0.9 & $\mathrm{kPa}$ \\
\hline
\end{tabular}

\footnotetext{
${ }^{1}$ Ver procedimento de discretização no Capítulo 5
} 
a)

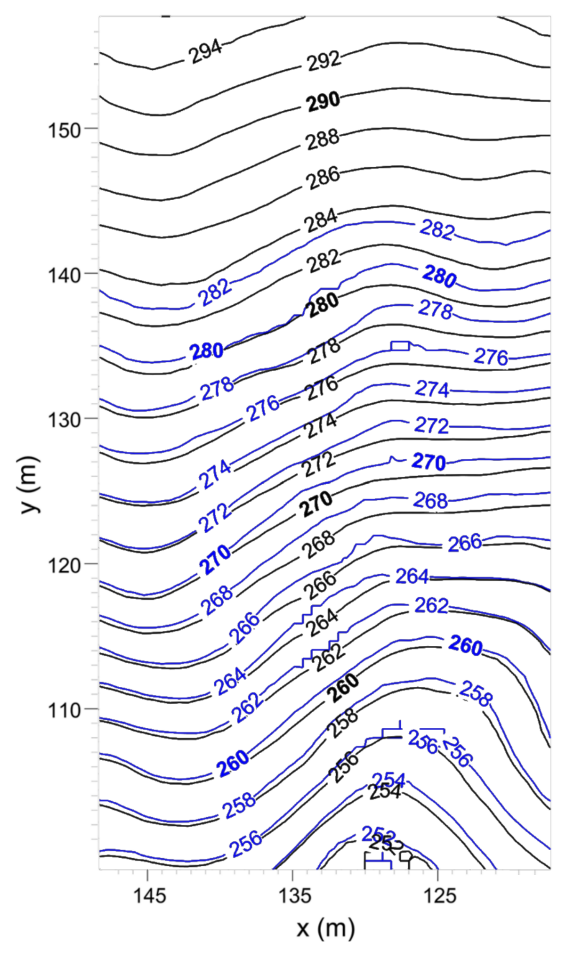

b)

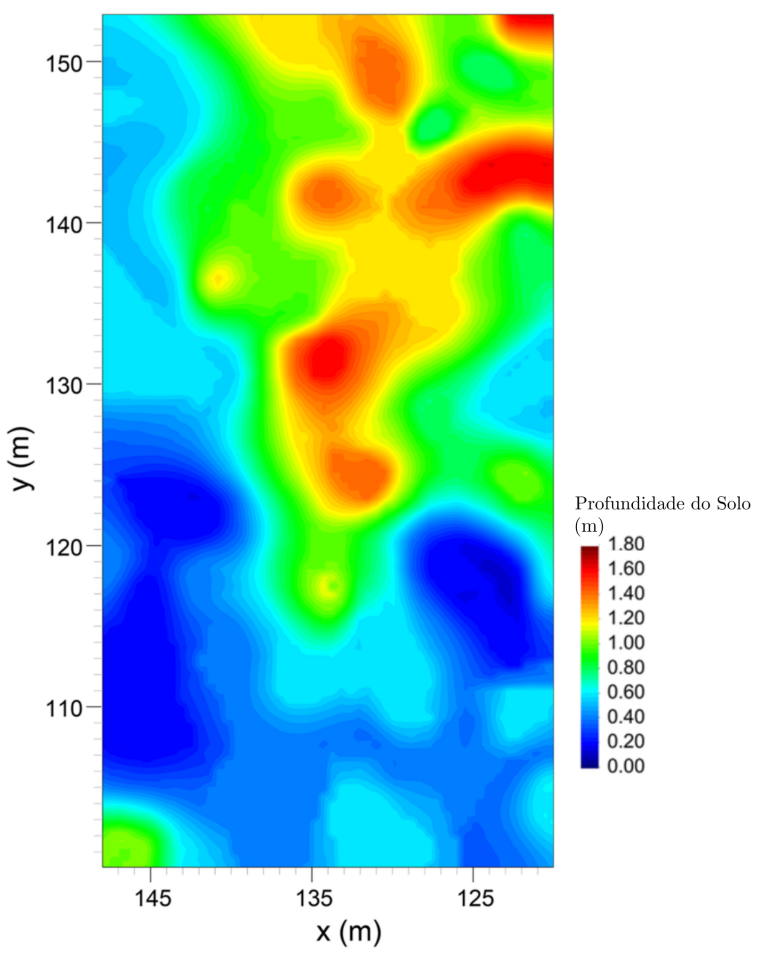

Figura 6.34: a) Curvas de nível do terreno e do nível de água. b) Altura da camada de solo sobre a rocha (Adaptado de Camargo et al.(2016) [112]).
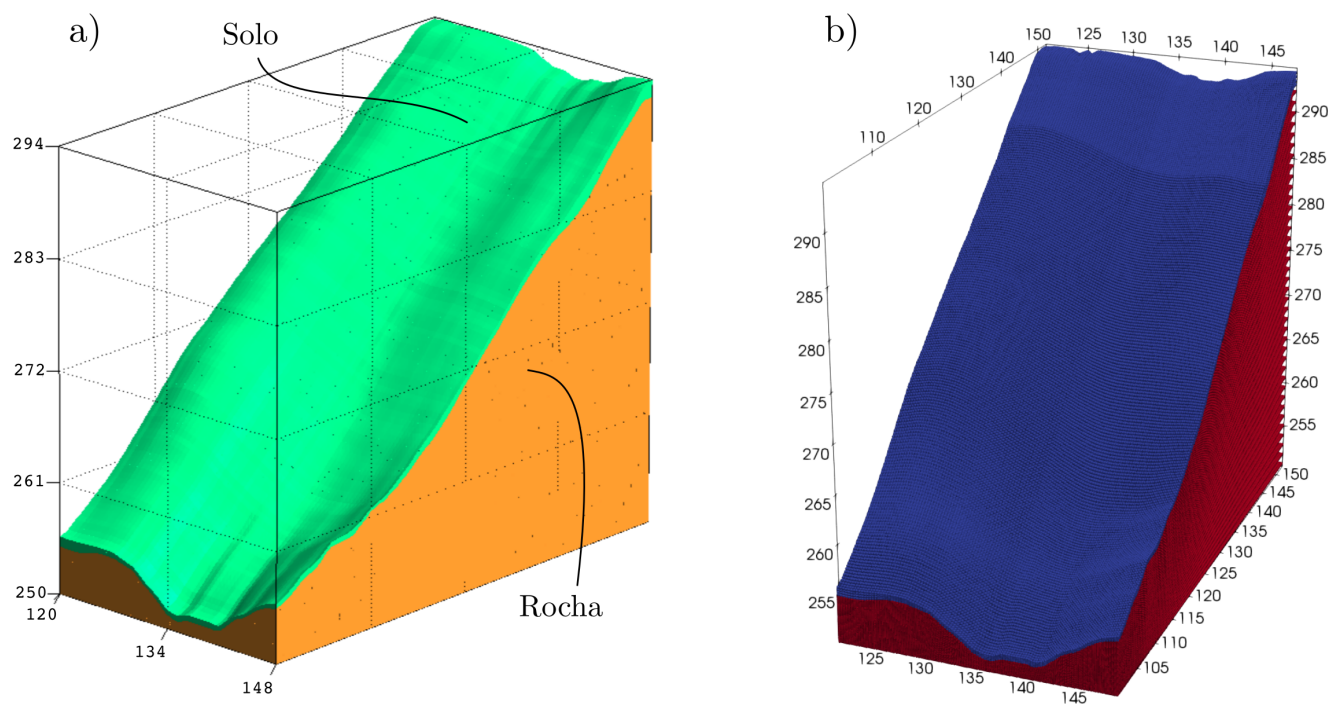

Figura 6.35: a) Geometria inicial e definição de materiais. b) Modelo MPM formado por $1130304 \approx 1.1 \mathrm{e}+6$ partículas.

A comparação dos fatores de segurança do talude natural apresenta-se na Tabela 6.13. Todos os valores comparados estão próximos de 1.0, indicando que nas condições analisadas, o talude se encontra no colapso iminente. 
Tabela 6.13: Comparação dos fatores de segurança do talude natural em Oregon.

\begin{tabular}{ll}
\hline Método & Fator de segurança \\
\hline NLA[112] & 1.02 \\
MD-STAB[113] & 1.00 \\
MPM & 0.97 \\
\hline
\end{tabular}

A zona de ruptura calculada pelo MPM resulta sensivelmente próxima à obtida com NLA. As zonas de rupturas obtidas por ambos métodos numéricos são consistentes com a zona de ruptura observada (ver Figura 6.36).

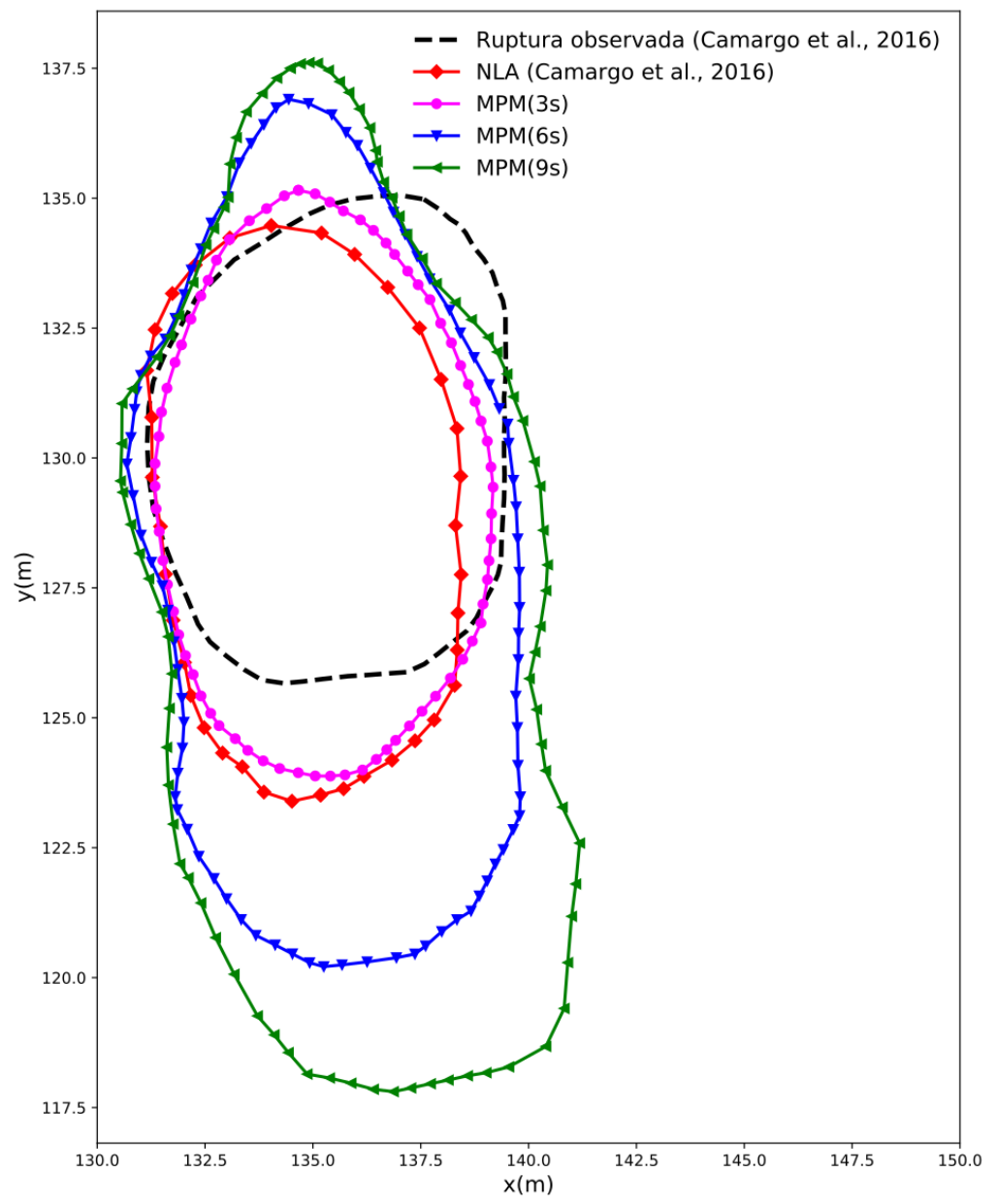

Figura 6.36: Comparação da zona de ruptura calculada com NLA [112] e MPM, com a zona de ruptura observada. Evolução da zona de ruptura para 3, 6 e 9 segundos obtida com MPM.

A possibilidade do MPM de simular processos de grandes deformações permite obter a evolução da zona de ruptura para 3, 6 e 9 segundos, como é mostrada na Figura 6.37. 
A evolução da zona de ruptura sugere que a massa escorrega predominantemente na direção y em sentido da menor cota de elevação.
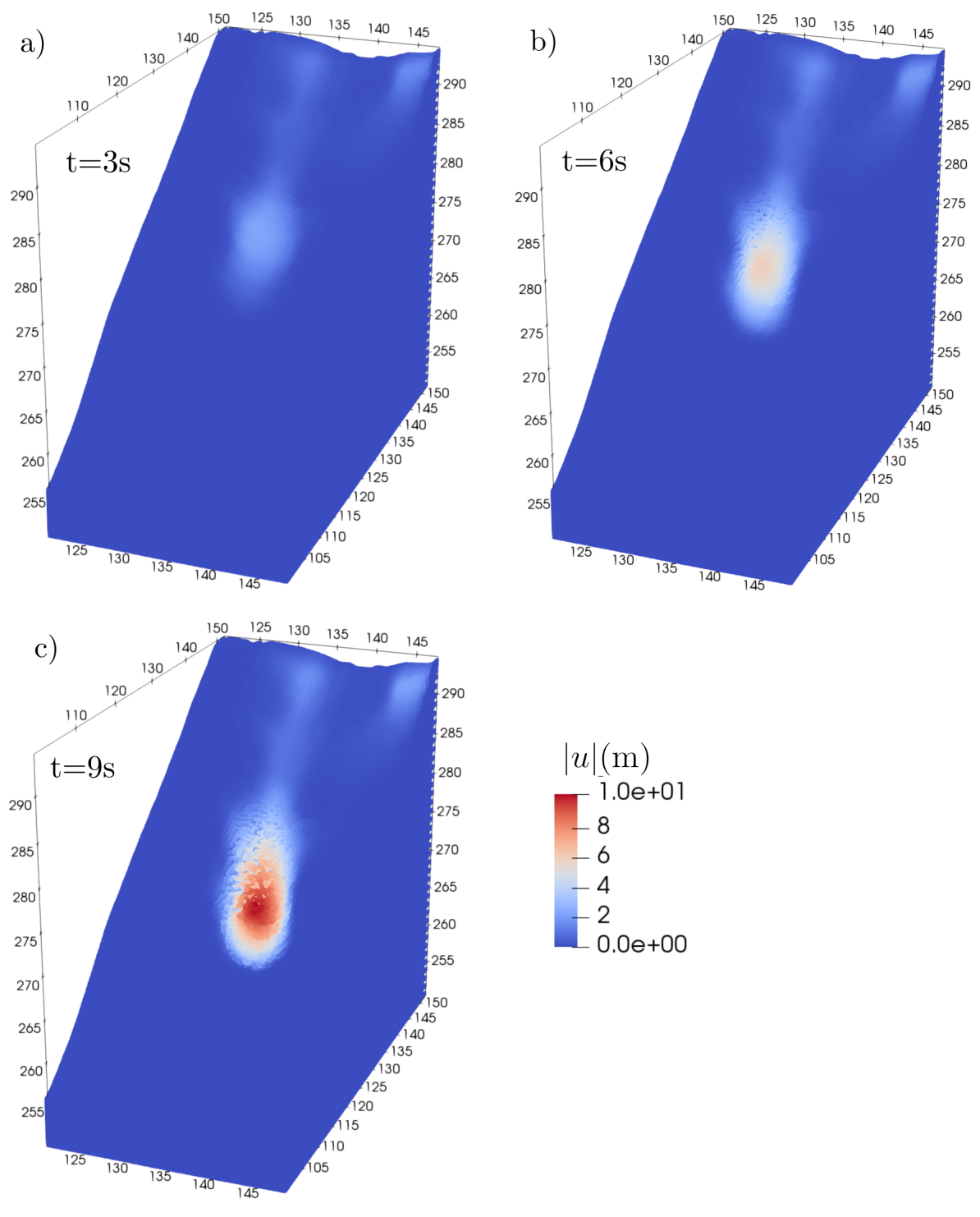

Figura 6.37: Evolução da zona de ruptura em termos da magnitude dos deslocamentos $|u|(m)$, para 3, 6 e 9 segundos. 


\section{5}

\section{Impacto de bloco de rocha sobre meio saturado}

No Rio de Janeiro, em 1988, um fluxo de detritos provocou a morte de 53 pessoas. Os detalhes do evento, documentado por Barros [114, 115] e Lacerda [116, 117], revelam que após 18 dias de intensa chuva, um bloco de rocha impactou sobre uma camada saturada de colúvio, iniciando um processo de falha e escorregamento da massa saturada. Este problema foi previamente analisado por Müller e Vargas (2019) [119]. Neste estudo, os autores usaram o MPM em 2D para resolver o problema acoplado de grandes deformações. Na modelagem constitutiva usaram um modelo com mudanças reológicas para descrever um comportamento sólido, antes da ruptura, e um comportamento viscoso durante processo de escorregamento.

Nesta seção apresenta-se a análise em 3D do problema do bloco de rocha impactando sobre um meio poroso saturado. Os principais objetivos da análise são: (1) capturar a zona de influência do impacto do bloco no meio saturado e descrever o mecanismo de falha provável de forma realista em 3D; (2) verificar a habilidade do MPM na modelagem de massas de solo que apresentam mudanças de reologia na sua modelagem constitutiva.

O comportamento do solo saturado como fluxo de detritos é considerado mediante a modelagem constitutiva usando um modelo de transição, entre um comportamento do tipo elasto-plástico e um do tipo fluido viscoso. O critério de Mohr-Coulomb descreve o início da ruptura e o modelo viscoso de Bingham descreve a resposta pós-ruptura. A transição entre os dois tipos de comportamento é dado pelo critério do trabalho de segunda ordem (ver modelo de transição na Seção 3.5.4).

A Figura 6.38 mostra a geometria do modelo, cuja extensão vertical e horizontal é de $50 \mathrm{~m}$ e de $100 \mathrm{~m} \times 30 \mathrm{~m}$, respectivamente. Um talude de $45^{\circ}$ é formado por uma camada de $H_{s}=2.5 \mathrm{~m}$ de solo saturado sobre uma camada de rocha de $H_{r}=1.7 \mathrm{~m}$. O impacto é produzido por um bloco de rocha de $5 \mathrm{~m} \times 5 \mathrm{~m} \times 2 \mathrm{~m}$ que cai desde uma posição inicial $u_{z}^{0}=44 \mathrm{~m} \mathrm{e}$ com velocidade inicial de $v_{z}^{0}=-10 \mathrm{~m} / \mathrm{s}$. A pressão inicial do fluido no material poroso é $p_{w}^{0}=0.0 \mathrm{MPa}$. A gravidade é considerada na análise e todos os planos do modelo possuem condições de contornos fixas em termos de deslocamentos. O modelo MPM consiste em $925968 \approx 1.0 \mathrm{e}+6$ partículas que se movimentam numa malha Euleriana regular de $\Delta x=\Delta y=\Delta z=0.5 \mathrm{~m}$. As partículas que representam a rocha são fixadas durante toda a simulação. Na Tabela 6.14 se apresentam os parâmetros da simulação. 

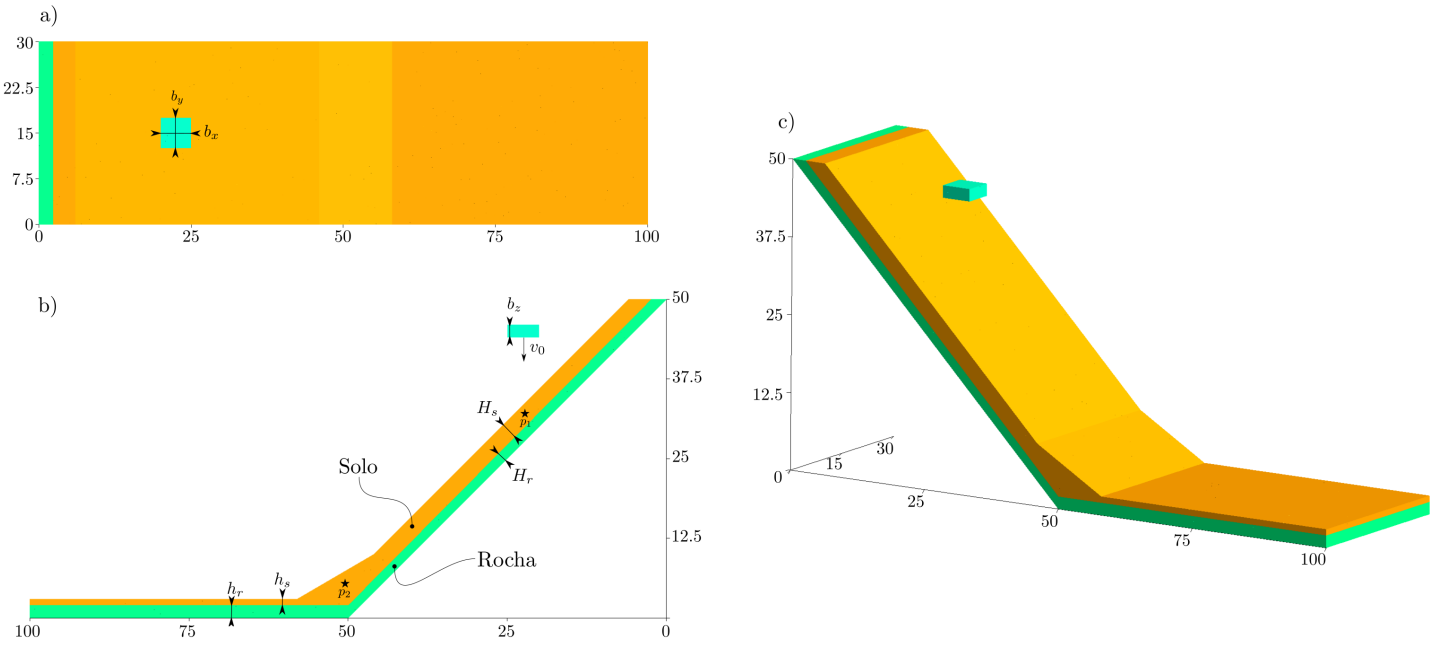

Figura 6.38: Geometria do problema do bloco de rocha impactando sobre meio poroso saturado. a) Plano X-Y, $b_{y}=b_{x}=5 \mathrm{~m}$; b) Plano Z-Y, $b_{z}=2 \mathrm{~m}, h_{r}=2$ $\mathrm{m}, h_{s}=1 \mathrm{~m}, H_{r}=1.7 \mathrm{~m}, H_{s}=2.5 \mathrm{~m}$; c) Perspectiva tridimensional.

Tabela 6.14: Parâmetros do impacto de bloco sobre meio saturado.

\begin{tabular}{llll}
\hline Malha Euleriana & $\Delta x, \Delta y, \Delta z$ & $5.0 \mathrm{e}-1$ & $\mathrm{~m}$ \\
Partículas & $n_{p}$ & $925968 \approx 1.0 \mathrm{e}+6$ & - \\
Passo de tempo & $\Delta t$ & $2.0 \mathrm{e}-5$ & $\mathrm{~s}$ \\
Velocidade inicial & $v_{z}^{0}$ & -10.0 & $\mathrm{~m} / \mathrm{s}$ \\
Parâmetros do Solo & & & \\
$\quad$ Módulo de Young & $E$ & 20.0 & $\mathrm{MPa}$ \\
$\quad$ Coeficiente de Poisson & $\nu$ & 0.40 & - \\
$\quad$ Coesão & $c$ & 0.02 & $\mathrm{MPa}$ \\
Massa específica & $\rho$ & 2000 & $\mathrm{~kg} / \mathrm{m}^{3}$ \\
Ângulo de atrito & $\phi$ & 36.0 & $\circ$ \\
Viscosidade & $\eta$ & $1.0 \mathrm{e}-3$ & $\mathrm{MPa} \cdot \mathrm{s}$ \\
$\quad$ Permeabilidade & $k$ & $1.0 \mathrm{e}-3$ & $\mathrm{~m} / \mathrm{s}$ \\
$\quad$ Módulo volumétrico da água & $K_{w}$ & 505.5 & - \\
$\quad$ Porosidade inicial & $n^{0}$ & 0.4 & $\mathrm{MPa}$ \\
Pressão inicial & $p_{w}^{0}$ & 0.0 & \\
Parâmetros da Rocha & & & $\mathrm{MPa}$ \\
$\quad$ Módulo de Young & $E$ & $1.0 \mathrm{e}+3$ & - \\
$\quad$ Coeficiente de Poisson & $\nu$ & 0.25 & $\mathrm{~kg} / \mathrm{m}^{3}$ \\
$\quad$ Massa específica & $\rho$ & 2500 & \\
\hline
\end{tabular}




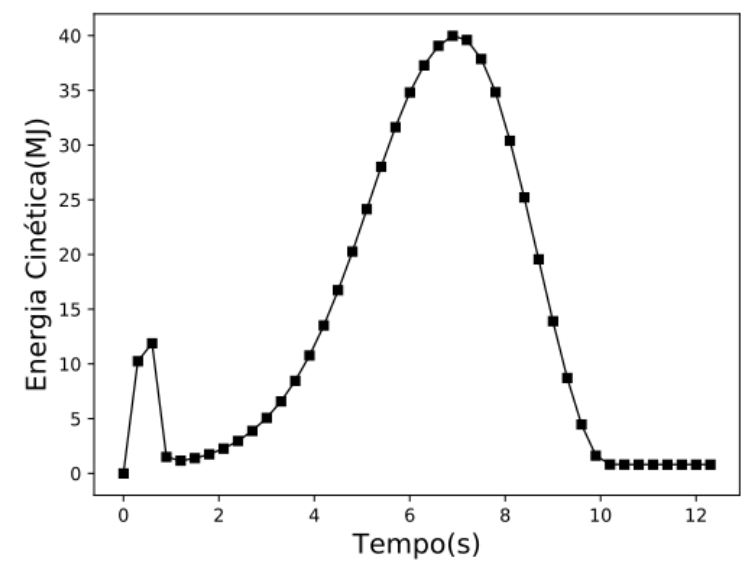

Figura 6.39: Evolução da energia cinética do sistema.

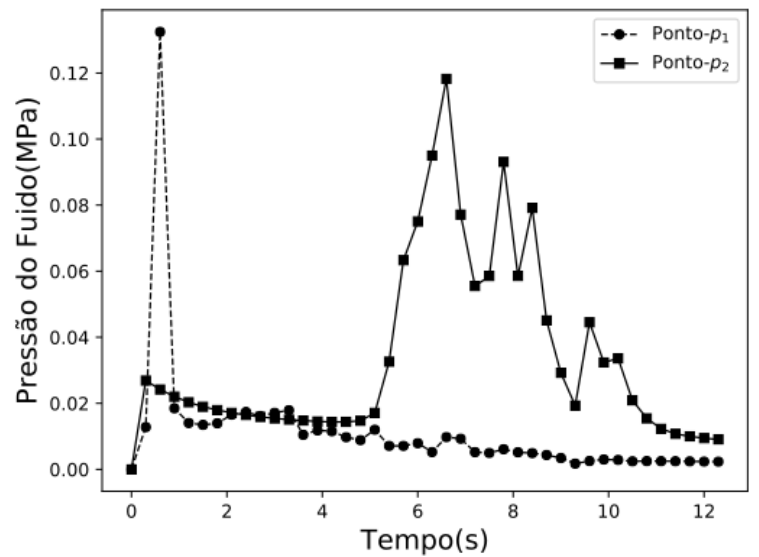

Figura 6.40: Evolução da pressão do fluido nos pontos de controle $p_{1}$ e $p_{2}$.

No tempo $t=0.6 \mathrm{~s}$ o bloco impacta sobre o solo saturado. A energia cinética do sistema se reduz e as deformações induzidas causam um acréscimo da pressão do fluido ao redor da zona de impacto, como é mostrado no ponto $p_{1}$ na Figura 6.40. O mecanismo generalizado de falha é ativado após a ruptura da camada de solo. A energia cinética do sistema aumenta progressivamente até atingir o valor máximo, no tempo $t=7 \mathrm{~s}$, quando o bloco se posiciona no pé do talude, em consequência disso, a pressão do fluido aumenta no ponto $p_{2}$. O bloco se detém após ter se deslocado $\Delta x \approx 42 \mathrm{~m}$.

O processo de escorregamento é inicializado após o impacto do bloco de rocha, o qual produz um incremento progressivo da energia cinética do sistema. A massa envolvida no escorregamento se incrementa progressivamente na direção do bloco e a extensão lateral atinge os $30 \mathrm{~m}$ em $t=7.5 \mathrm{~s}$. A massa se detém na coordenada $x=80 \mathrm{~m}$. 
a)
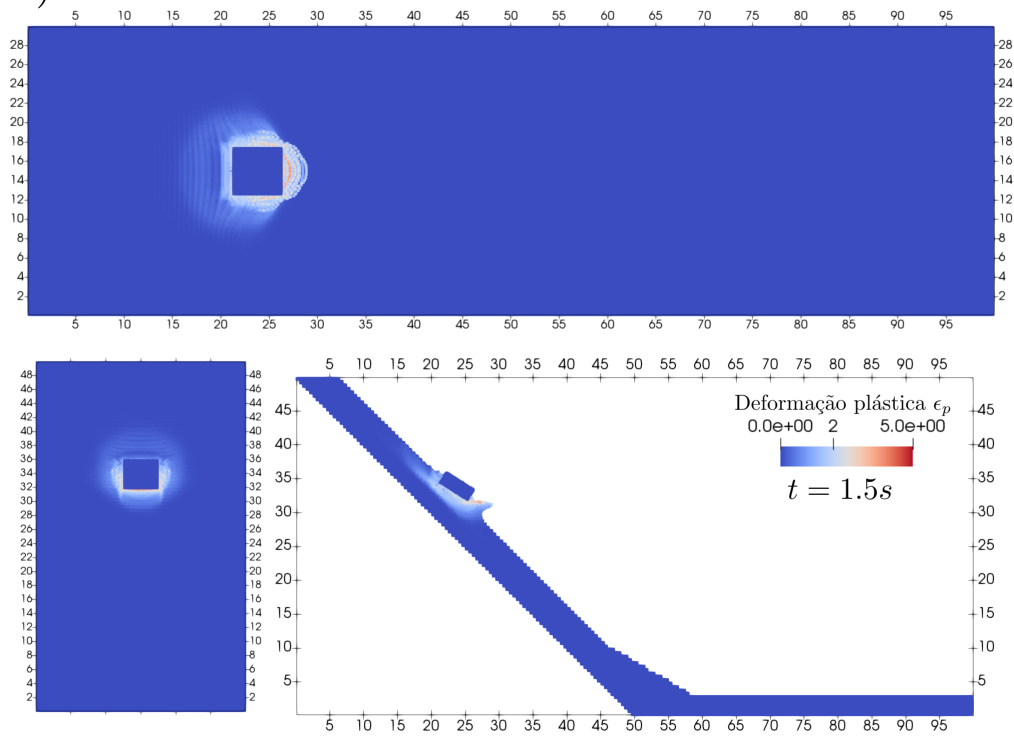

b)
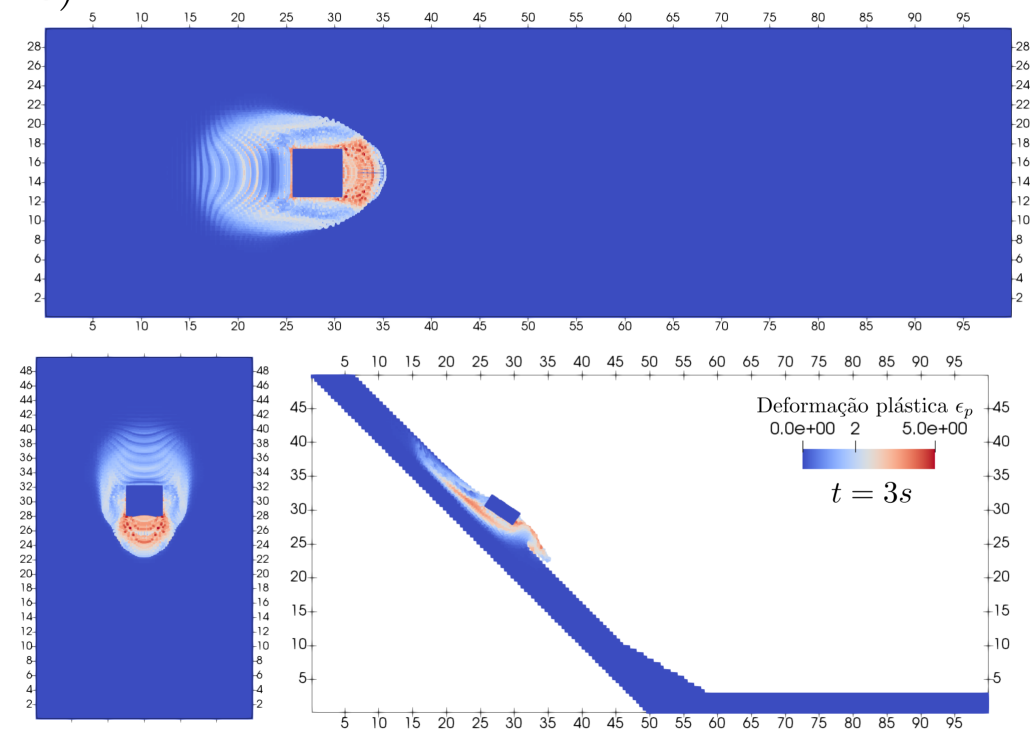

Figura 6.41: Processo de falha durante o impacto do bloco de rocha sobre o solo saturado. Evolução das zonas de falhas em termos da deformação efetiva plástica $\left.\epsilon^{p}=\sqrt{\left(2 / 3 \epsilon_{i j}^{p}\right.} \epsilon_{i j}^{p}\right)$. 
d)
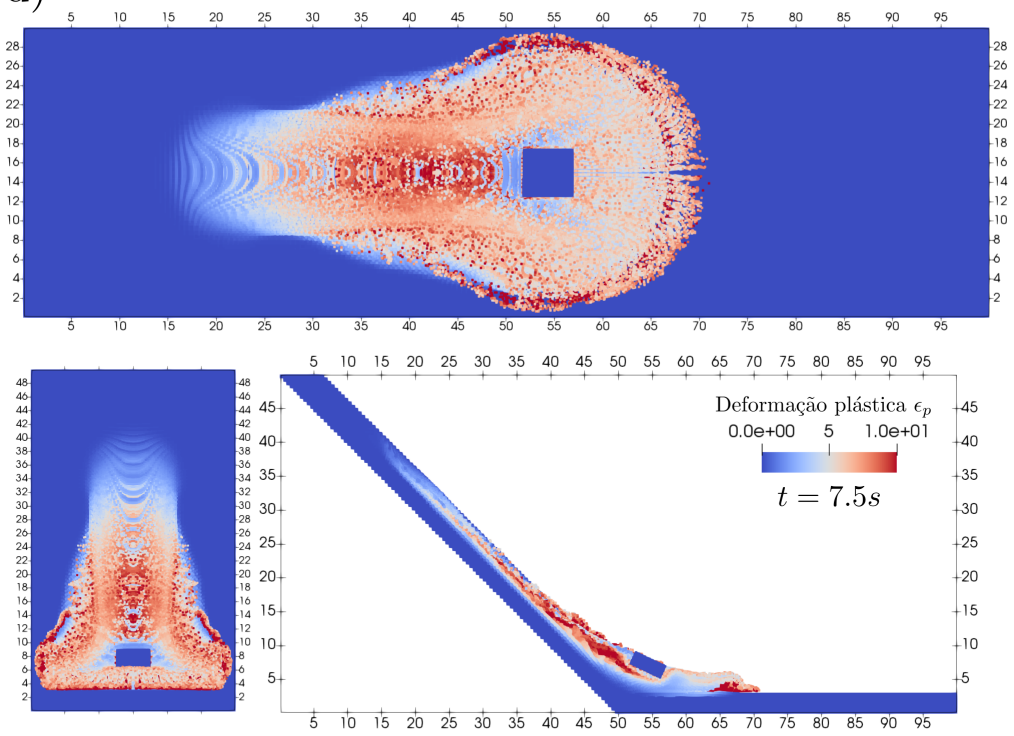

c)

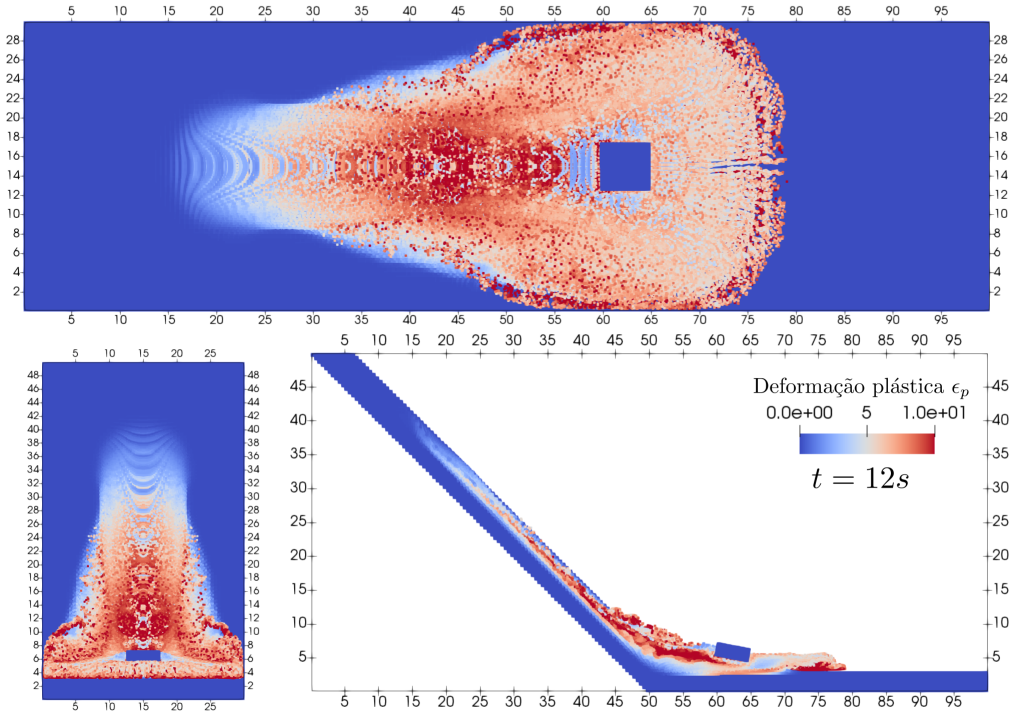

Figura 6.42: Processo de falha durante o impacto do bloco de rocha sobre o solo saturado. Evolução das zonas de falhas em termos da deformação efetiva plástica $\left.\epsilon^{p}=\sqrt{\left(2 / 3 \epsilon_{i j}^{p}\right.} \epsilon_{i j}^{p}\right)$. 


\section{6 \\ Deslizamento de Daguangbao, China}

Na seção seguinte apresenta-se a análise do deslizamento de Daguangbao usando MPM. Em primeiro lugar, são definidas as características relevantes do evento, a geometria e a topografia do local, as características geomorfológicas predominantes, a distribuição espacial dos materiais e o terremoto. Em segundo lugar, apresenta-se o processo de discretização do domínio em modelos numéricos MPM. Em terceiro lugar, apresentam-se as análises em 2D e 3D do evento. E finalmente, algumas considerações sobre os resultados obtidos.

O deslizamento de Daguangbao foi previamente analisado usando MPM [121]. Nesse trabalho, os autores usaram um modelo MPM em 2D, os materiais envolvidos na ruptura foram considerados elasto-plásticos perfeitos (sem amolecimento) e sem resistência a tração. Na presente tese, a análise do evento é feita em 2D e 3D. Os materiais são modelados com amolecimento, visando capturar o escorregamento da massa, e a resistência a tração é incorporada para capturar a formação de estruturas verticais, tais como as observadas no local do evento. Os parâmetros resistentes de pico são considerados iguais aos do trabalho acima mencionado. Os parâmetros de amolecimento são obtidos mediante retro-análise.

\subsection{1}

\section{Características do deslizamento de Daguangbao}

O terremoto de Wenchuan, ocorrido na China em 2008, produz centenas de deslizamentos [120]. O maior deles foi o deslizamento de Daguangbao, cuja área coberta foi estimada em $7.8 \mathrm{~km}^{2}$ com uma extensão máxima de $2.2 \mathrm{~km}$ e um volume estimado de $7.5 \mathrm{e}+8 \mathrm{~m}^{3}$ (ver Figura 6.43). A massa envolvida na ruptura deslocou-se aproximadamente $4.0 \mathrm{~km}$, bloqueando o vale Huangdongzi e formando uma barragem de $600 \mathrm{~m}$ de altura [120] (ver Figura 6.44). Devido a estas características, o deslizamento de Daguangbao é considerado um evento de elevada energia cinética cujo mecanismo de ruptura apresenta grandes deformações e fraturas [121].

O sistema litológico é formado principalmente pelo grupo Guanyinyan $\left(Z_{g}\right)$ e pelo grupo Dengyin $\left(Z_{d}\right)$, os quais estão formados principalmente por argilito, calcário e dolomita. Sobre o sistema rochoso encontra-se o grupo Shawozi do sistema Devonian $(D)$, caracterizado por rochas dolomíticas. Nas cotas superiores, encontram-se os grupos $P$ do sistema Permian, caracterizado por rochas calcárias e bioclásticas (ver mapa geológico na Figura 6.43). 
A topografia da região envolvida no evento apresenta uma extensão em planta de $5400 \mathrm{~m} \times 4500 \mathrm{~m}$. Em altura, uma cota máxima de $3047 \mathrm{~m}$ no cerro Daguangbao e uma cota mínima de 1080 m no vale Huangdongzi (ver Figura 6.45 e 6.44$)$.

A variação espacial de cada grupo litológico é caracterizada a partir de uma serie de seç̧ões: 1-1, 2-2, I-I, II-II, III-III e IV-IV, cujas posições em planta são definidas na Figura 6.46. Estas secções são utilizadas para determinar as características heterogêneas do domínio computacional em 3D.
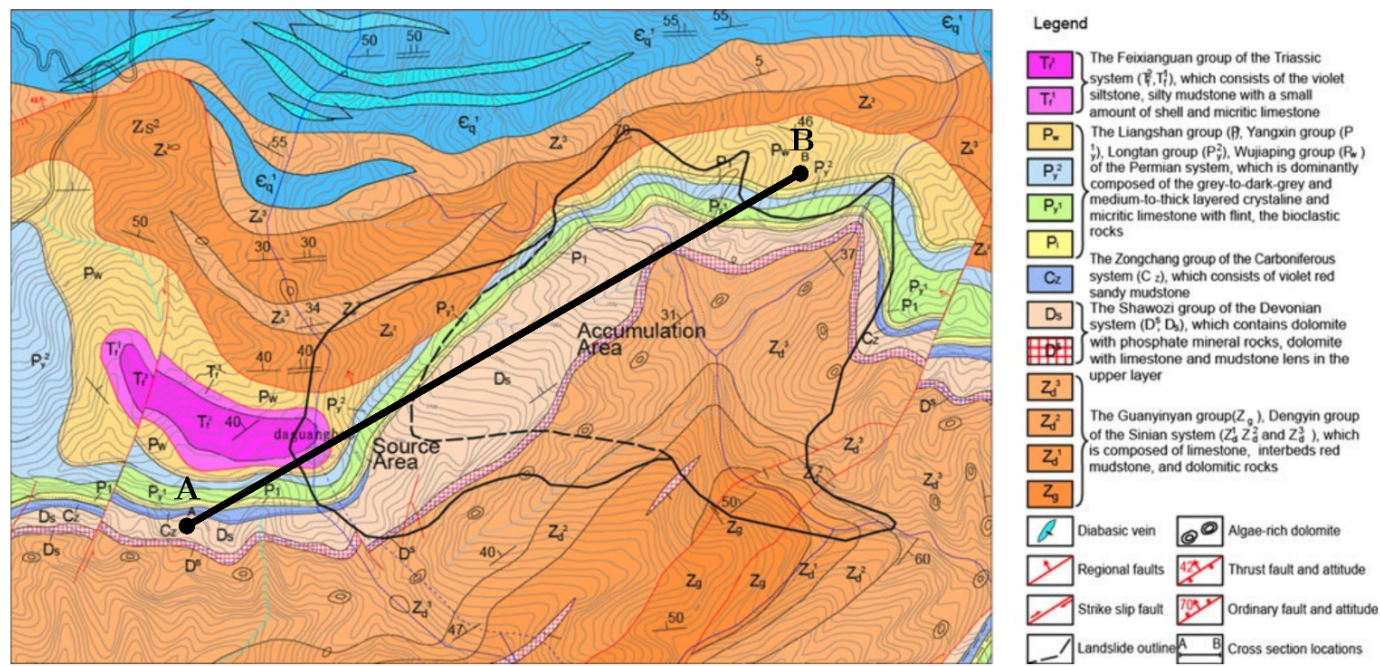

Figura 6.43: Mapa geológico do deslizamento de Daguangbao [120].

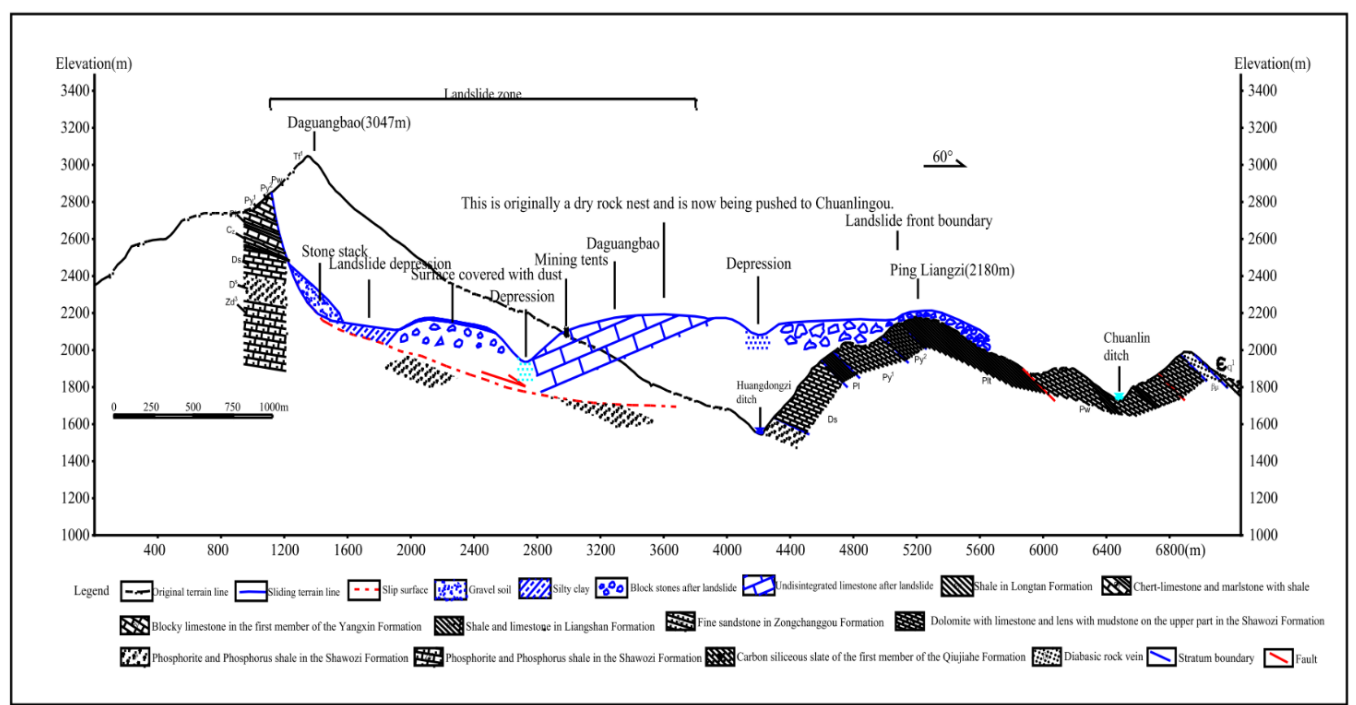

Figura 6.44: Seção geológica pós-terremoto [122] definida como $\overline{A B}$ na Figura 6.43 . 
a)

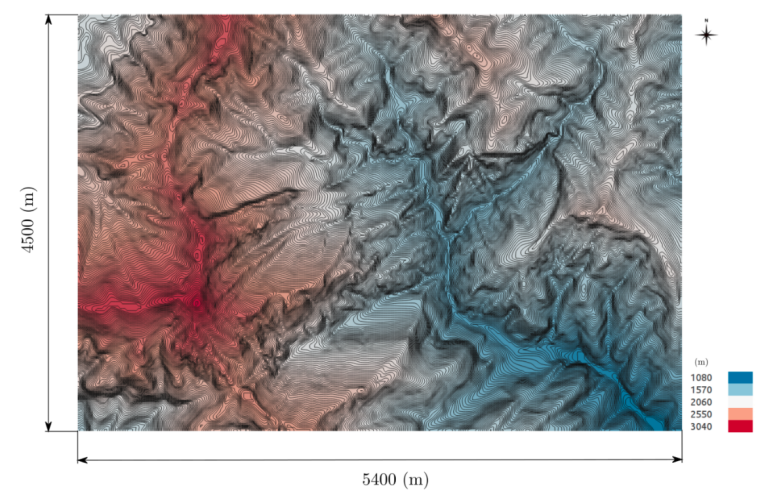

b)

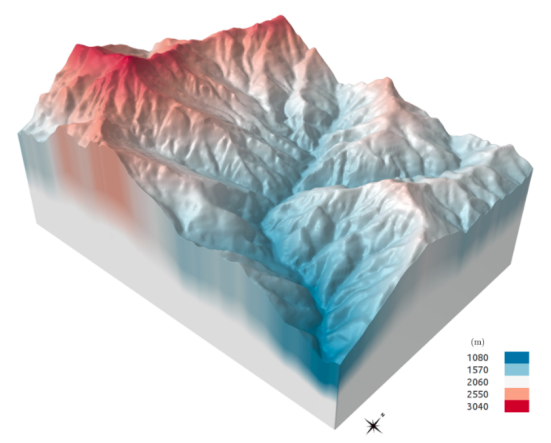

Figura 6.45: Topografia da região do deslizamento de Daguangbao antes do terremoto. a) Curvas de níveis e dimensões do domínio. b) Perspectiva tridimensional da topografia.

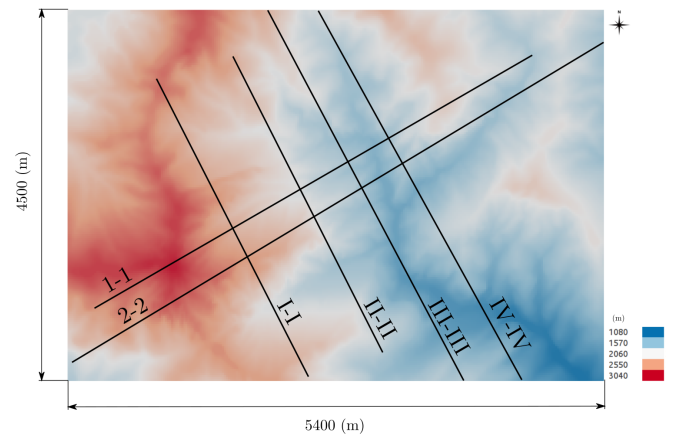

b)

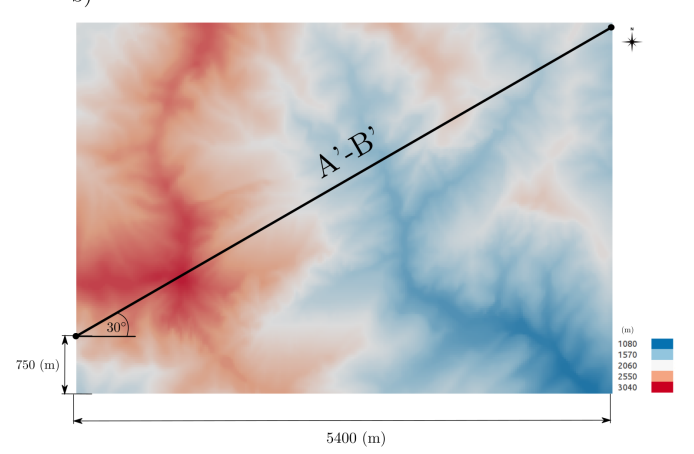

Figura 6.46: Posições das seções utilizadas para definir heterogeneidades.

\subsection{2}

\section{Discretização do domínio em modelo MPM}

A partir da distribuição de materiais nas secções 1-1, 2-2, I-I, II-II, III-III e IV-IV, são interpoladas três superfícies planas no espaço na forma de dados digitais de elevação ${ }^{2}$, um para cada grupo litológico $Z, D$ e $P$. Na Figura 6.47 mostram-se as três superfícies resultantes da interpolação usadas para definir as heterogeneidades do modelo 3D.

A discretização do domínio 3D heterogêneo em pontos materiais é feita seguindo o procedimento descrito no Capítulo 5 . Uma grade de $50 \mathrm{~m} \times 50 \mathrm{~m}$ é definida na planta do domínio. Para cada célula do grid se determina a altura

\footnotetext{
${ }^{2}$ Ver procedimento de discretização de modelos MPM de escala geológica no Capítulo 5
} 
a)

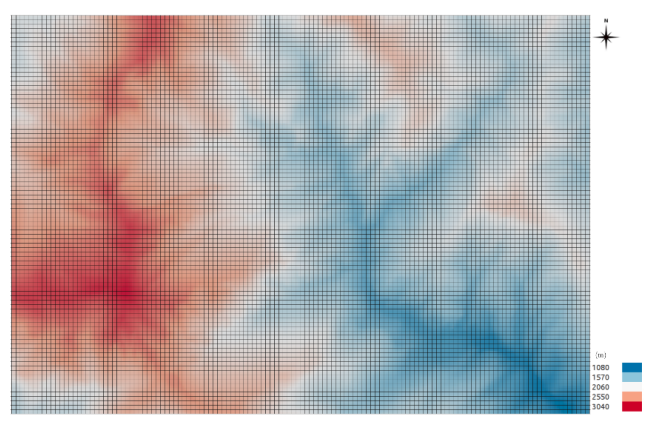

c)

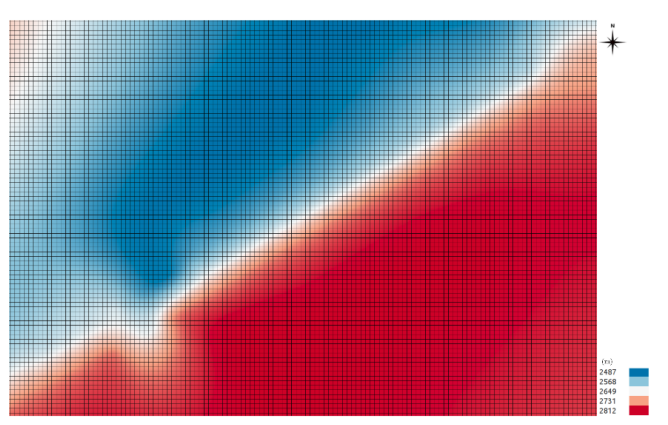

b)

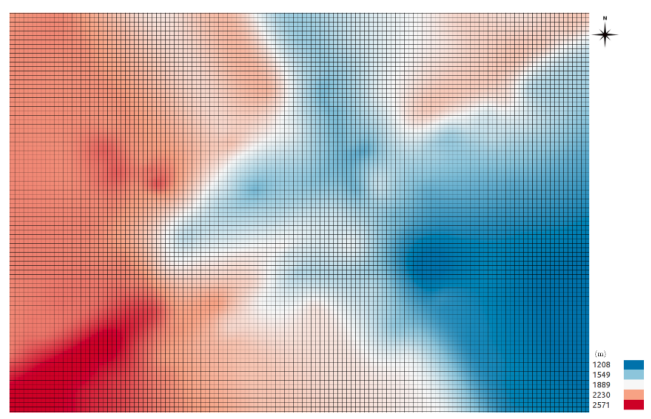

Figura 6.47: Dados digitais de elevação de cada material. a) Material $1=$ grupo $Z$. b) Material $2=\operatorname{grupo} D$. c) Material $3=\operatorname{grupo} P$.

máxima da topografia e as heterogeneidades, usando os dados de elevação de cada material.

a)

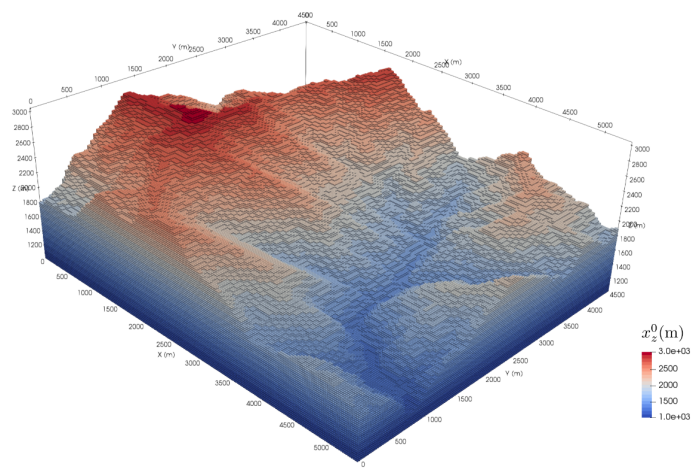

b)

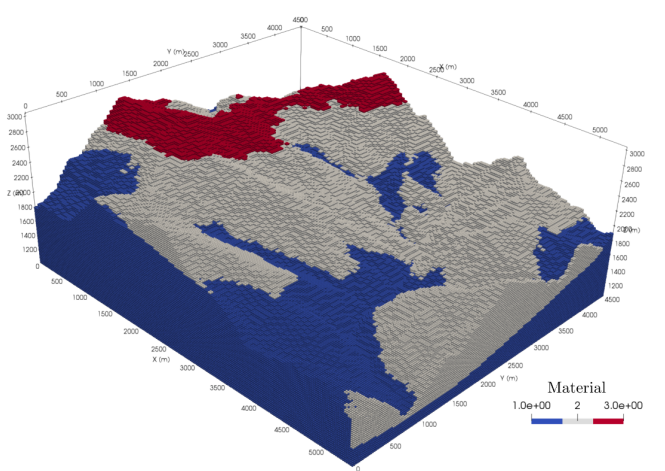

Figura 6.48: Modelo discreto MPM formado por 1.8e+6 partículas. a) Elevação $x_{z}^{0}(\mathrm{~m})$. b) Distribuição espacial de materiais.

Na Figura 6.49 mostra-se a seção característica do deslizamento de Daguangbao obtida com o MPM. Três pontos de controle são definidos para quantificar os deslocamentos durante o processo de escorregamento. 

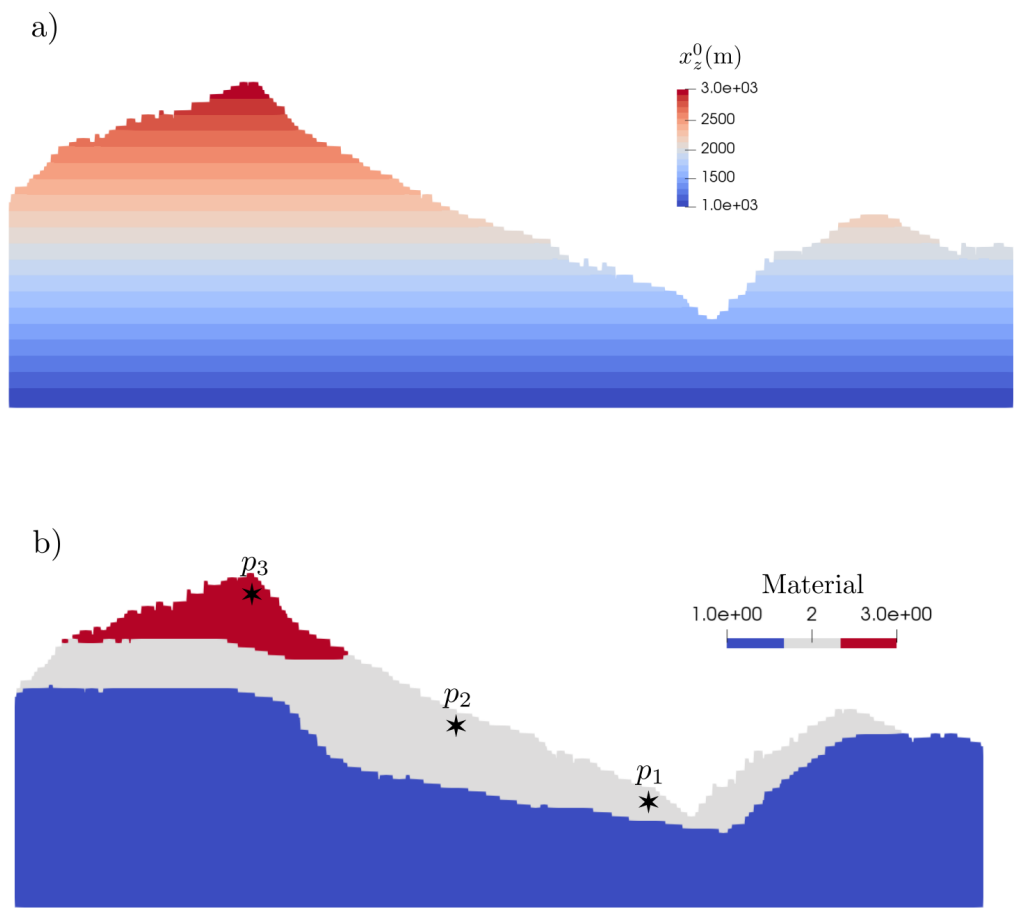

Figura 6.49: Seção característica do deslizamento de Daguangbao. Seção $\overline{A^{\prime} B^{\prime}}$ definida na Figura 6.47. a) Elevação $x_{z}^{0}(\mathrm{~m})$. b) Distribuição espacial dos materiais e posição dos pontos de controle $p_{1}, p_{2}$ e $p_{3}$.

Nas tabelas 6.17 e 6.18 são apresentados os parâmetros da modelagem do deslizamento de Daguangbao. A discretização adotada é de 1 partícula por célula numa célula de $25 \mathrm{~m}$ de lado, dando um volume representativo de 25 $\times 25 \times 25 \mathrm{~m}^{3}$ por partícula. Os parâmetros resistentes de referência para a modelagem dos materiais foram os publicados no trabalho de de He e outros [121]. Nesse trabalho, os materiais são assumidos sem amolecimento e sem resistência a tração. Os estudos de caracterização geomecânica da área do evento [120] revelam a presença de fraturas de tração e elevada deformação da massa pós-ruptura. Para atender as evidências observadas, principalmente na formação de um talude quase-vertical, são considerados o amolecimento e a resistência a tração nas análises 2D e 3D.

A zona de ruptura reportada no mapa geológico e os dados de elevação do terreno foram exportados para o programa Google Earth Pro, onde foi possível identificar a zona de ruptura do evento. A zona identificada permite assumir a hipótese de que a rocha fora da zona de ruptura permanece intacta durante o evento. Os materiais do modelo MPM em 3D foram modificados para levar em conta esta hipótese (ver Figura 6.50). 
a)

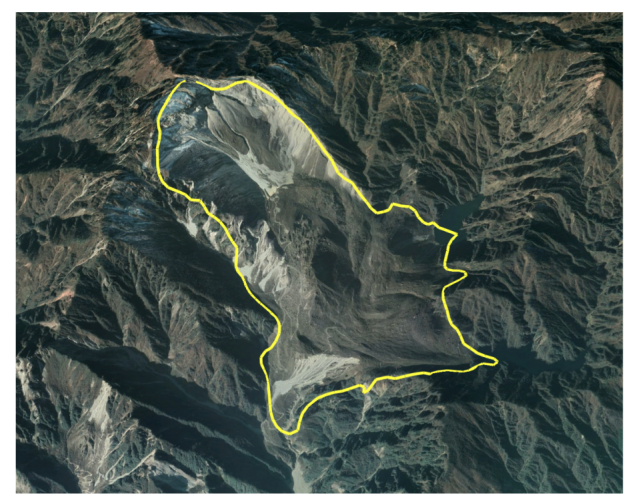

b)

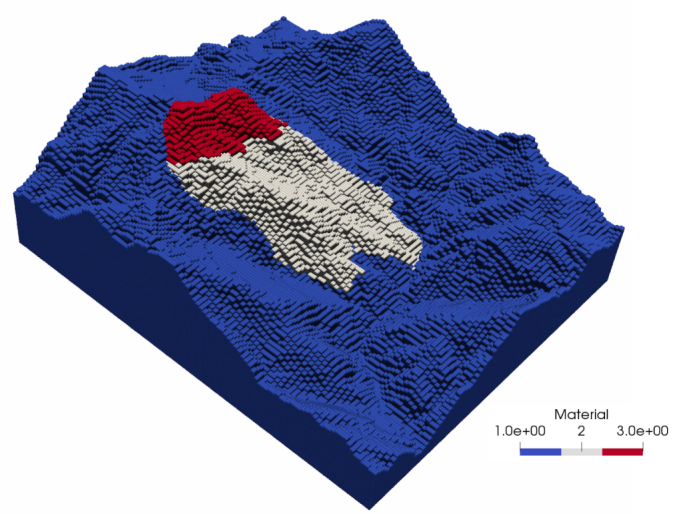

Figura 6.50: Identificação de zona de ruptura. a) Zona de ruptura observada. b) Zona de ruptura no modelo MPM.

\subsection{3}

\section{Características do terremoto de Wenchuan, China}

Em maio de 2008 , o terremoto de Wenchuan $\left(31.002^{\circ} \mathrm{N} ., 103.322^{\circ} \mathrm{E}\right.$.) de magnitude $M_{w}=7.9$ aconteceu como resultado de uma falha inversa oblíqua superficial ao noroeste (N.W.) da margem da bacia de Sichuan, a uma profundidade de $19.0 \mathrm{~km}$ [123]. O terremoto foi o mais importante desde 1955 $\left(29.981^{\circ} \mathrm{N}\right.$., $\left.101.613^{\circ} \mathrm{E} .-M_{w}=7.5\right)$ causando significantes perdas econômicas e humanas: ao menos 69185 pessoas morreram, 45.5 milhões de pessoas foram afetadas em 10 estados, e as perdas econômicas foram estimadas em 86 bilhões de dólares.

A partir do processamento dos registros do terremoto da estação Qingping é possível determinar as principais características do movimento, resumidas na Tabela 6.15.

O registro do terremoto contém acelerações em três direções: NS, EW e vertical. Estas acelerações devem ser filtradas com o objetivo de eliminar velocidades e deslocamentos residuais, produto do processo de integração [70]. A correção dos deslocamentos e velocidades residuais é chamada de correção da linha de base. A correção da linha de base é realizada usando o programa computacional SeismoSignal com os parâmetros dados na Tabela 6.16.

O terremoto corrigido é mostrado na Figura 6.51. O terremoto usado nas análises incorpora um tempo adicional de $15.0 \mathrm{~s}$ no início e no final do registro. Observe-se que durante o processo de filtragem a magnitude das acelerações não muda, pois o objetivo principal é modificar os deslocamentos para que sejam nulos após o terremoto [70]. 
Tabela 6.15: Características do terremoto de Wenchuan.

\begin{tabular}{lrrr}
\hline Característica & \multicolumn{1}{c}{ NS } & \multicolumn{1}{c}{ EW } & Vertical \\
\hline Aceleração máxima (g) & 0.803 & 0.824 & 0.623 \\
Tempo da aceleração máxima (s) & 48.515 & 46.860 & 47.240 \\
Velocidade máxima (cm/s) & 73.010 & 127.345 & 37.154 \\
Tempo da velocidade máxima (s) & 38.055 & 38.105 & 46.585 \\
Deslocamento máximo (cm) & 836.281 & 389.138 & 107.229 \\
Tempo do deslocamento máximo (s) & 159.990 & 150.735 & 138.470 \\
Período predominante (s) & 0.040 & 0.040 & 0.080 \\
Período médio (s) & 0.277 & 0.323 & 0.241 \\
\hline
\end{tabular}

Tabela 6.16: Parâmetros de correção do terremoto.

\begin{tabular}{lll}
\hline Tipo de polinômio & Linear & - \\
Tipo de Filtro & Butterworth & - \\
Configuração do Filtro & Bandpass & - \\
Ordem do Filtro & 4.0 & - \\
Frequência 1 & 0.1 & $\mathrm{~Hz}$ \\
Frequência 2 & 25.0 & $\mathrm{~Hz}$ \\
\hline
\end{tabular}

Para as análises em 2D o terremoto deve ser projetado conforme à direção da seção a analisar. Conforme orientação do modelo em relação ao terremoto (ver Figura 6.45), a correção é dada por

$$
\ddot{u}_{x}^{\prime}=\ddot{u}_{\mathrm{EW}} \cos \alpha_{\mathrm{EW}}+\ddot{u}_{\mathrm{NS}} \cos \alpha_{\mathrm{NS}}
$$

onde $\ddot{u}_{x}^{\prime}$ é a aceleração na direção $x^{\prime}$ e $\alpha_{\mathrm{EW}}$ é o ângulo formado entre a seção $x^{\prime}$ e o eixo EW. As velocidades devem ser projetadas de forma similar e os componentes verticais são mantidos sem modificações.

\subsection{4}

\section{Resultados das análises do deslizamento de Daguangbao}

Na seção seguinte apresentam-se os resultados das análises do deslizamento de Daguangbao. O evento foi analisado em 2D e em 3D. Em ambos os casos, os parâmetros de resistência dos materiais incorporam resistência a tração e amolecimento dos materiais para capturar as feições geomorfológicas observadas [120]. As principais características geomorfológicas do evento são: (1) formação de uma parede vertical na esquerda da seção característica de análise, de uma altura aproximada de $380 \mathrm{~m}$; (2) o enchimento do vale Huangdongzi, formando uma barragem de aproximadamente $540 \mathrm{~m}$ de altura. Devido a que os dados de amolecimento e resistência a tração dos materiais não estão disponíveis, uma serie de análises paramétricas foram feitas em $2 \mathrm{D}$ e $3 \mathrm{D}$ para calibrar a resposta do modelo de acordo com os registros topográficos 

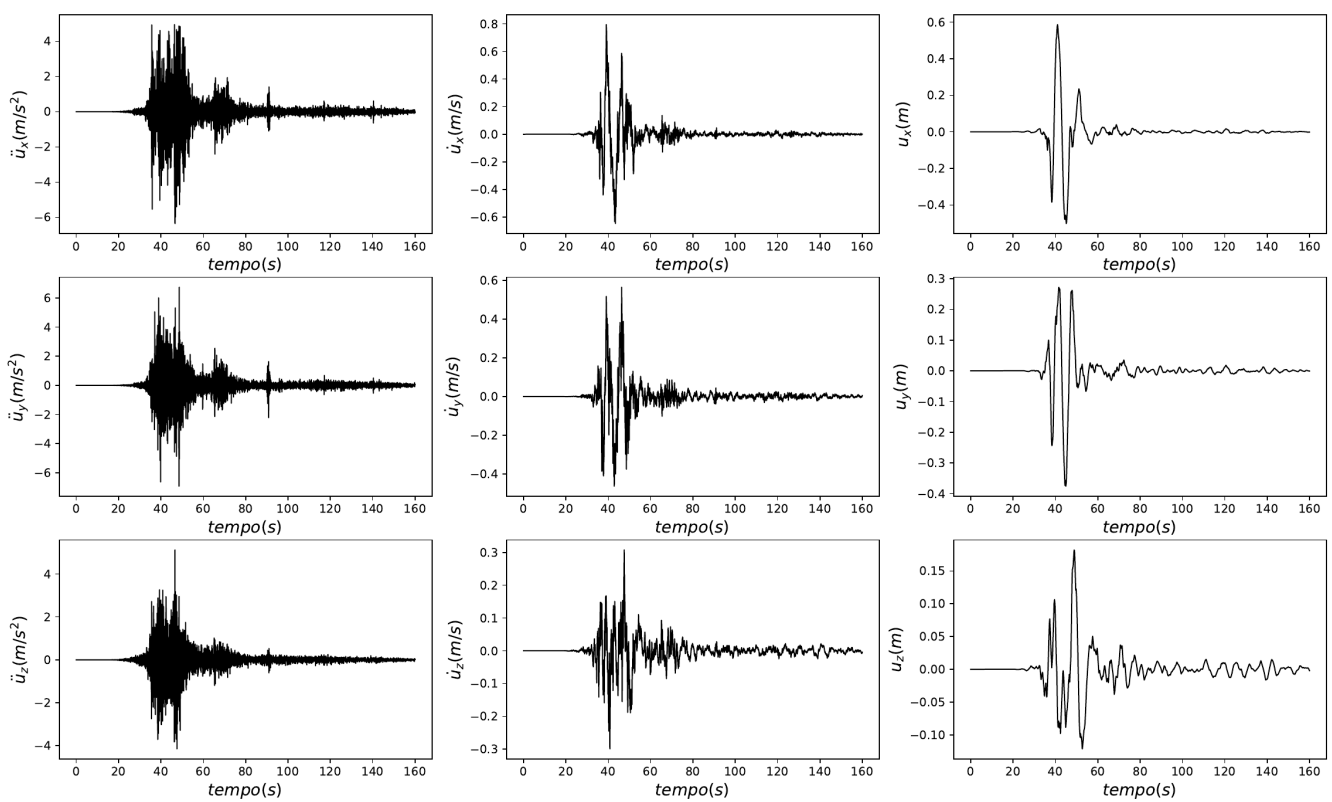

Figura 6.51: Terremoto considerado na análise. Deslocamentos $u$, velocidades $\dot{u}$ e acelerações $\ddot{u}$ no tempo, nas direções $x, y$ e $z$.

pós-terremoto [122]. A seção $\overline{A B}$ definida na Figura 6.44 é usada como seção de calibração.

\subsubsection{1}

Resultados da análise em 2D

Os resultados da análise em 2D são apresentados na sequência. Um estudo paramétrico sobre a resistência a tração e o amolecimento dos materiais, usando a seção $\overline{A B}$ para calibração, permite determinar que para capturar as principais feições observadas no evento deve-se: (1) incorporar uma resistência a tração no material $3 \mathrm{com}$ um valor de $\sigma_{t}=1.0 \mathrm{MPa}$; (2) incorporar amolecimento nos materiais 2 e 3 . Os parâmetros da análise 2D são detalhados na Tabela 6.17.

A seção $\overline{A B}$ apresenta três características geomorfológicas relevantes: (1) a superfície de falha apresenta um trecho quase-vertical formado principalmente pela presença de fraturas no material superior; (2) a superfície de ruptura é contínua e atinge quase o início do vale Huangdongzi (ver Figura 6.45 e 6.44); (3) a configuração da topografia pós-ruptura mostra que o vale é totalmente coberto pelo material que escorregou e a forma final dela é praticamente horizontal. 
Tabela 6.17: Parâmetros da análise 2D do deslizamento de Daguangbao.

\begin{tabular}{llll}
\hline Malha Euleriana & $\Delta x, \Delta y, \Delta z$ & $5.0 \mathrm{e}+1$ & $\mathrm{~m}$ \\
Passo de tempo & $\Delta t$ & $2.5 \mathrm{e}-3$ & $\mathrm{~s}$ \\
Partículas & $n_{p}$ & 26136 & - \\
Material 1 & & & \\
$\quad$ Módulo de Young & $E$ & 12500.0 & $\mathrm{MPa}$ \\
Coeficiente de Poisson & $\nu$ & 0.25 & - \\
$\quad$ Massa específica & $\rho$ & 2600 & $\mathrm{~kg} / \mathrm{m}^{3}$ \\
Material 2 & & & \\
Módulo de Young & $E$ & 4000.0 & $\mathrm{MPa}$ \\
Coeficiente de Poisson & $\nu$ & 0.25 & - \\
Massa específica & $\rho$ & 2250 & $\mathrm{~kg} / \mathrm{m}^{3}$ \\
Coesão & $c$ & 4.0 & $\mathrm{MPa}$ \\
Ângulo de atrito de pico & $\phi^{p}$ & 27.0 & $\circ$ \\
Ângulo de atrito residual & $\phi^{r}$ & 6.0 & $\circ$ \\
Deformação plástica de pico & $\epsilon_{p}^{p}$ & $1.0 \mathrm{e}-3$ & - \\
Deformação plástica residual & $\epsilon_{p}^{r}$ & $8.0 \mathrm{e}-3$ & - \\
Material 3 & & & \\
Módulo de Young & $E$ & 5750.0 & $\mathrm{MPa}$ \\
Coeficiente de Poisson & $\nu$ & 0.25 & - \\
Massa específica & $\rho$ & 2250 & $\mathrm{~kg} / \mathrm{m}^{3}$ \\
Coesão & $c$ & 2.7 & $\mathrm{MPa}$ \\
Ângulo de atrito de pico & $\phi^{p}$ & 25.5 & $\circ$ \\
Ângulo de atrito residual & $\phi^{r}$ & 10.0 & $\circ$ \\
Deformação plástica de pico & $\epsilon_{p}^{p}$ & $1.0 \mathrm{e}-2$ & - \\
Deformação plástica residual & $\epsilon_{p}^{r}$ & $8.0 \mathrm{e}-3$ & - \\
Resistência a tração & $\sigma_{t}$ & 1.0 & $\mathrm{MPa}$ \\
\hline
\end{tabular}

Na Figura 6.52 mostra-se a superfície de falha e a configuração final da topografia pós-terremoto, obtidas com MPM em 2D e as observadas [122]. A superfície de ruptura obtida com MPM mostra um trecho inicial quase-vertical com uma leve inclinação para a frente, em relação à superfície observada, que se estende continuamente até atingir o vale. A configuração final da topografia obtida com o MPM é praticamente horizontal na zona do vale e o cobre totalmente.

A evolução da superfície de falha, em termos da deformação efetiva plástica $\epsilon^{p}=\sqrt{\left(2 / 3 \epsilon_{i j}^{p} \epsilon_{i j}^{p}\right)}$, do modelo 2D se mostra na Figura 6.53. Inicialmente uma zona de plastificação é observada, coincidente com uma variação brusca na altura do material rochoso de suporte (ver Figura 6.54). Conforme o terremoto libera energia, as deformações plásticas são incrementadas e a ruptura generalizada é atingida por volta dos $63 \mathrm{~s}$. Observe-se que esse tempo corresponde a $48 \mathrm{~s}$ no registro corrigido (ver Figura 6.51). 
a) Superfície de Falha

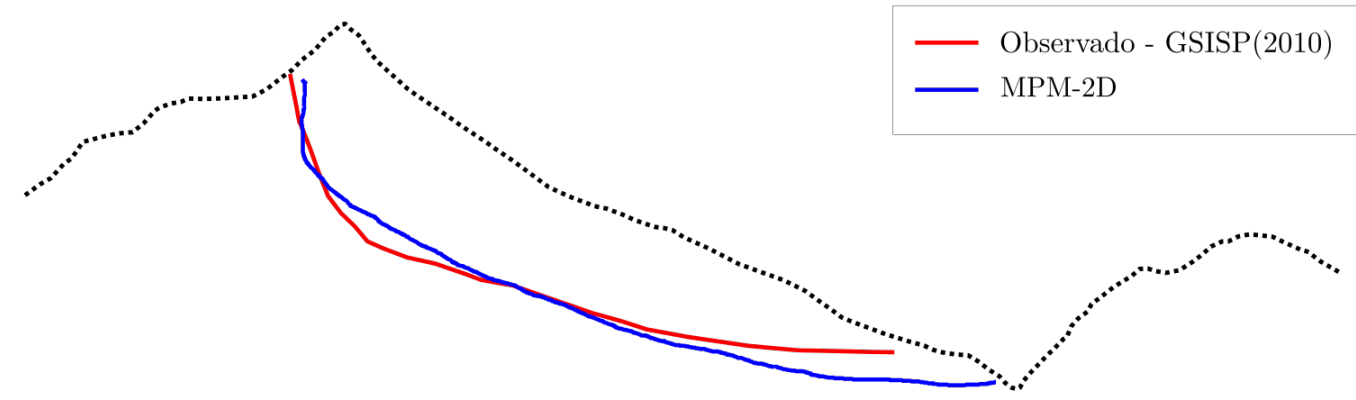

b) Topografia Pós-Falha

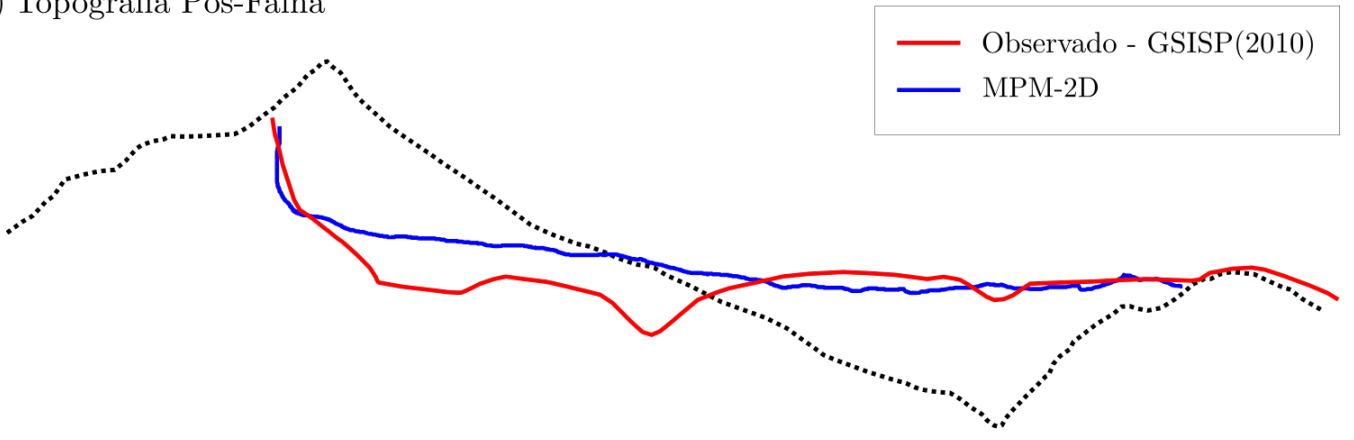

Figura 6.52: Comparação da superfície de falha e da configuração da topografia pós-terremoto. Resultados obtidos com MPM e valores reportados [122]. Modelo 2D.
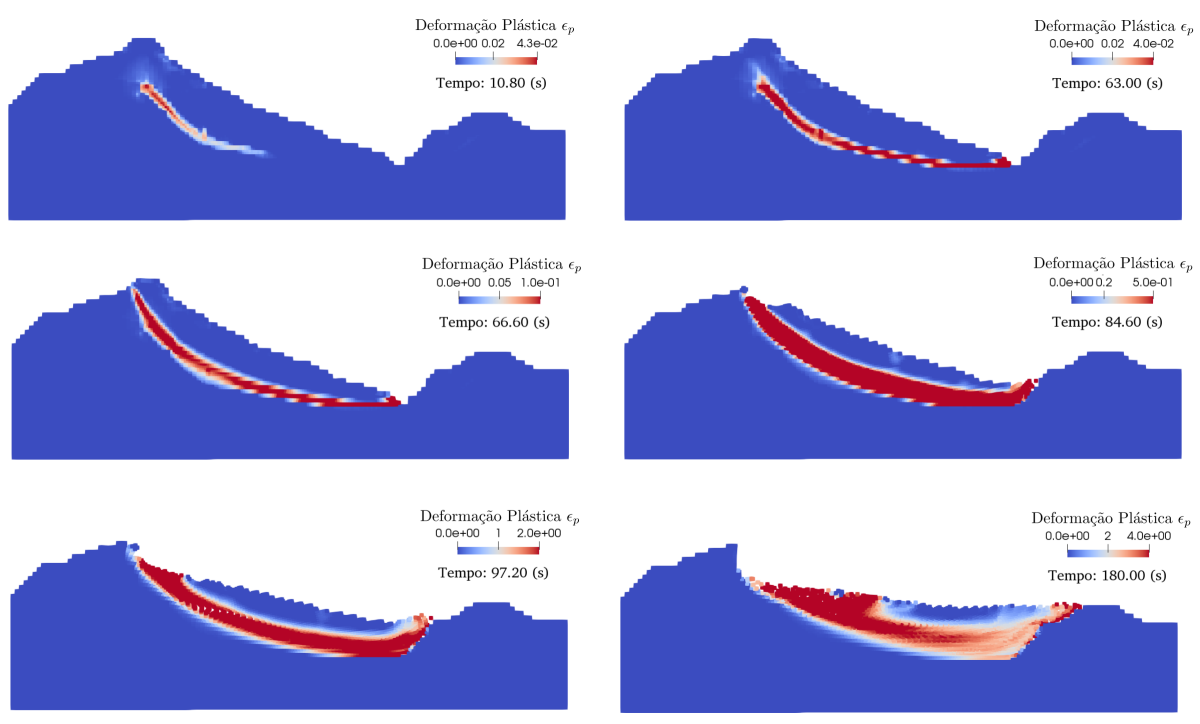

Figura 6.53: Evolução da superfície de falha em termos de deformação efetiva

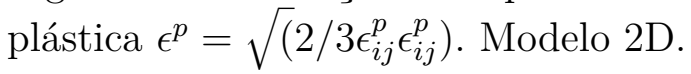

Três pontos de controle permitem capturar as características do evento através da evolução dos deslocamentos durante a ruptura (ver Figura 6.54). Os deslocamentos dos pontos de controle evidenciam a magnitude do evento, 
onde os deslocamentos estão na ordem de centenares de metros. O ponto $p_{3}$, na crista do talude, apresenta um deslocamento vertical de $-800 \mathrm{~m}$ no início da ruptura generalizada. O registro vertical do ponto $p_{2}$ permite ver que aos 100 s, o ponto registra ascensão pela presença do vale Huangdongzi. O registro de deslocamentos horizontais revela que o ponto $p_{2}$ apresenta um deslocamento horizontal de $1600 \mathrm{~m}$.

a)

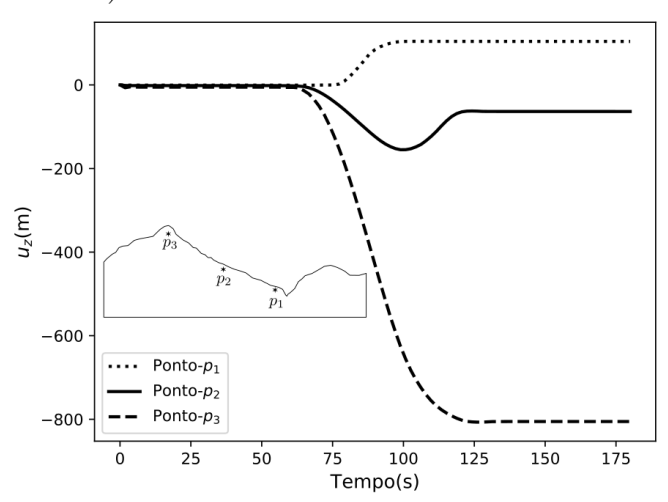

b)

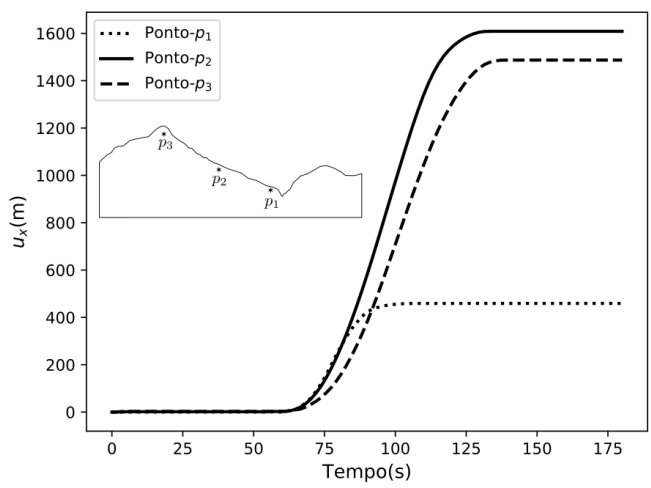

Figura 6.54: Evolução dos deslocamentos nos pontos de controle $p_{1}, p_{2}$ e $p_{3}$. a) Deslocamentos verticais $u_{z}(\mathrm{~m})$. b) Deslocamentos horizontais $u_{x}(\mathrm{~m})$. Modelo 2D.

\subsubsection{2}

\section{Resultados da análise em 3D}

Os resultados da análise em 3D são apresentados na sequência. Um estudo paramétrico da resistência a tração e do amolecimento dos materiais 2 e 3, usando a seção $\overline{A B}$ para calibração, permitiu estabelecer que para capturar as principais feições observadas no evento deve-se: (1) incorporar uma resistência a tração na modelagem constitutiva do material 3 , com um valor de $\sigma_{t}=0.8$ MPa; (2) incorporar amolecimento na modelagem constitutiva do material 2. Os parâmetros usados na análise em 3D são detalhados na Tabela 6.18.

Na Figura 6.55 mostram-se a superfície de falha e a configuração final da topografia pós-terremoto, obtidas numericamente com MPM em 3D e as reportadas [122]. A superfície de ruptura obtida com MPM em 3D resulta, em geral, coincidente com a reportada. Observa-se um trecho inicial quase-vertical, com uma leve inclinação para a frente da superfície observada. A superfície de ruptura obtida numericamente se estende continuamente até atingir o vale. A configuração final da topografia obtida com o MPM em 3D apresenta boa coincidência com a observada, tanto em relação à posição e à altura da parede vertical, quanto ao material depositado sobre o vale. 
Tabela 6.18: Parâmetros da análise 3D do deslizamento de Daguangbao.

\begin{tabular}{llll}
\hline Malha Euleriana & $\Delta x, \Delta y, \Delta z$ & $2.5 \mathrm{e}+1$ & $\mathrm{~m}$ \\
Passo de tempo & $\Delta t$ & $2.5 \mathrm{e}-3$ & $\mathrm{~s}$ \\
Partículas & $n_{p}$ & $1.8 \mathrm{e}+6$ & - \\
Material 1 & & & \\
$\quad$ Módulo de Young & $E$ & 12500.0 & $\mathrm{MPa}$ \\
$\quad$ Coeficiente de Poisson & $\nu$ & 0.25 & - \\
$\quad$ Massa específica & $\rho$ & 2600 & $\mathrm{~kg} / \mathrm{m}^{3}$ \\
Material 2 & & & \\
$\quad$ Módulo de Young & $E$ & 4000.0 & $\mathrm{MPa}$ \\
Coeficiente de Poisson & $\nu$ & 0.25 & - \\
$\quad$ Massa específica & $\rho$ & 2250 & $\mathrm{~kg} / \mathrm{m}^{3}$ \\
$\quad$ Coesão & $c$ & 4.0 & $\mathrm{MPa}$ \\
$\quad$ Ângulo de atrito de pico & $\phi^{p}$ & 27.0 & $\circ$ \\
Ângulo de atrito residual & $\phi^{r}$ & 4.0 & $\circ$ \\
Deformação plástica de pico & $\epsilon_{p}^{p}$ & $1.0 \mathrm{e}-4$ & - \\
$\quad$ Deformação plástica residual & $\epsilon_{p}^{r}$ & $2.0 \mathrm{e}-3$ & - \\
Material 3 & & & \\
Módulo de Young & $E$ & 5750.0 & $\mathrm{MPa}$ \\
Coeficiente de Poisson & $\nu$ & 0.25 & - \\
Massa específica & $\rho$ & 2250 & $\mathrm{~kg} / \mathrm{m}^{3}$ \\
Coesão & $c$ & 2.7 & $\mathrm{MPa}$ \\
Ângulo de atrito & $\phi^{p}$ & 25.5 & $\circ$ \\
Resistência a tração & $\sigma_{t}$ & 0.8 & $\mathrm{MPa}$ \\
\hline & & & \\
\hline
\end{tabular}

A caracterização geológica pós-terremoto do local do evento, feita por Huang (2012) [120], permite estimar a área total envolvida no escorregamento e suas características geométricas, tais como largura e comprimento. Na Tabela 6.19 são comparadas as áreas obtidas numericamente com MPM e as reportadas.

Tabela 6.19: Área afetada pelo evento. Estado de equilíbrio pós-terremoto.

\begin{tabular}{lcc} 
& Reportado [120] & MPM-3D \\
\hline Área de influência $\left(\mathrm{km}^{2}\right)$ & 7.3 & 7.28 \\
Comprimento da área afetada $(\mathrm{km})$ & 4.6 & 4.1 \\
Largura da área afetada $(\mathrm{km})$ & 3.2 & 3.6 \\
\hline
\end{tabular}

O reporte geológico sobre o evento, publicado pelo Instituto de Estudos Geológicos do Estado de Sichuan [122], permite quantificar a altura da parede vertical e o material depositado sobre o vale Huangdongzi. Na Tabela 6.20 são comparados os valores numéricos obtidos com MPM e os reportados. 
a) Superfície de Falha

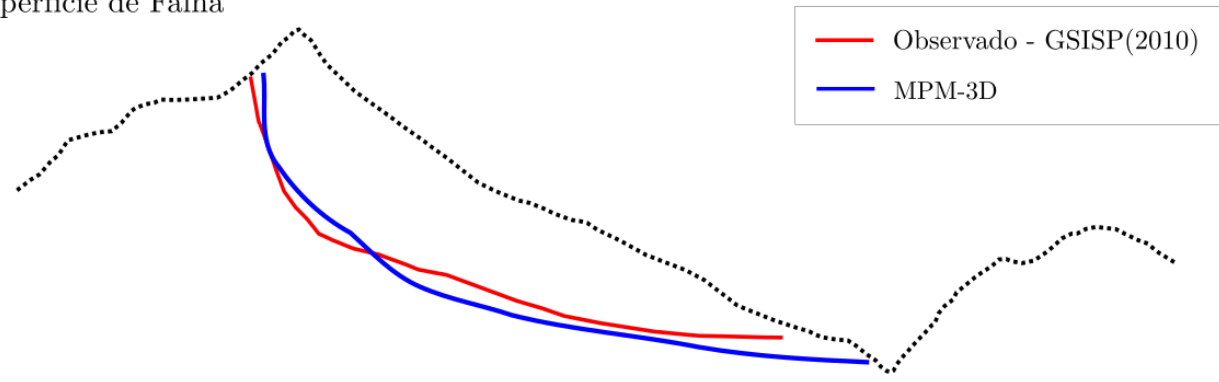

b) Topografia Pós-Falha

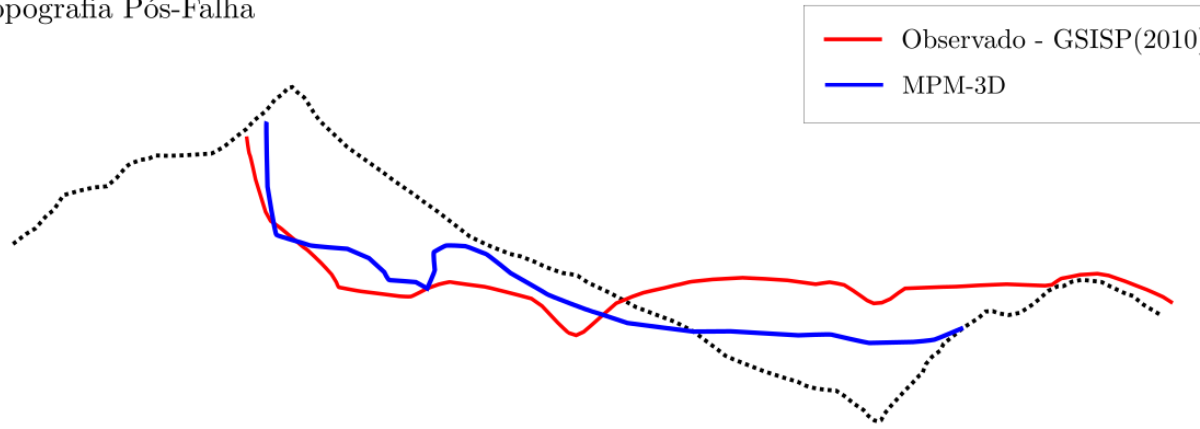

Figura 6.55: Comparação da superfície de falha e da configuração final da topografia pós-terremoto. Resultados numéricos obtidos com MPM em 3D e valores reportados [122].
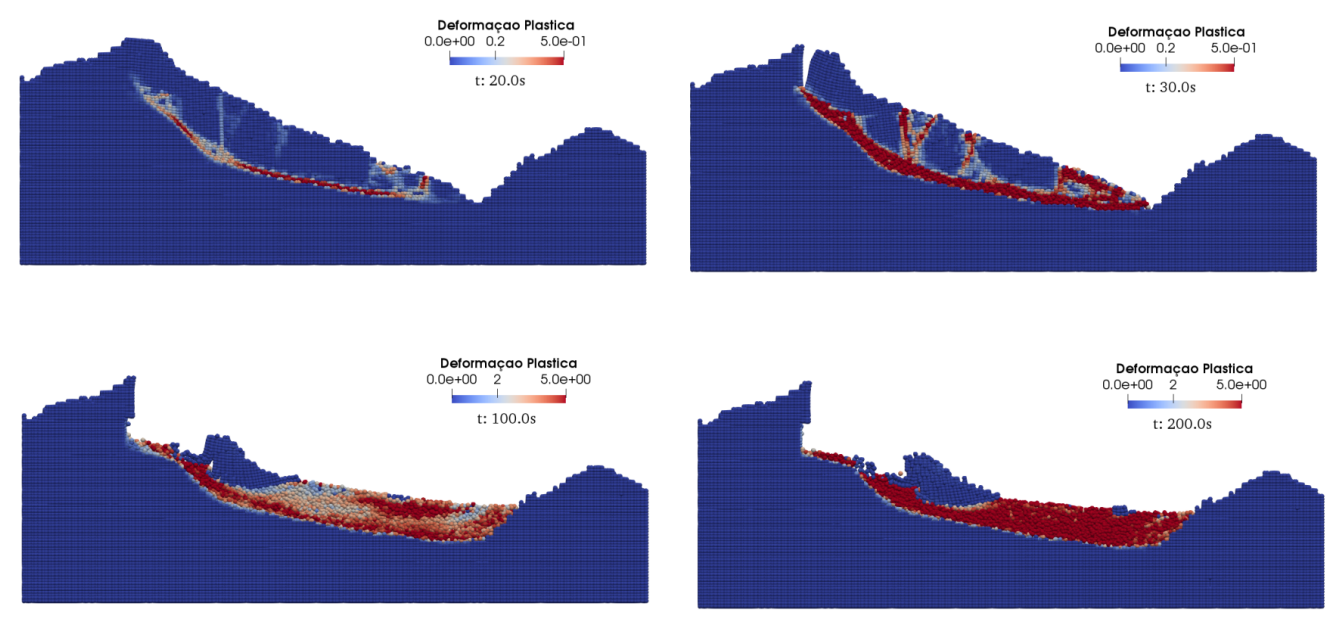

Figura 6.56: Evolução da superfície de falha em termos da deformação efetiva plástica $\left.\epsilon^{p}=\sqrt{(} 2 / 3 \epsilon_{i j}^{p} \epsilon_{i j}^{p}\right)$. Modelo 3D.

Uma característica relevante da análise MPM em 3D de grandes deformações é a possibilidade de estimar a área afetada pelo evento. Para estimar 
a) Superfície de Falha

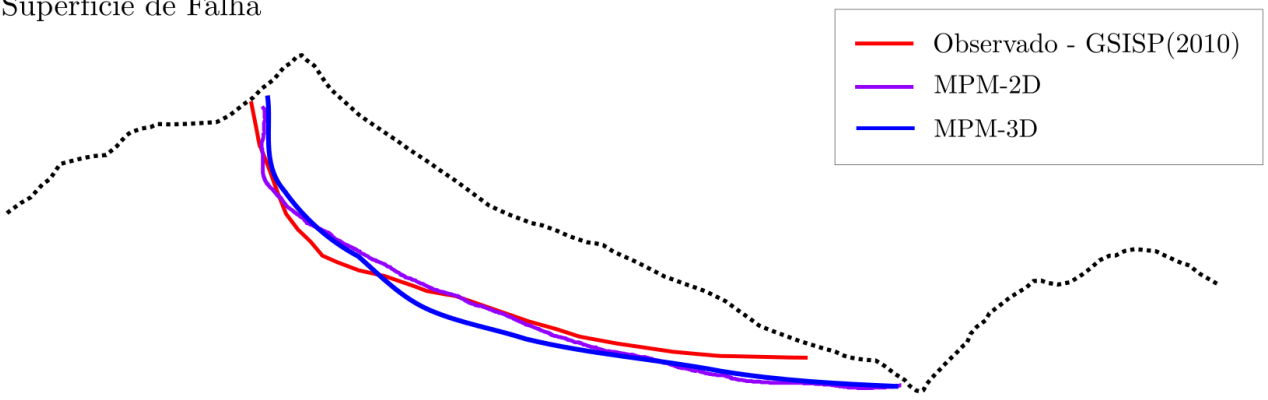

b) Topografia Pós-Falha

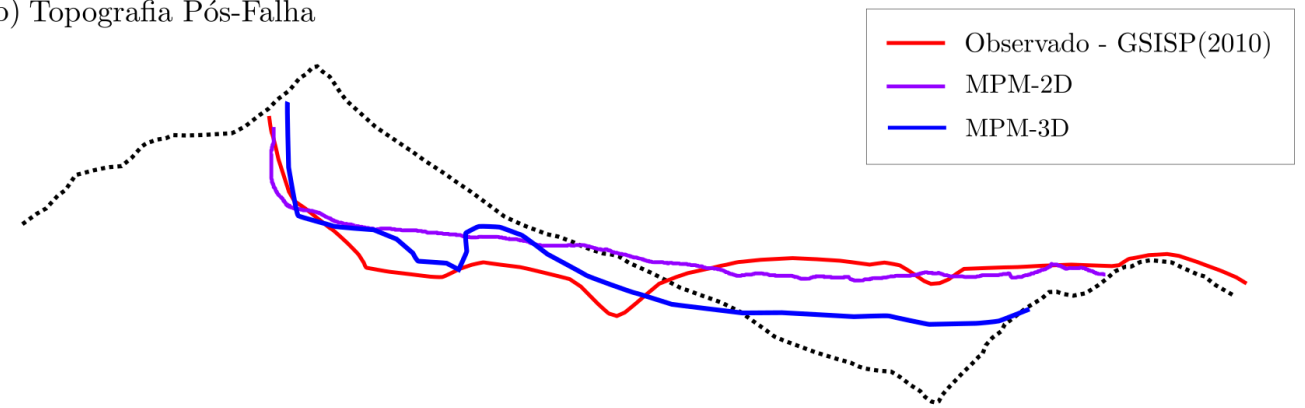

Figura 6.57: Comparação da superfície de falha e da configuração final da topografia pós-terremoto. Resultados numéricos obtidos com MPM e valores reportados [122].

Tabela 6.20: Altura da parede vertical e altura do material depositado sobre o vale Huangdongzi. Configuração pós-terremoto. Comparação de resultados numéricos com valores reportados.

\begin{tabular}{lccc} 
& Reportado [122] & MPM-2D & MPM-3D \\
\hline Seção & A-B & A-B & A-B \\
Altura parede $(\mathrm{m})$ & 639 & 638 & 601 \\
Altura material sobre vale $(\mathrm{m})$ & 536 & 573 & 306 \\
\hline
\end{tabular}

esta área, a magnitude dos deslocamentos na condição final de equilíbrio são plotados no plano YX do modelo. A área afetada é determinada pelo contorno de mínimos deslocamentos. A Figura 6.58.a mostra a magnitude dos deslocamentos do modelo numérico, na condição final de equilíbrio, e a Figura 6.58.b mostra a comparação com a área reportada.

A Tabela 6.19 mostra que a área estimada pelo MPM apresenta boa coincidência com a área reportada. O comprimento da área obtida com MPM resulta similar à reportada, mostrando que o alcance da massa que escorregou durante a ruptura foi estimado adequadamente. No entanto, a largura da área afetada é levemente superestimada pelo modelo MPM, mostrando que o espalhamento do material durante a ruptura foi estimado adequadamente. 

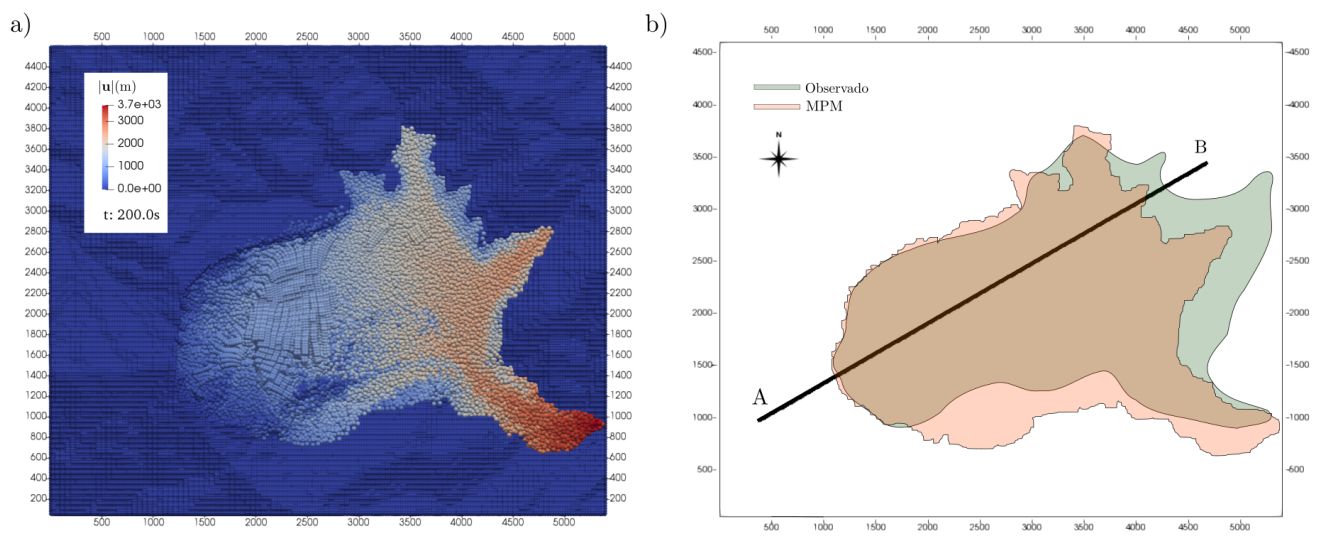

Figura 6.58: Área afetada pelo deslizamento de Daguangbao. a) Magnitude dos deslocamentos na condição de equilíbrio pós-terremoto. b) Comparação da área afetada obtida numericamente com a reportada.
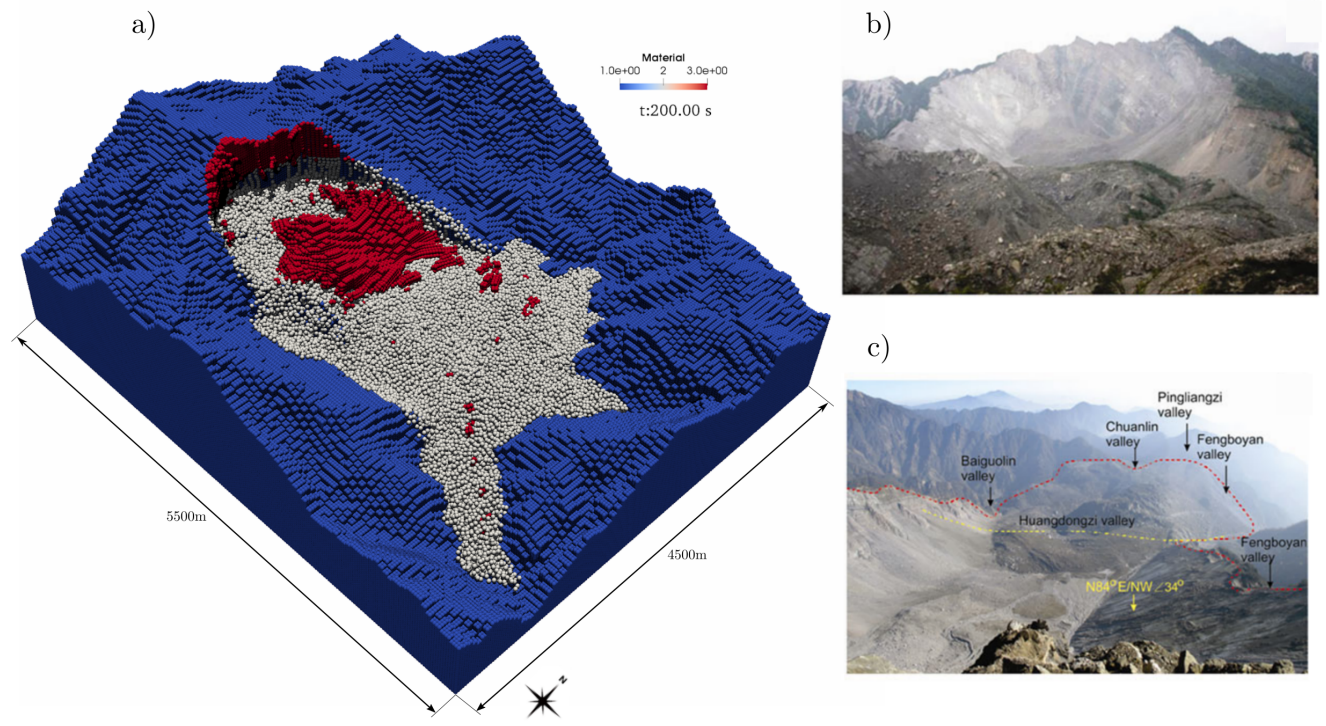

c)

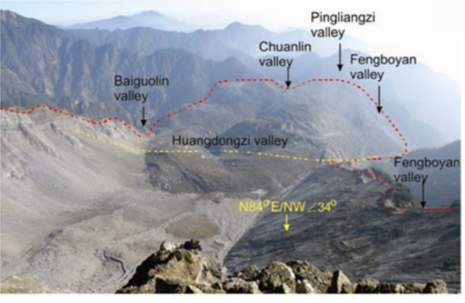

Figura 6.59: Comparação da topografia na configuração final pós-ruptura. a) Modelo numérico MPM em 3D. b) Parede vertical [120] . c) Zona de acumulação [120].

A Figura 6.59 mostra a topografia pós-terremoto obtida com o modelo MPM e duas imagens do local do evento. O modelo MPM capturou a formação de uma parede vertical, formando uma estrutura curva do tipo anfiteatro, e o enchimento do vale na zona de acumulação. Ambas características podem ser observadas nas imagens do local. A Figura 6.59.b mostra a parede vertical e a Figura 6.59.c mostra a zona de acumulação sobre o vale. 


\subsubsection{3}

\section{Comentários finais e discussão dos resultados}

O modelo MPM em 3D foi criado a partir de dados digitais de elevação, correspondentes a um estado topográfico prévio ao evento. A distribuição dos materiais no domínio foi estimada mediante a interpretação do mapa geológico e seis secções transversais, interpolando os horizontes de cada material entre as secções. A identificação de rocha intacta no local do evento permitiu delimitar a zona do modelo MPM envolvido na ruptura.

Os resultados das análises MPM em 3D de grandes deformações capturaram as principais características do evento com bastante aproximação: a superfície de ruptura, a configuração final da topografia, a quantidade de material sobre o vale e a formação de uma parede quase-vertical estável na condição de equilíbrio.

- A superfície de ruptura, em geral, apresenta boa coincidência tanto no trecho inicial quanto na sua extensão até o vale. Observa-se uma leve diferença no trecho central mais pronunciada no modelo 3D do que no modelo 2D. Esta diferença pode estar relacionada a eventuais discrepâncias na definição geológica dos materiais, em particular, à definição da rocha subjacente.

- Os dados reportados da topografia na configuração final podem ter sido influenciados pelas condições próprias do local. Em particular, observa-se uma leve depressão na zona do vale e uma marcada depressão na posição $X \approx 2800 \mathrm{~m}$ da seção reportada.

- Ambos modelos, 2D e 3D, capturaram a formação de uma parede vertical de $\approx 600 \mathrm{~m}$. Isto deve-se principalmente à consideração da resistência a tração na modelagem constitutiva do material envolvido na ruptura. 


\section{Considerações finais}

\section{1}

\section{Conclusões}

Os movimentos de grandes massas de material geológico, em particular os relacionados com instabilidades de taludes, requerem ferramentas computacionais específicas para sua modelagem: desde o início do evento, onde são evidenciados os principais mecanismos de ruptura, até o processo de escorregamento e sua posterior evolução no tempo. A modelagem constitutiva usada para representar o comportamento da massa que rompe, deve incluir modelos de diversos comportamentos incluindo mudança de reologia e eventualmente dano. Neste sentido, os método numéricos devem considerar as grandes deformações em suas formulações.

A ferramenta computacional desenvolvida na presente tese foi a implementação do MPM para simular problemas de grandes deformações em 3D. O programa MPM-PUCRio está desenvolvido na linguagem de programação $\mathrm{C}++$. Para reduzir o tempo computacional, as operações são paralelizadas usando OpenMP. A compilação do código é multiplataforma, possibilitando a sua execução em diversos sistemas operacionais. Um sistema de arquivos baseado em palavras-chaves é usado para carregar os modelos, e as análises prévias podem ser carregadas a partir de arquivos de estado.

Diversos modelos constitutivos foram implementados: elástico linear, Drucker-Prager, Mohr-Coulomb, cam-clay, fluidos Bingham e Newtoniano e um modelo de transição elasto-plástico viscoso, onde a transição é considerada mediante o critério do trabalho de segunda ordem.

Os modelos de escala geológica com feições heterogêneas de variação espacial, que eventualmente envolvem grande número de partículas, requerem procedimentos numéricos adequados para sua discretização. Na presente tese, uma metodologia de discretização foi desenvolvida e implementada computacionalmente num gerador de partículas para problemas com essas características. O gerador foi usado para a criação do modelo numérico do deslizamento de Daguangbao.

Os algoritmos implementados foram verificados com modelos de solução 
analítica e numérica. Após verificação do código, foram analisados cinco casos de interesse: a ruptura de um túnel em 3D; a simulação de processos geológicos de grandes deformações; o estudo da estabilidade do talude natural em Oregon; o impacto de um bloco de rocha sobre meio saturado; e o deslizamento de Daguangbao.

Os deslocamentos e a força na parede do modelo do túnel 3D estimados com o MPM apresentam boa coincidência com os dados do ensaio, e com os resultados numéricos publicados na literatura. Estes últimos, somente consideram a etapa inicial da ruptura e com pequenas deformações. A modelagem MPM com grandes deformações permitiu avaliar a evolução dos deslocamentos pós-ruptura, em particular, a forma da parede e a formação da cratera no topo do modelo durante o escorregamento. O estudo paramétrico dos valores residuais do ângulo de atrito revela que os deslocamentos máximos da massa envolvida na ruptura aumenta com a diminuição do ângulo residual.

A análise do talude natural em Oregon tem duas partes: o cálculo do fator de segurança e a evolução da massa pós-ruptura. O cálculo do fator de segurança com o MPM resulta menos eficiente que as técnicas baseadas na programação cônica de segunda ordem usadas em NLA. As técnicas de programação cônica de segunda ordem são altamente eficientes para modelos 3D de grande número de elementos. Porém, elas não permitem fluxo plástico não associado, amolecimento e o uso de modelos não cônicos requerem técnicas específicas menos eficientes. O fator de segurança obtido com o FEM requer da análise do modelo até que o algoritmo não converge: isto tem um custo computacional elevado. Neste sentido o MPM se revela como um método competente para este tipo de análises, onde diversos modelos podem ser implementados e não existem problemas de convergência associados ao fenômeno da ruptura ou às grandes deformações.

A influência da geração dinâmica de pressão do fluido nos poros do solo foi estudada mediante o modelo do impacto de um bloco de rocha sobre um meio poroso saturado. O modelo numérico considera grandes deformações, acoplamento fluido mecânico e modelagem constitutiva com transição de reologia. Os resultados mostraram que um aumento repentino da pressão devida ao impacto gera a instabilidade do talude e sua ruptura progressiva. O modelo de transição permitiu estimar o deslocamento total da massa pósruptura na direção do escorregamento e na direção perpendicular a ele.

A escala do evento do deslizamento de Daguangbao demandou um modelo de grande numero de partículas $(\approx 2.0 \mathrm{e}+6)$. A distribuição das partículas na malha Euleriana requereu do desenvolvimento de uma metodologia específica para levar em conta a variabilidade espacial das heterogeneidades no 
domínio. A ação do terremoto foi considerada em três direções e condições de contorno não refletoras foram usadas para dissipar a energia radiante. Os parâmetros de resistência do material envolvido na ruptura foram obtidos de trabalhos prévios, onde não foram considerados o amolecimento e a resistência à tração do material. Uma análise paramétrica dos parâmetros de amolecimento permitiu capturar com bastante aproximação a configuração final reportada. Nas análises 2D e 3D, a consideração da resistência a tração foi fundamental para capturar a formação de uma parede quase-vertical no talude na configuração final. A configuração final na zona do vale é reproduzida adequadamente por ambas análises, observando-se alguma diferença na zona esquerda do talude em 2D e uma leve diferença na altura do material sobre o vale no modelo 3D. O mecanismo de ruptura foi observado principalmente na interfase com o material rochoso da base, característica foi reproduzida pelas análises MPM. Na análise 3D se observam zonas no regime elástico dentro da massa que escorrega. Em quanto a área envolvida no evento, a análise em 3D capturou adequadamente o escorregamento do material, tanto em termos da área total afetada quanto em seu alcance e espalhamento durante o evento.

\section{2}

\section{Sugestões para futuros trabalhos}

Conforme as conclusões, diversos processos de problemas geomecânicos de grandes deformações e de acoplamento fluido mecânico foram capturados mediante as análises numéricas com o código MPM-PUCRio. Os resultados das análises permitem vislumbrar novas características a incorporar às formulações apresentadas. Devido ao estudo feito, as sugestões para futuros trabalhos são as seguintes:

- Algoritmo de Contato: Sugere-se implementar um algoritmo de contato para considerar as forças devidas à interação das massas de solo durante o escorregamento. Os algoritmos de contato são custosos computacionalmente quando são abordados mediante a modificação do campo de velocidades de cada corpo do modelo. Sendo assim, se propõe implementar um algoritmo de contato usando partículas especiais de contato, e pesquisar sua aplicação em diversos problemas geotécnicos, visando não aumentar consideravelmente o tempo de computacional.

- Fraturamento e Dano: Sugere-se pesquisar o uso do fraturamento numérico inerente ao MPM para capturar o fraturamento em materiais geológicos, assim como avaliar a incorporação do dano a partir da modelagem constitutiva e da remoção de partículas do domínio. 
- Múltiplas camadas de pontos materiais: os problemas de acoplamento fluido mecânico abordados com a teoria da mistura, mediante um ponto material na discretização do meio saturado, limitam a aplicabilidade do algoritmo. Sugere-se implementar múltiplas camadas de pontos materiais representando cada fase com uma partícula. Sugere-se pesquisar o uso de múltiplas camadas de pontos materiais em problemas de estabilidade de talude após chuvas intensas, estudo de enchimento de barragens e produção de areia em poços de petróleo.

- Paralelização de memoria distribuída: Sugere-se pesquisar o uso da paralelização de memoria distribuída junto com a memoria compartilhada implementada no presente trabalho. A combinação destas técnicas de paralelização poderia aumentar drasticamente a eficiência computacional ao distribuir o domínio em clusters de computação e paralelizando cada porção do domínio. 


\section{Referências bibliográficas}

[1] DE BLASIO, F. V.. Introduction to the physics of landslides: lecture notes on the dynamics of mass wasting. Springer Science \& Business Media, 2011.

[2] SOGA, K.; ALONSO, E.; YERRO, A.; KUMAR, K.; BANDARA, S.. Trends in largedeformation analysis of landslide mass movements with particular emphasis on the material point method. Géotechnique, 66(3):248-273, 2015.

[3] HIGHLAND, L.; BOBROWSKY, P. T. ; OTHERS. The landslide handbook: a guide to understanding landslides. US Geological Survey Reston, 2008.

[4] HUNGR, O.; EVANS, S. ; HUTCHINSON, I.. A review of the classification of landslides of the flow type. Environmental \& Engineering Geoscience, 7(3):221-238, 2001.

[5] NOVOTNỲ, J.. Varnes' landslide classification (1978). Faculty of Science, Charles University of Prague http://www. geology. cz/projekt681900/vyukovematerialy/2_Varnes_landslide_classification.pdf, 2013.

[6] HIGHLAND, L.. Landslide types and processes. Technical report, 2004.

[7] XU, X.; JIN, F.; SUN, Q.; SOGA, K. ; ZHOU, G. G.. Three-dimensional material point method modeling of runout behavior of the hongshiyan landslide. Canadian Geotechnical Journal, 56(9):1318-1337, 2019.

[8] TAKAHASHI, T.; DAS, D. K.. Debris flow: mechanics, prediction and countermeasures. CRC press, 2014.

[9] LACERDA, W. A.. Landslide initiation in saprolite and colluvium in southern brazil: field and laboratory observations. Geomorphology, 87(3):104-119, 2007.

[10] CHEN, H.; HAWKINS, A.. Relationship between earthquake disturbance, tropical rainstorms and debris movement: an overview from taiwan. Bulletin of Engineering Geology and the Environment, 68(2):161-186, 2009.

[11] GUTHRIE, R. H.; EVANS, S. G.; CATANE, S. G.; ZARCO, M. A. ; SATURAY, R. M.. The 17 february 2006 rock slide-debris avalanche at guinsaugon philippines: a synthesis. Bulletin of engineering geology and the environment, 68(2):201-213, 2009.

[12] GARIANO, S. L.; GUZZETTI, F.. Landslides in a changing climate. Earth-Science Reviews, 162:227-252, 2016.

[13] JIBSON, R. W.. Landslide hazards at La Conchita, California. Citeseer, 2005.

[14] SHANA REIS/REUTERS/VEJA/VEJA. https://veja.abril.com.br/tecnologia/ parentes-usam-redes-sociais-para-ter-noticias-da-familia/, 2011.

[15] TAYLOR, D.. Fundamentals of soil mechanics. Chapman And Hall, Limited.; New York, 1948. 
[16] JANBU, N.. Application of composite slip surface for stability analysis. In: PROCEEDINGS OF EUROPEAN CONFERENCE ON STABILITY OF EARTH SLOPES, SWEDEN, 1954, volumen 3, p. 43-49, 1954.

[17] DUNCAN, J. M.. State of the art: limit equilibrium and finite-element analysis of slopes. Journal of Geotechnical engineering, 122(7):577-596, 1996.

[18] FURUYA, T.. Review and comparison of limit equilibrium methods of slices for slope stability analysis: Revised equation of moment equilibrium and buoyancy under steady seepage flow condition. Bulletin of the National Research Institute of Agricultural Engineering (Japan), 2004.

[19] CUNDALL, P. A.; STRACK, O. D.. A discrete numerical model for granular assemblies. geotechnique, 29(1):47-65, 1979.

[20] ZIENKIEWICZ, O. C.; TAYLOR, R. L.; ZIENKIEWICZ, O. C. ; TAYLOR, R. L.. The finite element method, volumen 36. McGraw-hill London, 1977.

[21] CASCINI, L.; CUOMO, S.; PASTOR, M. ; SACCO, C.. Modelling the post-failure stage of rainfall-induced landslides of the flow type. Canadian Geotechnical Journal, 50(9):924-934, 2013.

[22] EICHENBERGER, J.; NUTH, M. ; LALOUI, L.. Modeling landslides in partially saturated slopes subjected to rainfall infiltration. Mechanics of unsaturated geomaterials, p. 233-250, 2013.

[23] GUGLIELMI, Y.; CAPPA, F.. Regional-scale relief evolution and large landslides: insights from geomechanical analyses in the tinée valley (southern french alps). Geomorphology, 117(1-2):121-129, 2010.

[24] JIANG, J.; EHRET, D.; XIANG, W.; ROHN, J.; HUANG, L.; YAN, S. ; BI, R.. Numerical simulation of qiaotou landslide deformation caused by drawdown of the three gorges reservoir, china. Environmental Earth Sciences, 62(2):411-419, 2011.

[25] DONEA, J.; GIULIANI, S. ; HALLEUX, J.-P.. An arbitrary lagrangian-eulerian finite element method for transient dynamic fluid-structure interactions. Computer methods in applied mechanics and engineering, 33(1-3):689-723, 1982.

[26] BROWN, K. H.; BURNS, S. P. ; CHRISTON, M. A.. Coupled eulerian-lagrangian methods for earth penetrating weapon applications. US Department of Commerce, 2002.

[27] QIU, G.; HENKE, S. ; GRABE, J.. Application of a coupled eulerian-lagrangian approach on geomechanical problems involving large deformations. Computers and Geotechnics, 38(1):30-39, 2011.

[28] ZHANG, X.; CHEN, Z. ; LIU, Y.. The material point method: a continuum-based particle method for extreme loading cases. Academic Press, 2016.

[29] ZABALA, F.; ALONSO, E.. Progressive failure of aznalcóllar dam using the material point method. Géotechnique, 61(9):795-808, 2011.

[30] JASSIM, I.; STOLLE, D. ; VERMEER, P.. Two-phase dynamic analysis by material point method. International journal for numerical and analytical methods in geomechanics, 37(15):2502-2522, 2013. 
[31] MONAGHAN, J. J.. Smoothed particle hydrodynamics. Reports on progress in physics, 68(8):1703, 2005.

[32] BUI, H. H.; FUKAGAWA, R.; SAKO, K. ; OHNO, S.. Lagrangian meshfree particles method (sph) for large deformation and failure flows of geomaterial using elastic-plastic soil constitutive model. International Journal for Numerical and Analytical Methods in Geomechanics, 32(12):1537-1570, 2008.

[33] OÑATE, E.; IDELSOHN, S. R.; DEL PIN, F. ; AUBRY, R.. The particle finite element method - an overview. International Journal of Computational Methods, 1(02):267307, 2004.

[34] MORESI, L.; DUFOUR, F. ; MÜHLHAUS, H.-B.. A lagrangian integration point finite element method for large deformation modeling of viscoelastic geomaterials. Journal of Computational Physics, 184(2):476-497, 2003.

[35] PRIME, N.; DUFOUR, F. ; DARVE, F.. Solid-fluid transition modelling in geomaterials and application to a mudflow interacting with an obstacle. International Journal for Numerical and Analytical Methods in Geomechanics, 38(13):1341-1361, 2014.

[36] BELYTSCHKO, T.; LU, Y. Y. ; GU, L.. Element-free galerkin methods. International journal for numerical methods in engineering, 37(2):229-256, 1994.

[37] BARDENHAGEN, S.; KOBER, E.. The generalized interpolation material point method. Computer Modeling in Engineering and Sciences, 5(6):477-496, 2004.

[38] COMDYM-MPM3D. http://comdyn.hy.tsinghua.edu.cn/english/mpm3d, 2018. Computational Dynamics Laboratory led by Professor Xiong Zhang at Tsinghua University in China.

[39] ANURA3D, A. M. R. C.. Anura3D MPM Software. Anura3D MPM Research Community.

[40] NAIRN, J. A.. Material point method calculations with explicit cracks. Computer Modeling in Engineering and Sciences, 4(6):649-664, 2003.

[41] KUMAR, K.; CAMBRIDGE-BERKELEY ; GEOMECHANICS RESEARCH GROUP. Cbgeo/mpm-point-generator: V1.0-alpha, 2018.

[42] OF UTAH, U. U.. A doe advanced simulation and computing (asc) center. http://uintah.utah.edu/15-projects/projects-old/16-csafe.html, 2011.

[43] MPMSIM. Mpmsim, material point method simulation. https://www.mpmsim. com/, 2019.

[44] GUILKEY, J. E.; WEISS, J. A.. Implicit time integration for the material point method: Quantitative and algorithmic comparisons with the finite element method. International Journal for Numerical Methods in Engineering, 57(9):1323-1338, 2003.

[45] LAI, W.; RUBIN, D.; KREMPL, E. ; RUBIN, D.. Introduction to Continuum Mechanics. Elsevier Science, 2009.

[46] REDDY, J.. An Introduction to Continuum Mechanics. An Introduction to Continuum Mechanics. Cambridge University Press, 2013. 
[47] SULSKY, D.; CHEN, Z. ; SCHREYER, H. L.. A particle method for historydependent materials. Computer methods in applied mechanics and engineering, 118(12):179-196, 1994.

[48] BATHE, K.-J.. Finite element procedures. Prentice Hall, 1995.

[49] SULSKY, D.; ZHOU, S.-J. ; SCHREYER, H. L.. Application of a particle-in-cell method to solid mechanics. Computer physics communications, 87(1-2):236-252, 1995.

[50] BARDENHAGEN, S.; BRACKBILL, J. ; SULSKY, D.. The material-point method for granular materials. Computer methods in applied mechanics and engineering, 187(3-4):529-541, 2000.

[51] SULSKY, D.; KAUL, A.. Implicit dynamics in the material-point method. Computer Methods in Applied Mechanics and Engineering, 193(12-14):1137-1170, 2004.

[52] CUMMINS, S.; BRACKBILL, J.. An implicit particle-in-cell method for granular materials. Journal of Computational Physics, 180(2):506-548, 2002.

[53] WANG, B.; VARDON, P. J.; HICKS, M. A. ; CHEN, Z.. Development of an implicit material point method for geotechnical applications. Computers and Geotechnics, 71:159-167, 2016.

[54] SMITH, G.. Numerical Solution of Partial Differential Equations: Finite Difference Methods. Open university set book. Clarendon Press, 1978.

[55] ZIENKIEWICZ, O.; TAYLOR, R.; TAYLOR, R. ; TAYLOR, R.. The Finite Element Method: The basis. Fluid Dynamics. Butterworth-Heinemann, 2000.

[56] BELYTSCHKO, T.; LIU, W.; MORAN, B. ; ELKHODARY, K.. Nonlinear Finite Elements for Continua and Structures. Wiley, 2014.

[57] KRAMER, S.. Geotechnical Earthquake Engineering. Prentice Hall International Series in Civil Engineering And. Prentice Hall, 1996.

[58] ZIENKIEWICZ, O.. Computational geomechanics with special reference to earthquake engineering. John Wiley, 1999.

[59] ABE, K.; NAKAMURA, S.; NAKAMURA, H. ; SHIOMI, K.. Numerical study on dynamic behavior of slope models including weak layers from deformation to failure using material point method. Soils and Foundations, 57(2):155-175, Apr. 2017.

[60] VERRUIJT, A.. An Introduction to Soil Dynamics. Theory and Applications of Transport in Porous Media. Springer Netherlands, 2009.

[61] LYSMER, J.; KUHLEMEYER, R. L.. Finite dynamic model for infinite media. Journal of the Engineering Mechanics Division, 95(4):859-878, 1969.

[62] SHEN, L.; CHEN, Z.. A silent boundary scheme with the material point method for dynamic analyses. Computer Modeling in Engineering \& Sciences, 7(3):305-320, 2005.

[63] BARDENHAGEN, S.. Energy conservation error in the material point method for solid mechanics. Journal of Computational Physics, 180(1):383-403, 2002. 
[64] Henderson, A.; AHRENS, J.; LAW, C. ; OTHERS. The ParaView Guide, volumen 366. Kitware Clifton Park, NY, 2004.

[65] GEUZAINE, C.; REMACLE, J.-F.. Gmsh: A 3-d finite element mesh generator with built-in pre-and post-processing facilities. International journal for numerical methods in engineering, 79(11):1309-1331, 2009.

[66] SIMO, J.; HUGHES, T.. Computational Inelasticity. Interdisciplinary Applied Mathematics. Springer New York, 2000.

[67] SZABÓ, L.; BALLA, M.. Comparison of some stress rates. International journal of solids and structures, 25(3):279-297, 1989.

[68] ZIENKIEWICZ, O. C.; TAYLOR, R. L. ; ZHU, J. Z.. The finite element method: its basis and fundamentals. Elsevier, 2005.

[69] ZIENKIEWICZ, O.; TAYLOR, R. ; TAYLOR, R.. The Finite Element Method: Solid mechanics. Fluid Dynamics. Butterworth-Heinemann, 2000.

[70] ITASCA, F.. Fast lagrangian analysis of continua. Itasca Consulting Group Inc., Minneapolis, Minn, 2000.

[71] PASTOR, M.; QUECEDO, M.; FERNÁNDEZ MERODO, J.; HERRORES, M.; GONZALEZ, E. ; MIRA, P.. Modelling tailings dams and mine waste dumps failures. Geotechnique, 52(8):579-591, 2002.

[72] NICOT, F.; DAOUADJI, A.; LAOUAFA, F. ; DARVE, F.. Second-order work, kinetic energy and diffuse failure in granular materials. Granular Matter, 13(1):19-28, 2011.

[73] TERZAGHI, K.. Erdbaumechanik. Franz Deuticke, Vienna, 1, 1925.

[74] BIOT, M. A.. General theory of three-dimensional consolidation. Journal of applied physics, 12(2):155-164, 1941.

[75] BIOT, M. A.. Theory of propagation of elastic waves in a fluid-saturated porous solid. ii. higher frequency range. The Journal of the acoustical Society of america, 28(2):179-191, 1956.

[76] ZIENKIEWICZ, O.; SHIOMI, T.. Dynamic behaviour of saturated porous media; the generalized biot formulation and its numerical solution. International journal for numerical and analytical methods in geomechanics, 8(1):71-96, 1984.

[77] BANDARA, S.; SOGA, K.. Coupling of soil deformation and pore fluid flow using material point method. Computers and Geotechnics, 63:199-214, 2015.

[78] VAN ESCH, J.; STOLLE, D. ; JASSIM, I.. Finite element method for coupled dynamic flow-deformation simulation. In: 2ND INTERNATIONAL SYMPOSIUM ON COMPUTATIONAL GEOMECHANICS (COMGEO II), número 1, 2011.

[79] KAFAJI, I. K. A.. Formulation of a dynamic material point method (MPM) for geomechanical problems. 2013.

[80] ZHANG, H.; WANG, K. ; CHEN, Z.. Material point method for dynamic analysis of saturated porous media under external contact/impact of solid bodies. Computer Methods in Applied Mechanics and Engineering, 198(17-20):1456-1472, 2009. 
[81] GHASEMI, P.; MARTINELlI, M.; CUOMO, S. ; CAlVELlO, M.. Mpm modelling of static liquefaction in reduced-scale slope. In: NUMERICAL METHODS IN GEOTECHNICAL ENGINEERING IX, VOLUME 2, p. 1041-1046. CRC Press, 2018.

[82] YERRO, A.; ALONSO, E. ; PINYOL, N.. Modelling the initiation and run-out of rainfall-induced slope instability. In: LANDSLIDES AND ENGINEERED SLOPES. EXPERIENCE, THEORY AND PRACTICE, p. 2087-2095. CRC Press, 2016.

[83] ZHANG, H.; WANG, K. ; ZHANG, Z.. Material point method for numerical simulation of failure phenomena in multiphase porous media. In: COMPUTATIONAL MECHANICS, p. 36-47. Springer, 2007.

[84] ABE, K.; SOGA, K. ; BANDARA, S.. Material point method for coupled hydromechanical problems. Journal of Geotechnical and Geoenvironmental Engineering, 140(3):04013033, 2013.

[85] ZHANG, H.; WANG, K. ; CHEN, Z.. Material point method for dynamic analysis of saturated porous media under external contact/impact of solid bodies. Computer methods in applied mechanics and engineering, 198(17-20):1456-1472, 2009.

[86] SULSKY, D.; SCHREYER, H. L.. Axisymmetric form of the material point method with applications to upsetting and taylor impact problems. Computer Methods in Applied Mechanics and Engineering, 139(1-4):409-429, 1996.

[87] BARDENHAGEN, S.; GUILKEY, J. E.; ROESSIG, K.; BRACKBILL, J.; WITZEL, W. ; FOSTER, J.. An improved contact algorithm for the material point method and application to stress propagation in granular material. CMES: Computer Modeling in Engineering \& Sciences, 2(4):509-522, 2001.

[88] NØST, H. A.. Undrained soft soil modelling with the material point method. Master's thesis, Norges teknisk-naturvitenskapelige universitet, Fakultet for ingeniørvitenskap og teknologi, Institutt for bygg, anlegg og transport, 2011.

[89] BEUTH, L.. Formulation and application of a quasi-static material point method. PhD thesis, Verlag nicht ermittelbar, 2012.

[90] NAIRNMPM. http://osupdocs.forestry.oregonstate.edu/index.php/ NairnMPM, 2016. Computational mechanics software from Oregon State University in the research group of Prof. John A. Nairn.

[91] MAGUIRE, D. J.. Arcgis: general purpose gis software system. Encyclopedia of GIS, p. 25-31, 2008.

[92] QGIS-DEVELOPMENT-TEAM; OTHERS. Qgis geographic information system. Open Source Geospatial Foundation Project, 2016.

[93] FERNÁNDEZ, F.. mpm-generator:v1.0-alpha, 2019.

[94] BRINKGREVE, R.; ENGIN, E.; SWOLFS, W.; WATERMAN, D.; CHESARU, A.; BONNIER, P. ; GALAVI, V.. Plaxis 2d 2006 v.8. Plaxis bv, 2006.

[95] KRABBENHØFT, K.; LYAMIN, A.; SLOAN, S.. Formulation and solution of some plasticity problems as conic programs. International Journal of Solids and Structures, 44(5):1533-1549, 2007. 
[96] MAKRODIMOPOULOS, A.; MARTIN, C.. Lower bound limit analysis of cohesivefrictional materials using second-order cone programming. International Journal for Numerical Methods in Engineering, 66(4):604-634, 2006.

[97] ANDERHEGGEN, E.; KNÖPFEL, H.. Finite element limit analysis using linear programming. International Journal of Solids and Structures, 8(12):1413-1431, 1972.

[98] BOTTERO, A.; NEGRE, R.; PASTOR, J. ; TURGEMAN, S.. Finite element method and limit analysis theory for soil mechanics problems. Computer Methods in Applied Mechanics and Engineering, 22(1):131-149, 1980.

[99] LYSMER, J.. Limit analysis of plane problems in soil mechanics. Journal of Soil Mechanics \& Foundations Div, 1970.

[100] GRIFFITHS, D.; MARQUEZ, R.. Three-dimensional slope stability analysis by elasto-plastic finite elements. Geotechnique, 57(6):537-546, 2007.

[101] FERNÁNDEZ, F.; VARGAS JR, E. ; VELLOSO, R. Q.. A study of collapse in slopes using mpm and nla (numerical limit analysis). In: 2ND INTERNATIONAL CONFERENCE ON THE MATERIAL POINT METHOD FOR MODELLING SOIL-WATERSTRUCTURE INTERACTION ,UK,2019, 2019.

[102] CARRIÓN, M.; VARGAS, E. A.; VELLOSO, R. Q. ; FARFAN, A. D.. Slope stability analysis in 3d using numerical limit analysis (nla) and elasto-plastic analysis (epa). Geomechanics and Geoengineering, 12(4):250-265, 2017.

[103] LIU, C.; SUN, Q.; JIN, F. ; ZHOU, G. G.. A fully coupled hydro-mechanical material point method for saturated dense granular materials. Powder technology, 314:110-120, 2017.

[104] CRYER, C.. A comparison of the three-dimensional consolidation theories of biot and terzaghi. The Quarterly Journal of Mechanics and Applied Mathematics, 16(4):401-412, 1963.

[105] STERPI, D.; CIVIDINI, A.; SAKURAI, A.; NISHITAKE, S. ; OTHERS. Laboratory model tests and numerical analysis of shallow tunnels. In: ISRM INTERNATIONAL SYMPOSIUM-EUROCK 96. International Society for Rock Mechanics and Rock Engineering, 1996.

[106] STERPI, D.; CIVIDINI, A.. A physical and numerical investigation on the stability of shallow tunnels in strain softening media. Rock Mechanics and Rock Engineering, 37(4):277-298, 2004.

[107] GRAY, G. G.; MORGAN, J. K. ; SANZ, P. F.. Overview of continuum and particle dynamics methods for mechanical modeling of contractional geologic structures. Journal of Structural Geology, 59:19-36, 2014.

[108] BUITER, S. J.; BABEYKO, A. Y.; ELLIS, S.; GERYA, T. V.; KAUS, B. J.; KELLNER, A.; SCHREURS, G. ; YAMADA, Y.. The numerical sandbox: comparison of model results for a shortening and an extension experiment. Geological Society, London, Special Publications, 253(1):29-64, 2006.

[109] ANDERSON, S. P.; DIETRICH, W. E.; MONTGOMERY, D. R.; TORRES, R.; CONRAD, M. E. ; LOAGUE, K.. Subsurface flow paths in a steep, unchanneled catchment. Water Resources Research, 33(12):2637-2653, 1997. 
[110] EBEL, B. A.; LOAGUE, K.; VANDERKWAAK, J. E.; DIETRICH, W. E.; MONTGOMERY, D. R.; TORRES, R. ; ANDERSON, S. P.. Near-surface hydrologic response for a steep, unchanneled catchment near coos bay, oregon: 2. physics-based simulations. American Journal of Science, 307(4):709-748, 2007.

[111] MONTGOMERY, D. R.; SCHMIDT, K. M.; DIETRICH, W. E. ; MCKEAN, J.. Instrumental record of debris flow initiation during natural rainfall: Implications for modeling slope stability. Journal of Geophysical Research: Earth Surface, 114(F1), 2009.

[112] CAMARGO, J.; VELLOSO, R. Q. ; VARGAS, E. A.. Numerical limit analysis of three-dimensional slope stability problems in catchment areas. Acta Geotechnica, 11(6):1369-1383, 2016.

[113] MILledGE, D. G.; BELLUGI, D.; MCKEAN, J. A.; DENSMORE, A. L. ; DIETRICH, W. E.. A multidimensional stability model for predicting shallow landslide size and shape across landscapes. Journal of Geophysical Research: Earth Surface, 119(11):2481-2504, 2014.

[114] BARROS, W.; AMARAL, C.; SOBREIRA, F.; D'ORSI, R.; MAIA, H. ; CUNHA, R. Catastrophic avalanche at st. Genoveva clinic slope: Solos e Rochas, 11:17-25, 1988.

[115] BARROS, W.; AMARAL, C.; SOBREIRA, F.; D'ORSI, R.; MAIA, H. ; CUNHA, R.. Avalanche catastrófica na encosta À montante da clínica danta genova, rio de janeiro. Secretaria Municipal de Obras do Rio de Janeiro., 1988.

[116] LACERDA, W. A.. Landslide initiation in saprolite and colluvium in southern brazil: field and laboratory observations. Geomorphology, 87(3):104-119, 2007.

[117] LACERDA, W.. The behavior of colluvial slopes in a tropical environment. Landslides: Evaluation and Stabilization, 2:1315-1342, 2004.

[118] BORJA, R. I.; LIU, X. ; WHITE, J. A.. Multiphysics hillslope processes triggering landslides. Acta Geotechnica, 7(4):261-269, 2012.

[119] MÜLLER, A.; VARGAS, E. A.. Stability analysis of a slope under impact of a rock block using the generalized interpolation material point method (gimp). Landslides, 16(4):751-764, 2019.

[120] HUANG, R.; PEI, X.; FAN, X.; ZHANG, W.; LI, S. ; LI, B.. The characteristics and failure mechanism of the largest landslide triggered by the wenchuan earthquake, may 12, 2008, china. Landslides, 9(1):131-142, 2012.

[121] HE, M.; E SOUSA, L. R.; MÜLLER, A.; VARGAS JR, E.; SOUSA, R.; OLIVEIRA, C. S. ; GONG, W.. Numerical and safety considerations about the daguangbao landslide induced by the $\mathbf{2 0 0 8}$ wenchuan earthquake. Journal of Rock Mechanics and Geotechnical Engineering, 11(5):1019-1035, 2019.

[122] GEOlogical SURVEY InStitute OF SiCHUAN PROVINCE, CHANGDU, .. Daguangbao landslide survey, 2010.

[123] USGS. Magnitude 7.9 - eastern sichuan, china, 2008 may 12 06:28:01utc. https://earthquake.usgs.gov/earthquakes/eventpage/usp000g650/executive, 2008. 
A

\section{Publicações produzidas durante o presente trabalho}

1. Fernández, F., Vargas, E., Velloso, R. Q. (2019). A 3D discretization procedure for the material point method (MPM). DOI: 10.1007/s40571-019-00303-7. Computational Particle Mechanics, 19.

2. Fernández, F., Vargas, E., Velloso, R., 2019. A study of collapse in slopes using Material Point Method (MPM) and Numerical Limit Analysis (NLA). Trabalho em revisão na Soil and Foundation Journal.

3. García, J., Fernández, F., Vargas, E., Velloso, R. Face stability analysis in 3D of shallow tunnels through numerical limit analysis (NLA) and the material point method (MPM). Trabalho em revisão na Tunnelling and Underground Space Technology.

4. Fernández, F., Vargas, E., Velloso, R., 2019. A study of collapse in slopes using MPM and NLA (Numerical Limit Analysis). In 2nd International Conference on the Material Point Method for Modelling Soil-Water-Structure Interaction. 8 - 10 January 2019, University Of Cambridge, United Kingdom.

5. Fernández, F., Vargas, E., 2018. Considerações sobre o uso do MPM (Material Point Method) na simulação numérica de processos de deformação em geologia estrutural. 49ํㅡㄹ Congresso Brasileiro de Geologia / 9o Simpósio do Cretáceo do Brasil / VII Simpósio de Vulcanismo e Ambientes Associados. Rio de Janeiro, Brasil, 20 a 24 de agosto de 2018 .

6. Moraes, T., Fernández, F., Vargas, E., Velloso, R., 2018. Análise de Ruptura de Talude Infinito Usando o Método do Ponto Material. V Simpósio Pan-Americano de Deslizamentos. Rio de Janeiro, Brasil. 


\section{B \\ Exemplo de Arquivo de Entrada de Dados}

No anexo seguinte apresenta-se um arquivo de entrada de dados para simulação de um exemplo simples usando o programa MPM-PUCRio. A Figura B mostra um cubo de $1.0 \mathrm{~m}^{3}$ de volume a ser discretizado por 64 partículas usando uma malha de suporte de 8 elementos. A descrição de cada palavrachave é descrita na Seção 2.3 na Página 46.

a)

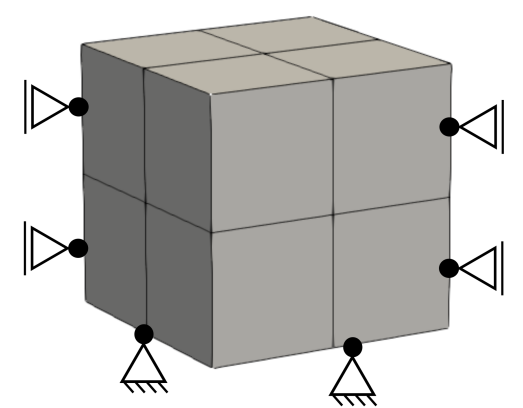

b)

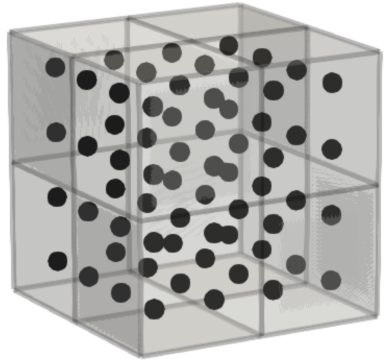

Figura B.1: Exemplo de arquivo de entrada de dados do programa MPMPUCRio. a) Malha de cubo de $1 \mathrm{~m} \times 1 \mathrm{mx} 1 \mathrm{~m}$ formada por 8 elementos de 8 nós. b) Modelo MPM com 8 partículas por elemento.

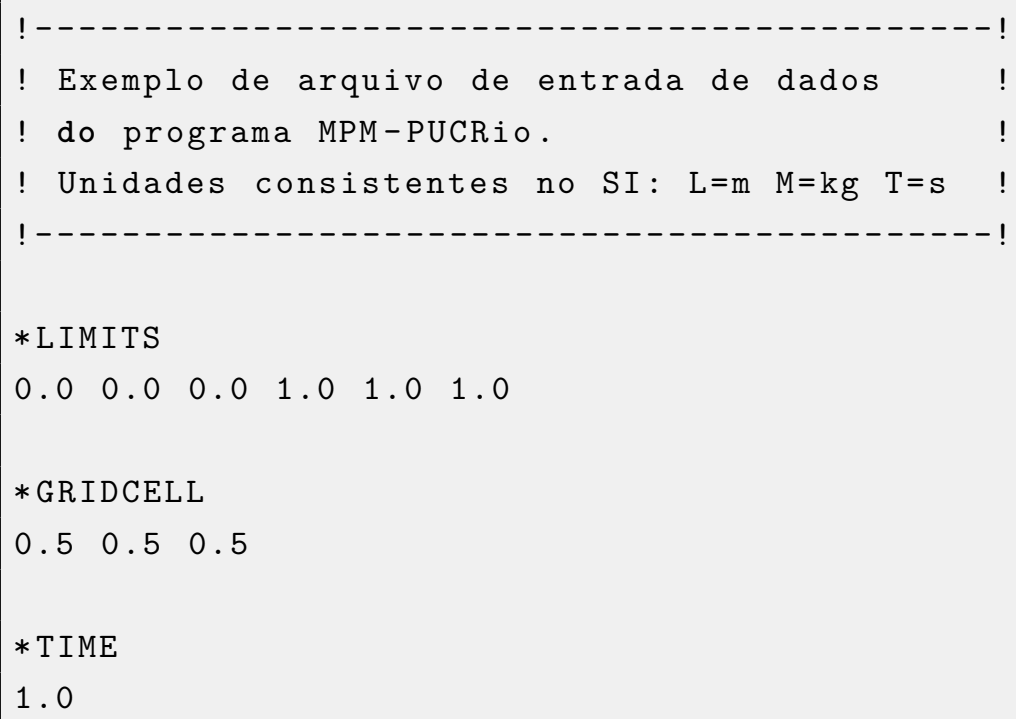




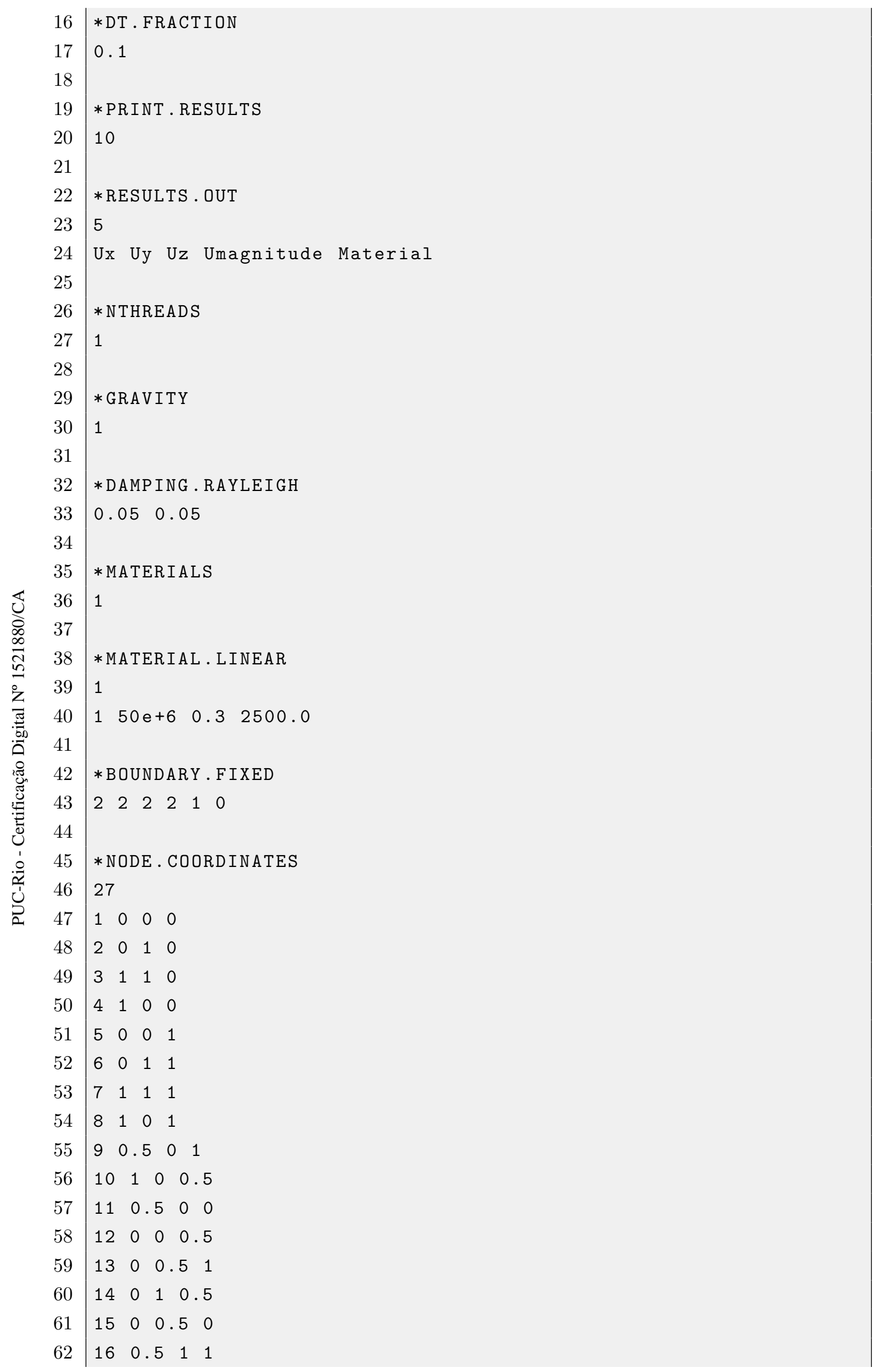




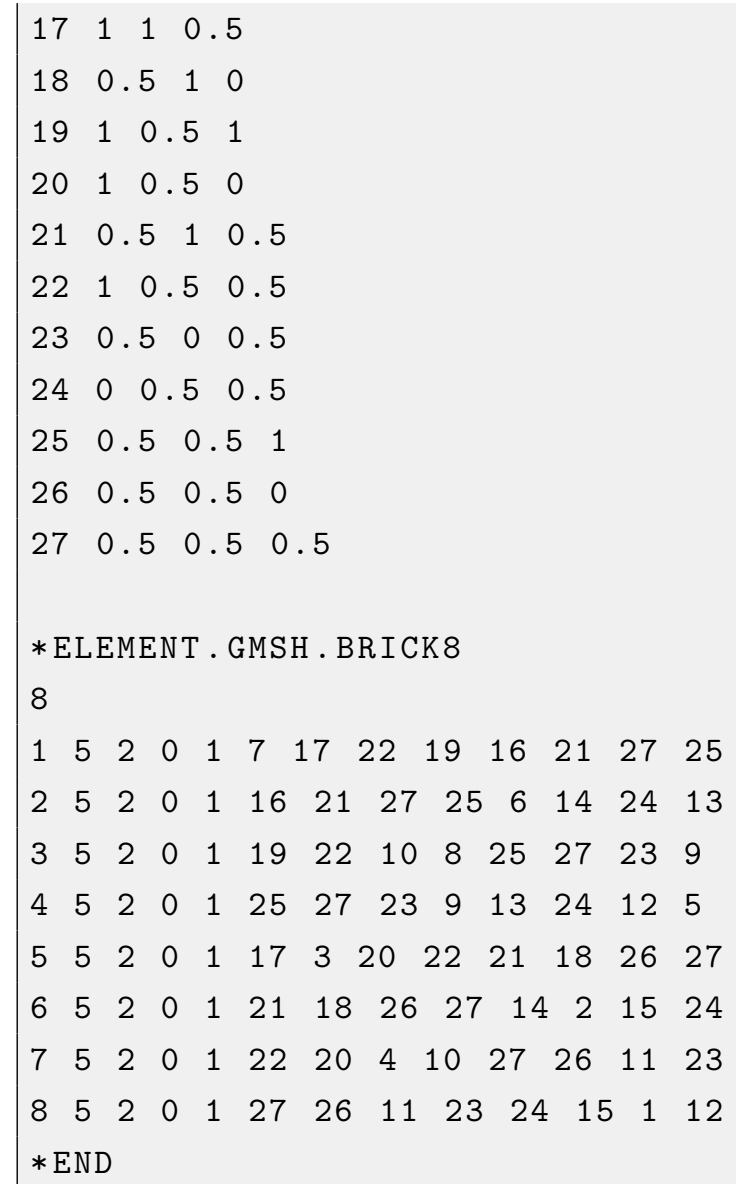

\section{B.1}

\section{Convenção da numeração dos nós do elementos do 8 nós}

O exemplo do arquivo de entrada de dados do programa MPM-PUCRio usa a convenção de nós do elemento de 8 nós conforme se mostra na Figura B.2.
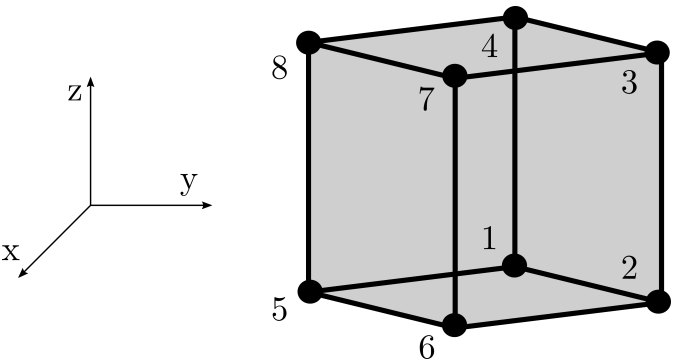

Figura B.2: Convenção de numeração do elemento de 8 nós. 